\title{
Review and Assessment of Commercial Vendors/Options for Feeding and Pumping Biomass Slurries for Hydrothermal Liquefaction
}

\section{EJ Berglin \\ CW Enderlin \\ AJ Schmidt}

November 2012

\section{Pacific Northwest}




\title{
DISCLAIMER
}

This report was prepared as an account of work sponsored by an agency of the United States Government. Neither the United States Government nor any agency thereof, nor Battelle Memorial Institute, nor any of their employees, makes any warranty, express or implied, or assumes any legal liability or responsibility for the accuracy, completeness, or usefulness of any information, apparatus, product, or process disclosed, or represents that its use would not infringe privately owned rights. Reference herein to any specific commercial product, process, or service by trade name, trademark, manufacturer, or otherwise does not necessarily constitute or imply its endorsement, recommendation, or favoring by the United States Government or any agency thereof, or Battelle Memorial Institute. The views and opinions of authors expressed herein do not necessarily state or reflect those of the United States Government or any agency thereof.

\author{
PACIFIC NORTHWEST NATIONAL LABORATORY \\ operated by \\ BATTELLE \\ for the \\ UNITED STATES DEPARTMENT OF ENERGY \\ under Contract DE-AC05-76RL01830
}

Printed in the United States of America
Available to DOE and DOE contractors from the Office of Scientific and Technical Information,
P.O. Box 62, Oak Ridge, TN 37831-0062;
ph: (865) 576-8401
fax: $(865)$ 576-5728
email: reports@adonis.osti.gov

\begin{abstract}
Available to the public from the National Technical Information Service, U.S. Department of Commerce, 5285 Port Royal Rd., Springfield, VA 22161 ph: (800) 553-6847 fax: $(703) 605-6900$ email: orders@ntis.fedworld.gov online ordering: http://www.ntis.gov/ordering.htm
\end{abstract}

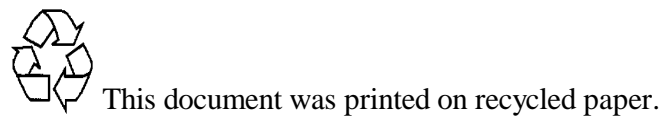




\section{Review and Assessment of Commercial Vendors/Options for Feeding and Pumping Biomass Slurries for Hydrothermal Liquefaction}

EJ Berglin

CW Enderlin

AJ Schmidt

November 2012

Prepared for

the U.S. Department of Energy

under Contract DE-AC05-76RL01830

Pacific Northwest National Laboratory

Richland, Washington 99352 



\section{Summary}

The National Advanced Biofuels Consortium (NABC) is working to develop improved methods for producing high-value hydrocarbon fuels. The development of one such method, the hydrothermal liquefaction (HTL) process, is being led by the Pacific Northwest National Laboratory (PNNL). The HTL process uses a wet biomass slurry at elevated temperatures (i.e., 570 to $680^{\circ} \mathrm{F}$ [300 to $360^{\circ} \mathrm{C}$ ) and pressures above the vapor pressure of water (i.e., 2200 to 2900 psi [150 to 200 bar] at these temperatures) to facilitate a condensed-phase reaction medium. The process has been successfully tested at bench-scale and development and testing at a larger scale is required to prove the viability of the process at production levels. Near-term development plans include advancing the process to pilot-scale readiness.

A significant challenge to the scale-up of the HTL process is feeding a highly viscous fibrous biomass wood/corn stover feedstock into a pump system that provides the required pressure for downstream processing at $\sim 3000$ psi (206 bar). In October 2011, PNNL began investigating commercial feed and pumping options that would meet these HTL process requirements. Initial efforts focused on generating a HTL feed and pump specification titled "PNNL Biomass Process Feed \& Pump Equipment Needs" (see Appendix C). That specification was provided to prospective vendors to determine the suitability of their pumps for the pilot-scale (i.e., 1 dry metric tons per day [DMTPD] production rate or 0.5 to $2 \mathrm{gpm}$ at $15 \mathrm{wt} \%$ solids and $3000 \mathrm{psi}$ ) and production-scale plants (i.e., 2000 DMTPD production rate or $2300 \mathrm{gpm}$ at $15 \mathrm{wt} \%$ solids and $3000 \mathrm{psi}$ ). Figure ES.1 presents the problem statement diagram used in the specification.

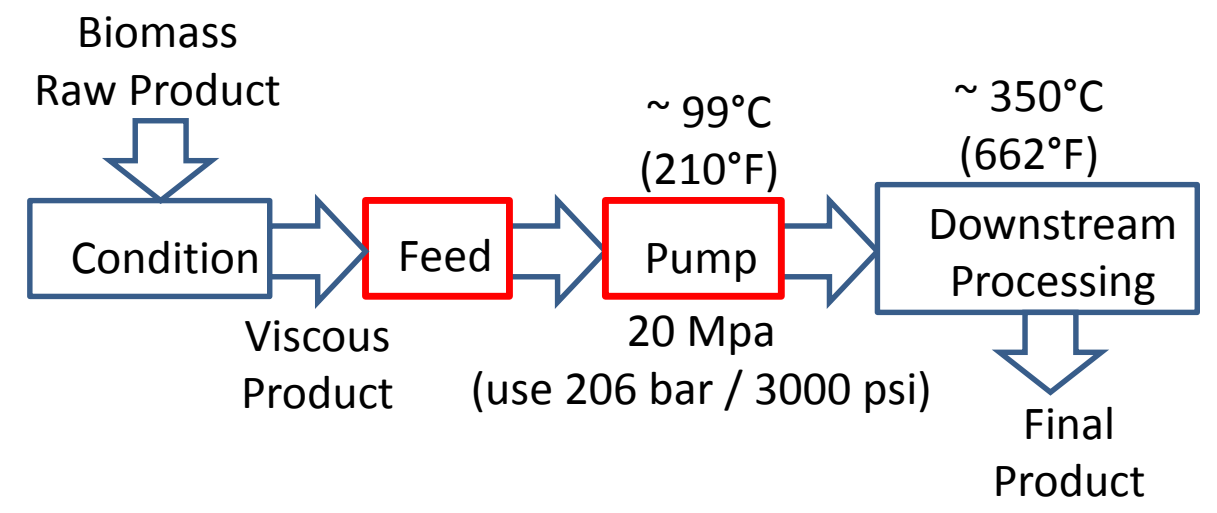

HTL Biomass Processing System

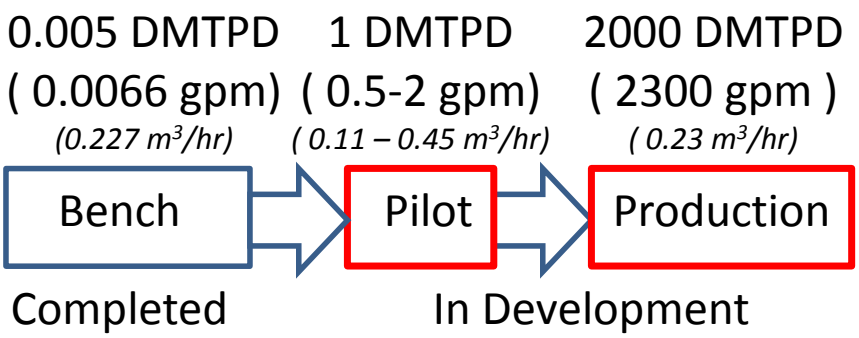

HTL Process Scale-Up

Figure ES.1. Problem Statement Diagram Provided to Pump Vendors 
By December 2011, many vendors had responded to PNNL's inquiries. Six vendors (Table ES.1) were identified that could provide viable equipment to meet HTL feed and/or pump needs. Those six vendors provided options consisting three types of positive displacement pumps (i.e., diaphragm, piston, and lobe pumps).

Vendors provided capabilities and equipment related to HTL needs (see Appendix C). This information was collected, assessed, and summarized in individual reports and used as the basis of this report. The six chosen vendors and their equipment are compared as a group and assessed as related to HTL application. A PNNL HTL pump vendor summary comparison is shown in Appendix A. Vendor contact information is provided in Appendix B.

Table ES.1. Vendors Identified in Pumpability Assessment

\begin{tabular}{lll}
\hline \multicolumn{1}{c}{ Vendor (Location) } & \multicolumn{1}{c}{ Pump Equipment Type } & \multicolumn{1}{c}{ Overall Summary Information } \\
\hline ABEL (Germany) & diaphragm - hydraulic membrane & $\begin{array}{l}\text { Appendix A (Pump Vendor } \\
\text { Comparison) } \\
\text { Appendix B (Vendor Contact }\end{array}$ \\
FELUWA (Germany) & diaphragm - hydraulic hose & $\begin{array}{l}\text { Details) } \\
\text { Putzmeister Holding GmbH (Germany) }\end{array}$ \\
piston - hydraulic dual piston & \\
Schwing Bioset (USA) & & \\
Weir Minerals (Netherlands) & & \\
Zeilfelder Pumpen (Germany) & lobe - rotary & \\
\hline
\end{tabular}

Feeding and pumping HTL biomass appears to be viable with commercial off-the-shelf equipment and specialized designs. All vendors were confident of feeding and pumping a flowable biomass like the HTL finely ground (0.0012-in./30-micron/0.03-mm) wood feedstock at $15 \mathrm{wt} \%$ dry solids with a measured 4-in. (102-mm) slump (see Figure ES 2). Other HTL feedstock with less slump and/or larger particle sizes can likely be pumped; however, feed and pump testing will be required.

Because biomass feedstock can have many variables (e.g., type, particle size, moisture content), pumpability testing is highly recommended for any new biomass feedstock, including HTL feedstock. Pumpability, pump selection, and required feed and pump options need to be verified. Past success with feeding and pumping HTL biomass at high pressures has been limited. However, new feed and pumping options from the vendors presented in Table ES. 1 and recent vendor experience pumping very challenging feedstock media gives new optimism for successfully pumping high-pressure HTL biomass. 

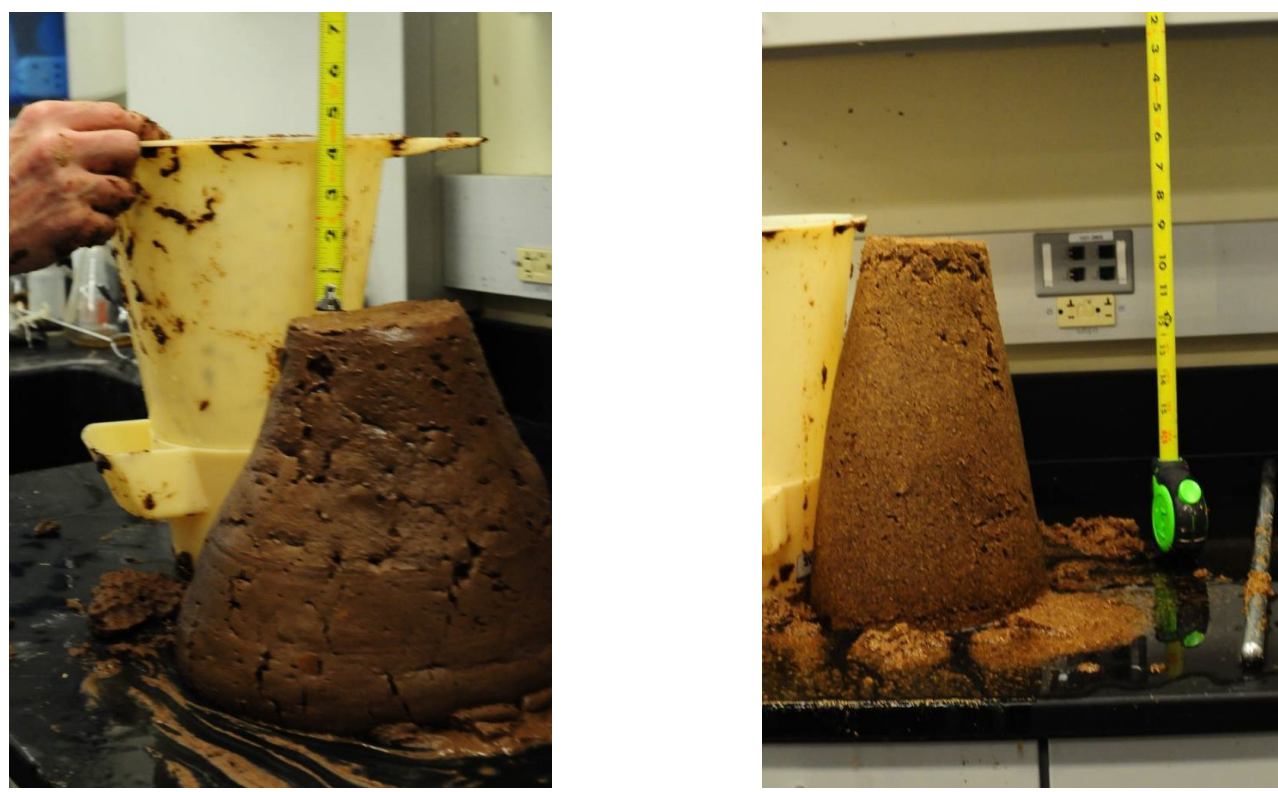

Figure ES 2. Slump Testing of HTL Feedstock. Left: 0.0012-in. (0.0-mm) immersion milled wood feedstock, $13 \mathrm{wt} \%$ solids, after 2.5 minutes, 4 in. (102 mm) of slump. Right: minus 0.0625-in. (1.59-mm) wet wood feedstock, $18 \mathrm{wt} \%$ solids, after 4 minutes, 0.5 in. (13 mm) of slump. Further dewatering is evident. 

PNNL-21981

\section{Acknowledgments}

This work was supported by the National Advanced Biofuels Consortium, which is funded by the U.S. Department of Energy's Office of Biomass Program with funds from the American Recovery and Reinvestment Act. 

PNNL-21981

\section{Acronyms and Abbreviations}

COTS

DMTPD

HTL

NABC

NPSH

PNNL

PWR

ROM

TEA

CAT-HTR

$\mathrm{HTU}^{\circledR}$

$\mu \mathrm{m}$

gpm

HP

in.

$\mathrm{kW}$

$\mathrm{m}^{3} / \mathrm{hr}$

$\mathrm{mm}$

$\mathrm{MPa}$

$\mathrm{Na}_{2} \mathrm{CO}_{3}$

Pas

psi (psig and psia) commercial off-the-shelf

dry metric tons per day

hydrothermal liquefaction

National Advanced Biofuels Consortium

net positive suction head

Pacific Northwest National Laboratory

Pratt \& Whitney Rocketdyne

rough order of magnitude

technical economic analysis

Catalytic Hydrothermal Reactor

Hydro-Thermal Upgrading

\section{Symbols and Units}

\section{Conversion Factors}

$\begin{array}{ll}\text { flow } & 1 \mathrm{gpm}=0.227 \mathrm{~m}^{3} / \text { hour; } 1 \mathrm{~m}^{3} / \text { hour }=4.403 \mathrm{gpm} \\ \text { length } & 1 \mathrm{in} .=25.4 \mathrm{~mm}=25400 \mathrm{micron} ; 1 \mathrm{~mm}=1000 \text { micron }=0.0394 \mathrm{in} . \\ \text { pressure } & 1 \mathrm{psi}=0.0069 \mathrm{MPa}=0.069 \mathrm{bar} ; 1 \mathrm{MPa}=145 \mathrm{psi}=10 \mathrm{bar} \\ \text { power } & 1 \mathrm{HP}=0.747 \mathrm{~kW} ; 1 \mathrm{~kW}=1.341 \mathrm{HP} \\ \text { viscosity (dynamic) } & 1 \mathrm{Pas}=1000 \text { centipoise }\end{array}$





\section{Contents}

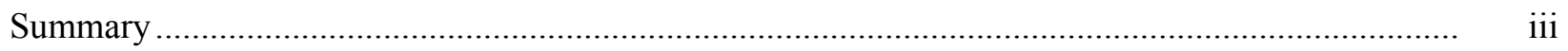

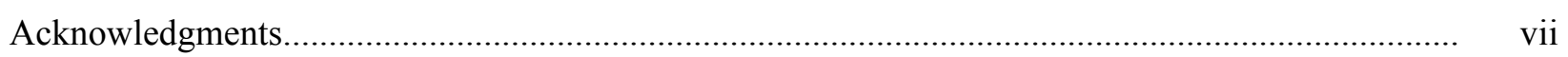

Acronyms and Abbreviations …………………………................................................. ix

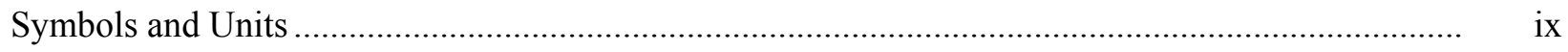

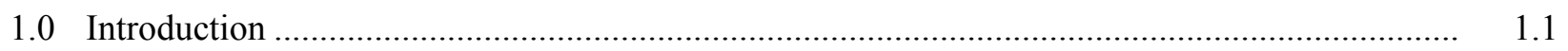

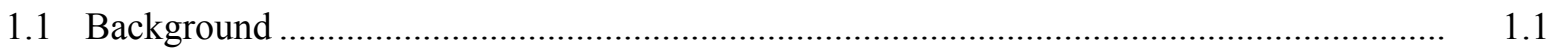

1.2 Objective of Assessment .......................................................................................... 1.1

2.0 Pump Vendor Assessment .................................................................................................. 2.1

2.1 Relevant Vendors Identified.................................................................................. 2.1

2.2 Vendor Equipment Capabilities/Equipment Types........................................................... 2.1

2.3 Vendor Biomass Experience .......................................................................................... 2.1

2.4 Vendor Pumpability of HTL Feedstock …………………………………………........ 2.2

2.5 Vendor Pump Capabilities, Features, Assessment ……………………………………... 2.3

3.0 Description of Pumps ........................................................................................................ 3.1

3.1 Diaphragm Membrane Pump (ABEL) ……………....................................................... 3.1

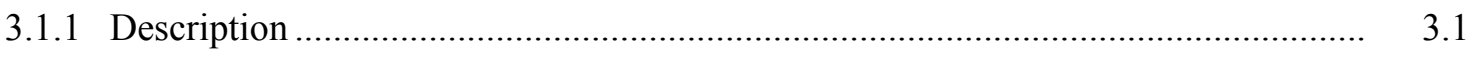

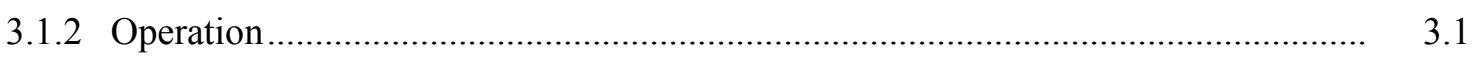

3.1.3 Vendors Identified..................................................................................... 3.2

3.1.4 Vendor Capabilities for HTL Application............................................................... 3.2

3.1.5 Assessment for HTL Application........................................................................ 3.3

3.2 Diaphragm Hose Pump (FELUWA) ………………................................................... 3.3

3.2.1 Description ................................................................................................ 3.3

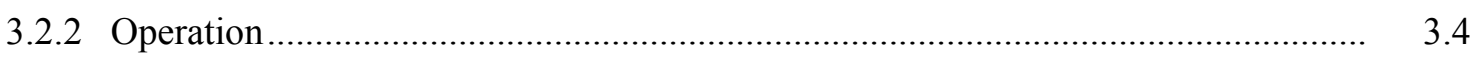

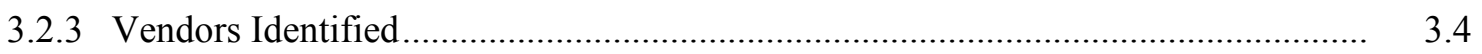

3.2.4 Vendor Capabilities for HTL Applciation............................................................... 3.5

3.2.5 Assessment for HTL Application...................................................................... 3.6

3.3 Solids Piston Pump (Schwing Bioset, Weir Minerals, Putzmeister)..................................... 3.6

3.3.1 Description .............................................................................................. 3.6

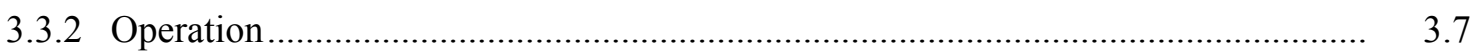

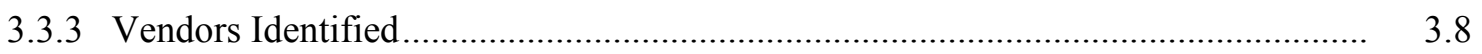

3.3.4 Vendor Capabilities for HTL Application............................................................ 3.8

3.3.5 Assessment for HTL Application.................................................................. 3.9

3.4 Rotary Lobe Pump (Zeilfelder Pumpen) ……………................................................ 3.10

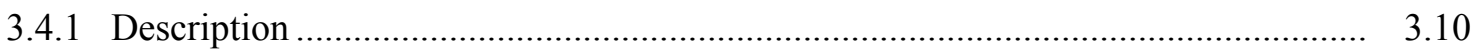

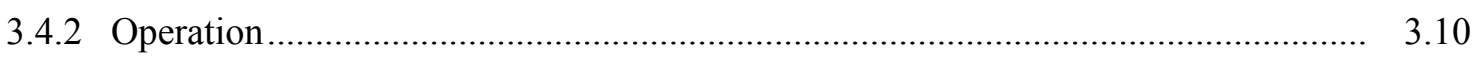

3.4.3 Vendor Capabilities for HTL Application............................................................ 3.11 
3.4.4 Assessment for HTL Application.................................................................... 3.12

4.0 Pump and Feeding System Components ..................................................................

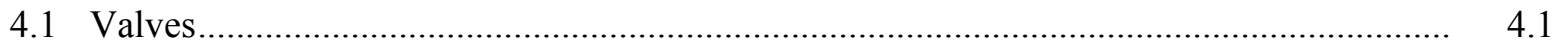

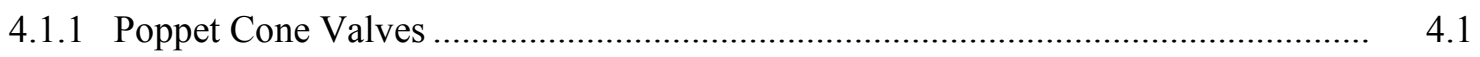

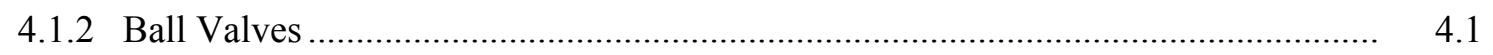

4.1.3 Swing Pipe Valves ............................................................................... 4.2

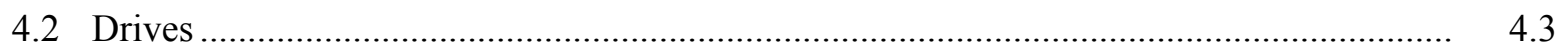

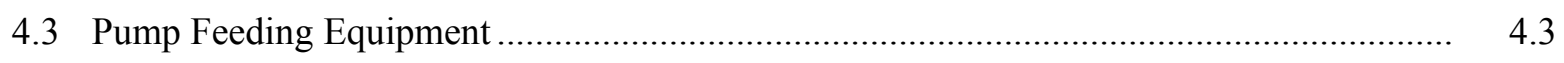

4.3.1 Screw Feeders/Augers .................................................................................... 4.3

4.3.2 Raw Feedstock Storage and Transport Systems................................................ 4.4

4.4 Specialized Component .............................................................................................. 4.5

4.4.1 Pipeline Injection System ................................................................................ 4.5

5.0 Feed and Pump System HTL Application ....................................................................... 5.1

5.1 HTL Processing Parameter Considerations................................................................. 5.1

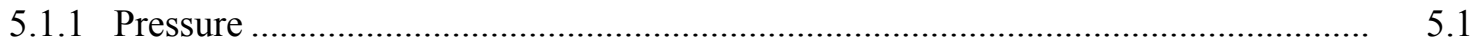

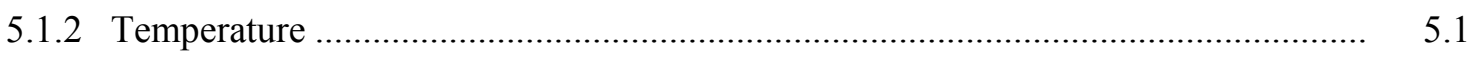

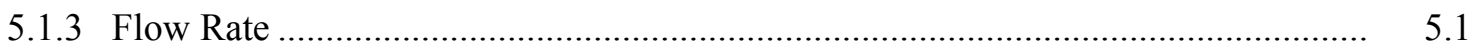

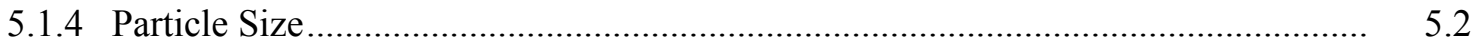

5.1.5 Weight Percent Solid Concentration ............................................................. 5.3

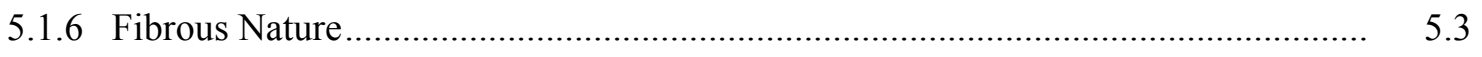

5.1.7 Abrasive Material .......................................................................................... 5.3

5.2 Vendor Summary - Pumpability Assessment ................................................................ 5.3

5.3 Vendor Summary - Pilot Plant................................................................................ 5.4

5.4 Vendor Summary - Production Plant........................................................................ 5.4

5.5 Suggested HTL Configuration and Options to Consider ................................................. 5.5

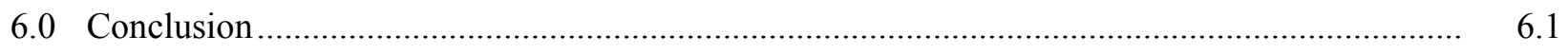

Appendix A - Pump Vendor Comparison Summary ................................................................. A.1

Appendix B - Pump Vendor Contact Details ............................................................................. B.1

Appendix C - "PNNL Biomass Process Feed \& Pump Equipment Needs" dated November 3, 2011 .

Appendix D - "Pumpability Assessment Query by PNNL to Vendors" dated early December, 2011

D.1

Appendix E - Other Vendors Explored/Contacted/Summary Results.......................................... E.1 


\section{Figures}

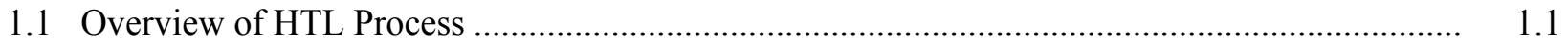

3.1 Diaphragm Membrane Pump - Schematic ......................................................................

3.2 Triplex Diaphragm Membrane Pump - ABEL HTM Series …................................................ 3.2

3.3 MULTISAFE Double Hose-Membrane Pump - Schematic..................................................... 3.4

3.4 MULTISAFE Triplex Double Hose-Membrane Pump .......................................................... 3.5

3.5 Solids Piston Pump - Dual Cylinder ..................................................................................... 3.7

3.6 Solids Piston Pump - Dual Cylinder …................................................................................ 3.7

3.7 Rotary Lobe Shapes Convex and Concave ....................................................................... 3.10

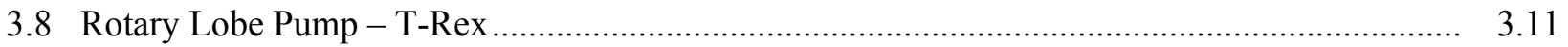

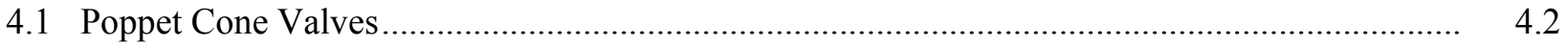

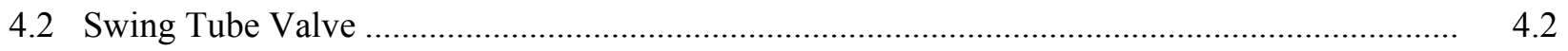

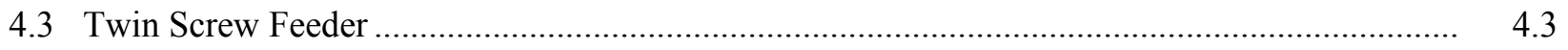

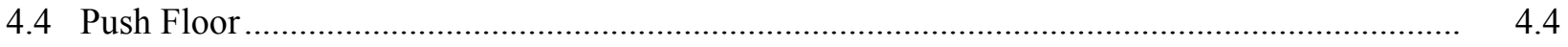

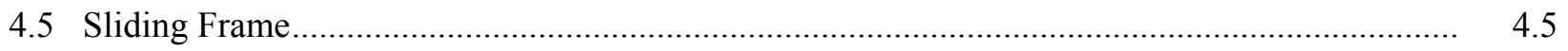

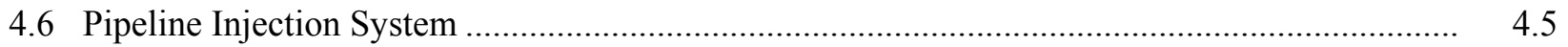

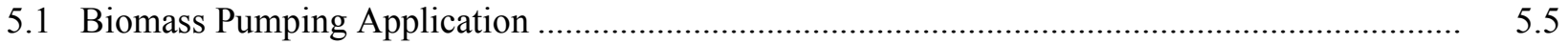

\section{Tables}

1.1 Pumpability Assessment Objective and Resolutions ........................................................... 1.2

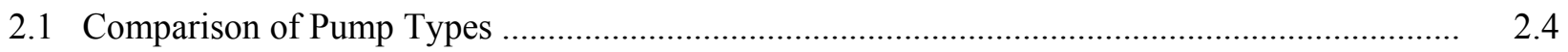



PNNL-21981

\subsection{Introduction}

\subsection{Background}

Pacific Northwest National Laboratory (PNNL), working as a partner in the National Advanced Biofuels Consortium (NABC), has the lead role in developing the hydrothermal liquefaction (HTL) process for converting biomass to biofuels. ${ }^{1}$ A technical-economic analysis (TEA) of the HTL process confirmed its high carbon yields and desirable biofuel product distribution; however, questions remained regarding scalability to a pilot- or production-plant with respect to pumping and reactor design. This assessment was conducted to address those questions by identifying commercially available pumping systems suitable for a production-scale plant.

In the HTL process application being investigated, fibrous base raw biomass feedstock, pine wood chips, or corn stover particles are mixed with water to form a paste-type slurry (nominally $15 \%$ dry weight solids). The slurry is highly viscous with non-Newtonian flow properties. Small amounts of other material (e.g., $\mathrm{Na}_{2} \mathrm{CO}_{3}$ ) may be added to this biomass feedstock to aid (e.g., adjust the $\mathrm{pH}$ ) in downstream processing. In the pilot- and production-scale systems, an aqueous stream (process recycle) containing $\sim 5 \%$ weight organic acids and alcohols (e.g., glycolic acid, acetic acid, methanol, ethylene glycol) will be used as the makeup water for the biomass slurry. The slurry is pumped to 15-20 MPa (2200-2900 psi $150-200 \mathrm{bar})$ and then heated to $300-350^{\circ} \mathrm{C}\left(570-662^{\circ} \mathrm{F}\right)$. The pressure is maintained above the vapor pressure of water to facilitate a condensed-phase reaction medium. The biomass solids are converted to a bio-oil, and the bio-oil is separated from the solids and aqueous phase. The generated bio-oil can then be upgraded (via hydrotreating) to produce a hydrocarbon product. Figure 1.1 presents a simplified sketch of the process.

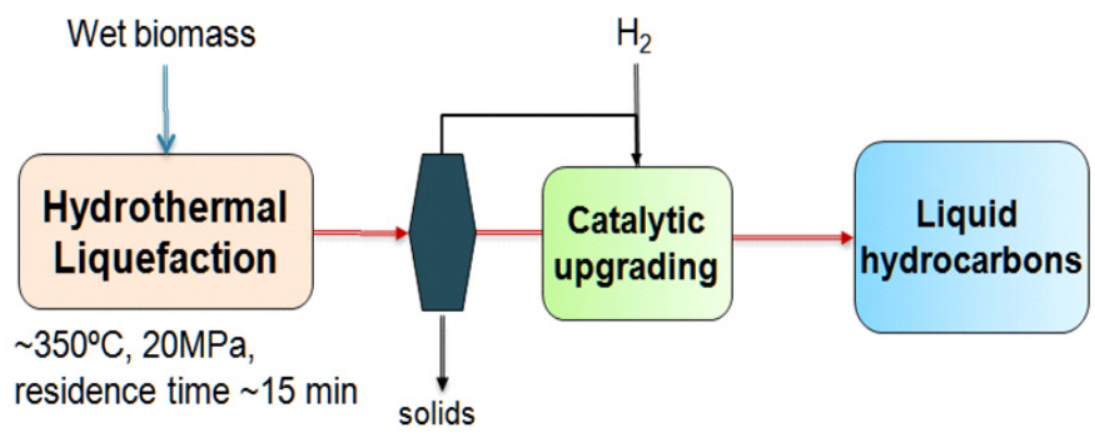

Figure 1.1. Overview of HTL Process

\subsection{Objective of Assessment}

The goal of this assessment is to identify viable industrial feed system and pump options for a 2000 dry metric tons per day (DMTPD) production-scale HTL plant. The key objectives of this assessment and their resolutions are summarized in Table 1.1.

\footnotetext{
${ }^{1}$ for more information see http://www.nabcprojects.org/hydrothermal liquefaction.html
} 
PNNL-21981

Table 1.1. Pumpability Assessment Objective and Resolutions

\begin{tabular}{|c|c|}
\hline Objective & Resolution \\
\hline $\begin{array}{l}\text { Identify relevant applications and industries operating } \\
\text { at comparable scales }\end{array}$ & $\begin{array}{l}\text { Pump and bulk material handling vendors were identified } \\
\text { in the following industries: } \\
\text { - biomass pelletization and briquetting (biomass feed } \\
\text { systems) } \\
\text { - concrete pumping (abrasive slurry) } \\
\text { industrial pumping - high-pressure and viscous } \\
\text { material pumping } \\
\text { municipal sludge handling/treatment - biomass feed } \\
\text { and pumping } \\
\text { pulp and paper industry - biomass feed and } \\
\text { pumping. }\end{array}$ \\
\hline $\begin{array}{l}\text { Interact with commercial vendors and pursue } \\
\text { integration between vendors }\end{array}$ & $\begin{array}{l}\text { Vendor searches within the relevant industries were } \\
\text { conducted. Vendors were contacted and information } \\
\text { exchanged. Further discussions were pursued when } \\
\text { viable HTL vendors were found. Six vendors were } \\
\text { identified, offering three pump types and various feeder } \\
\text { systems. Time and budget limitations did not allow the } \\
\text { pursuit of integration between vendors. }\end{array}$ \\
\hline $\begin{array}{l}\text { Take advantage of commercial off-the-shelf (COTS) } \\
\text { technology }\end{array}$ & $\begin{array}{l}\text { All six vendors could provide COTS technology but } \\
\text { would customize the equipment for HTL application. }\end{array}$ \\
\hline $\begin{array}{l}\text { Supply and support vendor needs for biomass } \\
\text { feedstock rheology characterization }\end{array}$ & $\begin{array}{l}\text { Some rheology testing was conducted at PNNL. } \\
\text { Additional rheology testing was performed at the request } \\
\text { of a vendor for slump test. HTL feedstock samples were } \\
\text { shipped to vendors at their request for pumpability } \\
\text { assessment that could include rheology testing. }\end{array}$ \\
\hline $\begin{array}{l}\text { Provide vendors with process requirements to support } \\
\text { selection of conceptual design for feedstock handing } \\
\text { and pump system. }\end{array}$ & $\begin{array}{l}\text { The document "PNNL Biomass Process Feed \& Pump } \\
\text { Equipment Needs," dated November } 3,2011 \text { was } \\
\text { generated by PNNL and supplied to vendors (see } \\
\text { Appendix C). This document included process } \\
\text { requirements and initial feedstock and rheology data. }\end{array}$ \\
\hline $\begin{array}{l}\text { Obtain cost data to the extent possible from equipment } \\
\text { vendors to support the TEA. }\end{array}$ & $\begin{array}{l}\text { Cost data was received from the six vendors and passed } \\
\text { along for TEA incorporation. }\end{array}$ \\
\hline Identify issues associated scale-up. & $\begin{array}{l}\text { Scale-up issues are addressed by vendor submittals of } \\
\text { pilot- and production-scale equipment. In addition, a } \\
\text { pump assessment query to vendors (see Appendix D) } \\
\text { addressed scale-up. Scale-up discussions and concerns } \\
\text { from vendors are noted. }\end{array}$ \\
\hline
\end{tabular}


PNNL-21981

\subsection{Pump Vendor Assessment}

\subsection{Relevant Vendors Identified}

The majority of vendors found to have feed and pump equipment suitable for HTL application are located in Europe - four in Germany and one in the Netherlands. Only one viable vendor is based in the United States. However, some of the European companies have U.S. subsidiaries. The larger European vendor base is believed to be the result of Europe's longer term and more extensive investment in biomass processes compared to the United States. Further, Europe has historically been a manufacturer of heavy-duty pumps for the world market. A summary of the relevant vendors selected for this assessment is provided in Appendix A. Vendor contact information is provided in Appendix B.

All viable vendors provide equipment for large industrial applications. Each vendor has at least 20 years of experience in biomass pumping or similar, difficult, pumping applications. Vendor company sizes range from large (e.g., Weir Minerals, Putzmeister), to medium (e.g., FELUWA, ABEL, Schwing Bioset), to small (e.g., Zeilfelder Pumpen) and, in general, the larger companies are equipped to provide full turnkey feed and pump systems whereas the small company is more focused on component supply (e.g., pumps). It should be noted that the medium-sized companies were very specialized to biomass or difficult pumping applications and may be considered equivalent to specialized groups within the large companies. The large vendors likely have more capital and resources available to develop specialized pumping applications. However, they may also have less enthusiasm for smaller, specialized applications like HTL unless they see a potential market.

Many vendors were explored in the search for viable HTL pump vendors. Appendix E summarizes vendor contacts that were identified, but not selected, for detailed assessment.

\subsection{Vendor Equipment Capabilities/Equipment Types}

All six viable vendors provide positive displacement pumps of various types (i.e., diaphragm, piston, and rotary lobe) to meet HTL application needs. Full feed system equipment, from raw stock storage (e.g., silos, bins, hoppers) to material handling (e.g., push floors, sliding frames) to the pump inlet were available as integrated systems from both large and at least one medium company (Schwing Bioset). Local feed systems connected to the pump (generally twin screw augers) are routinely provided as needed for the application. In addition, downstream components (e.g., line injection systems for reducing pipe friction) are provided by many of the vendors (i.e., ABEL, Putzmeister, Weir Minerals).

Further details regarding the various equipment offered by vendors and relative comparisons are presented throughout this assessment.

\subsection{Vendor Biomass Experience}

The wood chips and corn stover (i.e., dried, chopped corn stalks) biomass HTL feedstock is a difficult material to pump; especially at solids loadings above $15 \mathrm{wt} \%$. This type of biomass feedstock tends to form bridges in opening, especially when larger particle sizes are involved. In addition, it can pack/plug at a constriction when under pressure; especially if dewatering occurs. However, some recent pumping application developments show great promise for pumping this feedstock. New equipment and process 
configurations allow pumping of materials that, in the past, were impossible to pump. The vendors included in this assessment are specialized in this type of application and use rheology, characterization test (e.g. slump test, dewatering test, etc.) and past experience to solve new pumping applications, including biomass.

The typical biomass application of all vendors is the pumping of dewatered sewage sludge, which has different pumping characteristics than the HTL feedstock of wood chips and corn stover. Putzmeister has direct experience pumping biomass with its solids piston pumps at HTL pressures and has supplied the pumps for a condensed-phase liquefaction pilot-plant demonstration. Schwing Bioset has direct experience pumping wood chips in several testing applications with its solids piston pumps, but likely at pressures below 500 psi (34 bar). Other non-sewage biomass experience includes FELUWA pumping agriculture mixtures with its diaphragm hose pump and Zeilfelder Pumpen pumping silage with its rotary lobe pump with chopping blades. The vendor information presented in this report was extracted from more detailed PNNL write-ups; those write-ups are not publicly available and for NABC use only.

Pumping HTL-type feedstock at pressures of 3000 psi (206 bar) is likely a new application for most vendors. In general, vendors that have direct application with HTL-type feedstock pump at much lower pressures (e.g., $\leq 725$ psi [50 bar]). Although the selected vendors may not have pumped biomass exactly like that used in HTL, they have specialized in pumping difficult materials and understand the issues associated with pumping HTL feedstock. In all cases, vendors recommended pumpability testing to verify pump designs and suggested that production-scale equipment is likely to be more successful than pilot-scale equipment.

\subsection{Vendor Pumpability of HTL Feedstock}

The target HTL biomass feedstock are at the extreme edge of pumpability, especially at higher solid concentrations (above 15\% weight dry solids) and larger particle sizes 0.08 to 0.2 in. ( 2 to $6 \mathrm{~mm}$ ). Biomass feedstock, with its fibrous nature, tends to adhere to itself, entangle, and bridge across openings, which makes it difficult to feed and pump. However, the vendors were extremely confident that the finely ground (0.0012-in/30-micron/0.03-mm.) wood feedstock at $15 \%$ weight dry solids with a measured 4-in. (102-mm) slump is a pumpable biomass material.

Vendor experience indicated that biomass feedstock needs to be tested for pumpability if it is not flowable (i.e., slump less than 4 in. [102 mm]) and/or has one or more of the following conditions: contains little moisture; dewaters easily; has large particles. Feedstock testing may include rheology testing on small feedstock samples or pump testing on actual material. PNNL has performed rheology tests on some HTL feedstock and two vendors have the capability to perform rheology tests (FELUWA, Weir Minerals). Tests involving actual pumping of the feedstock material using full-scale equipment are ultimately what determine if a feedstock can be pumped. Vendors cautioned that pump testing on a smaller-than-production scale could return false results that the feedstock is "not pumpable," when in fact it could be pumped at production scale. When it comes to feeding and pumping biomass, larger openings and pipe sizes are generally preferred to limit feedstock bridging and thus enhance feedstock pumpability.

Vendors can employ various methods to enhance feedstock pumpability (e.g., pump speed adjustment, screw feeder and mixers, feedstock size reduction equipment [like macerators], and line injectors that coat surfaces with fluid to reduce friction). Equipment is likely to need adjustment for each feedstock to achieve flow through the system and optimize performance and efficiency. Only testing will 
show which equipment combinations and operating parameters can be used to successfully pump the more challenging HTL feedstock and feedstock conditions (i.e., type, particle size, wt $\%$ dry solids).

Finally, there appears to be a renewed interest worldwide in developing applications like HTL to convert biomass to biofuels. In our vendor queries for HTL, some vendors responded that they had similar pumping requests to HTL for pumping biomass and HTL biomass feedstock but must maintain confidentiality about the inquiring organizations and their associated processes. In some of these processes, like the Steeper Energy's proprietary technology Hydrofaction ${ }^{\mathrm{TM}}$ process, the required pumping pressures are much higher than HTL. Further, other HTL-like processes (e.g., Licella's CATHTR and the older HTU ${ }^{\circledR}$ process) in various states of development have had success in pumping HTL biomass material at HTL pressures or higher. In addition, many biomass gasifier processes exist for pumping HTL-type feedstock, but generally at pressures below 500 psi (34 bar).

\subsection{Vendor Pump Capabilities, Features, Assessment}

During these HTL biomass pumpability investigations, three types of positive displacement pumps (i.e., diaphragm, solid piston, and rotary lobe) were identified to pump the HTL feedstock of wood chips and corn stover to $3000 \mathrm{psi}$ (206 bar) and $2300 \mathrm{gpm}\left(637 \mathrm{~m}^{3} / \mathrm{hr}\right)$. Vendors were most confident in their ability to pump HTL feedstock finely ground in an immersion mill and exhibiting a slump of at least 4 in. (102 mm). Each type of pump has advantages and disadvantages for pumping HTL biomass. Table 2.1 compares each pump type, provides the operating principles for each pump type, and lists features that can be employed with the pumps to enhance pumpability.

It should be noted that one of the criteria of our investigation into HTL biomass pumping was that the pump be scalable (i.e., the pilot plant pump could be scaled up for the production plant). All six vendors were able to offer scalable pumps, but generally the pumps had flow rates appreciable larger than required for a 1 DMTPD pilot plant. Smaller pumps that scale up to the production plant scale are not available. Therefore, to maintain pump scalability between the pilot- and production-scale plants, either the pilot plant will need be larger or pumped product will have to be bled off in a slipstream arrangement to meet pilot-plant flow requirements and the excess product flow recycled. 
PNNL-21981

Table 2.1. Comparison of Pump Types

\begin{tabular}{|c|c|c|c|c|}
\hline \multirow[b]{3}{*}{ Pump Type } & \multicolumn{4}{|c|}{ Positive Displacement } \\
\hline & \multicolumn{2}{|c|}{ Diaphragm } & \multirow[b]{2}{*}{ Piston } & \multirow[b]{2}{*}{ Rotary Lobe } \\
\hline & Membrane & Hose & & \\
\hline Vendor & ABEL & FELUWA & $\begin{array}{l}\text { Putzmeister, Schwing } \\
\text { Bioset, Weir Minerals }\end{array}$ & Zeilfelder Pumpen \\
\hline \multirow[t]{15}{*}{ Key Advantages } & Pressure obtained in a & High viscosity handling & Highest viscosity & Simple design \\
\hline & single stage -3625 psi & Pressure obtained in a & handling & Operation to $842^{\circ} \mathrm{F}$ \\
\hline & (250 bar) exceeds HTL & single stage up to 4600 & Pressure obtained in a & $\left(450^{\circ} \mathrm{C}\right)$ \\
\hline & Ginim & psi (320 bar) greatly & single stage -3000 to & Lobe blades chop fiber \\
\hline & $\begin{array}{l}\text { Minimal contact of } \\
\text { components with }\end{array}$ & $\begin{array}{l}\text { exceeds } \mathrm{H} 1 \mathrm{~L} \text { pressure } \\
\text { requirement }\end{array}$ & $\begin{array}{l}4350 \text { ps1 (206 to } 300 \\
\text { bar) }\end{array}$ & material \\
\hline & feedstock & Large particle handling & Large particle handling & Largest particle size \\
\hline & Minimal pulsation & to 3 in. $(75 \mathrm{~mm})$ & to 2 in. $(51 \mathrm{~mm})$ with & $(102 \mathrm{~mm})$ \\
\hline & & Minimal contact of & swing tube valve & High viscosity handling \\
\hline & & $\begin{array}{l}\text { components with } \\
\text { feedstock }\end{array}$ & $\begin{array}{l}\text { Flow rate adjustable } \\
\text { over large range }\end{array}$ & High solids content, \\
\hline & & $\begin{array}{l}\text { Rupture of hose } \\
\text { diaphragm is protected }\end{array}$ & $\begin{array}{l}\text { Proven in past } \\
\text { applications similar to }\end{array}$ & $\begin{array}{l}\text { Pressure up to } 3625 \text { psi } \\
\text { ( } 250 \text { bar) possible }\end{array}$ \\
\hline & & by a second hose & HTL & No valving required, No \\
\hline & & diaphragm & Low stroke rate & pulsation \\
\hline & & Minimal pulsation & & $\begin{array}{l}\text { Run backwards as a } \\
\text { generator to recover } \\
\text { power }\end{array}$ \\
\hline & & & & Low maintenance \\
\hline & & & & $\begin{array}{l}\text { Replaceable wear } \\
\text { components }\end{array}$ \\
\hline \multirow{8}{*}{$\begin{array}{l}\text { Key } \\
\text { Disadvantages }\end{array}$} & Solids content limited to & Viscosity handling may & Possible flow pulsation & Multiple stages required \\
\hline & around $10 \%$ & $\begin{array}{l}\text { be slightly lower than } \\
\text { piston pumps }\end{array}$ & Available Putzmeister & $\begin{array}{l}\text { to build pressure }-710 \\
\text { psi ( } 50 \text { bar) per stage }\end{array}$ \\
\hline & handling than piston & Higher stroke rates than & 1885 psi (130 bar) & Suction feed requires \\
\hline & pumps & piston pumps & Use of cone valves may & sufficient NPSH \\
\hline & $\begin{array}{l}\text { Rupture of diaphragm } \\
\text { exposes process media }\end{array}$ & $\begin{array}{l}\text { Suction feed requires } \\
\text { sufficient NPSH }\end{array}$ & $\begin{array}{l}\text { limits particle size to } \\
0.5 \mathrm{in} .(12.7 \mathrm{~mm})\end{array}$ & ble \\
\hline & to hydraulic fluid & available & Highest maintenance & \\
\hline & $\begin{array}{l}\text { Higher stroke rates than } \\
\text { piston pumps }\end{array}$ & & & \\
\hline & $\begin{array}{l}\text { Suction feed requires } \\
\text { sufficient net positive } \\
\text { suction head (NPSH) } \\
\text { available }\end{array}$ & & & \\
\hline
\end{tabular}




\subsection{Description of Pumps}

\subsection{Diaphragm Membrane Pump (ABEL)}

\subsubsection{Description}

Diaphragm membrane pumps (subsequently referred to as membrane pumps) are positive displacement pumps. A pump cavity is formed by a suction valve on the inlet side and a discharge valve on the outlet side. A moveable membrane between these valves can alter the volume of the pump cavity. Movement of the membrane is typically actuated by a piston connected directly to the membrane or by using an intermediate mechanism like hydraulic fluid to transfer pressure to the membrane. Membrane pumps come in various configurations, but are often ganged together in duplex, triplex, or quadplex configurations to increase total flow and/or reduce pulsation peaks by offsetting the timing between ganged pumps. This offset is typically defined by the drive system, which consists of an engine-type crankshaft, rods, and pistons.

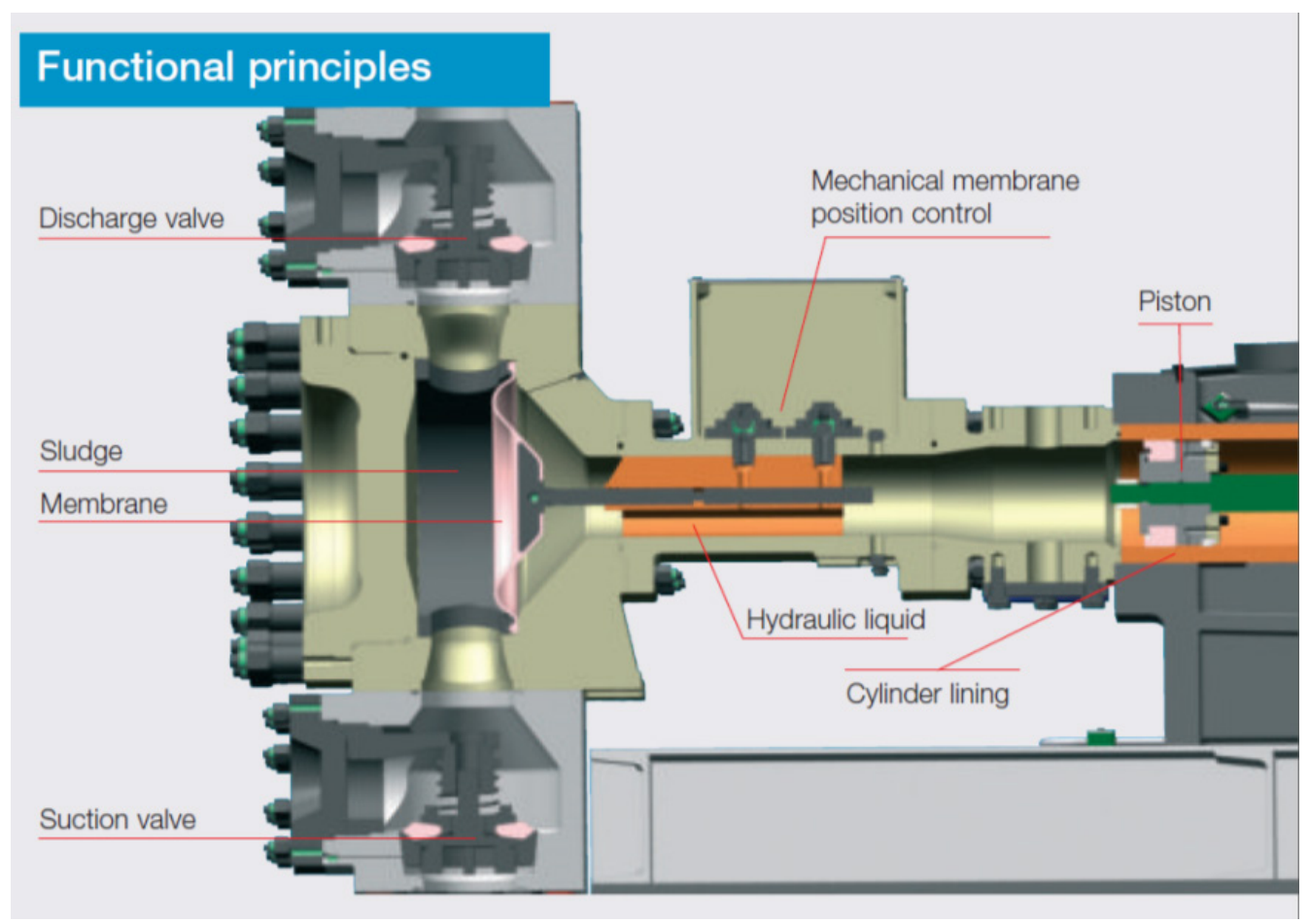

Figure 3.1. Diaphragm Membrane Pump - Schematic (information from ABEL literature)

\subsubsection{Operation}

Material to be pumped is drawn into the pump cavity by suction force by first closing the discharge valve, then opening the suction valve, and then moving the membrane to increase the cavity volume (i.e., suction). When full cavity volume is obtained by membrane movement, the suction valve closes, the discharge valve opens, and membrane moves to decrease pump cavity volume and thus push materials out of the pump with increasing pressure. This synchronous process is repeated to create continuous pump flow. Pump flow can be adjusting by varying the stroke rate. 
PNNL-21981

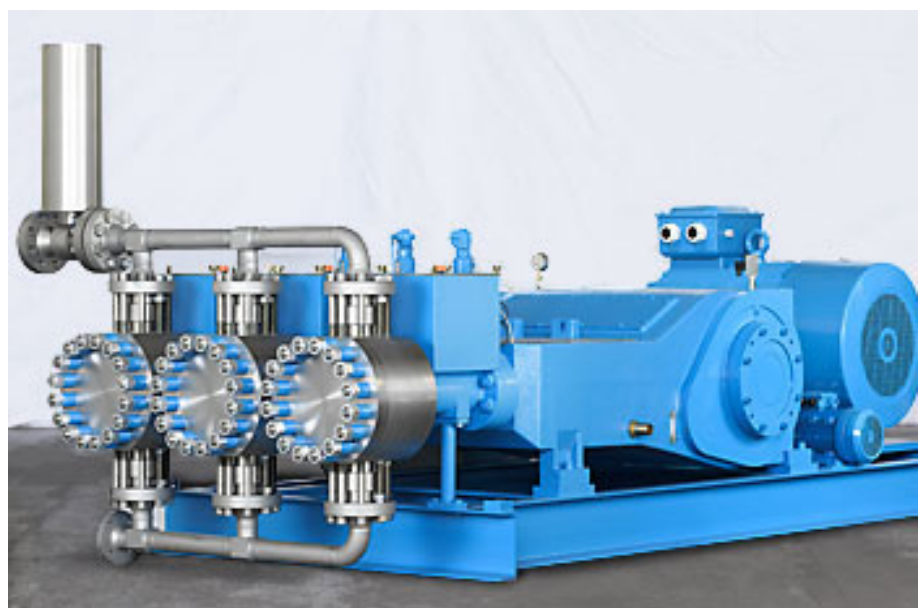

Figure 3.2. Triplex Diaphragm Membrane Pump - ABEL HTM Series (information from ABEL literature)

\subsubsection{Vendors Identified}

Many manufacturers build membrane pumps; however, those identified for consideration in HTL application are ABEL, FELUWA, and Weir Minerals. FELUWA and Weir Mineral membrane pumps have similar capabilites to the ABEL pump and likely would be viable substitutes. To simplify the discussion, only the ABEL membrane pump will be discussed. ABEL was the sole manufacturer to propose a membrane pump for HTL application.

\subsubsection{Vendor Capabilities for HTL Application}

The ABEL membrane pump is a robust pump built for industial application and continous operation. ABEL custom designs each pump for the application and, therefore, long lead times can be expected. ABEL has designed a pre-formed membrane for its pumps that does not stretch during stroking action; this is advantageous to longivity of ABEL membrane pumps compared to similar membrane pumps. The piston is isolated from the membrane by using a hydraulic liquid interface. The ABEL membrane pump can operate at temperatures up to $392^{\circ} \mathrm{F}\left(200^{\circ} \mathrm{C}\right)$ with standard materials and up to $572^{\circ} \mathrm{F}\left(300^{\circ} \mathrm{C}\right)$ with available customizations.

ABEL has specified a triplex pump for HTL application that should produce a continous flow with small pulsation variations. Pumps are sychronized 120 degrees apart. If required, pulsation variations can be reduced further with pulsation dampers. ABEL has stated that use of this pump in biomass applications may be limited to solid concentrations of around $10 \mathrm{wt} \%$ (more if the medium is flowable) and that the pump is often used in biomass solid concentrations in the $5 \mathrm{wt} \%$ or lower range - usually sewage wastewater or similar. The check valves on this pump, suction and discharge, are spring loaded cone valves typically specified for high-pressure operation with fibrous material. Hydraulically operated cone valves are not available with this pump type. The pump requires that the media be flowable. The pump cavity suction feed requires sufficient NPSH, which might require a screw feeder with HTL feedstock. 
ABEL's biomass pumping experience primarily includes biosolids related to sewage treatment and feedstock that may be more fibrous (e.g., wine lees and sugar beet slurries). ABEL did provide an example of wood chip pumping using an ABEL membrane pump (EM series); however, details and applicability of this process to HTL were not ascertained. Recently, ABEL used its solids piston pump to pump biosolids at the Enertech biomass plant producing SlurryCarb ${ }^{\mathrm{TM}}$.

\subsubsection{Assessment for HTL Application}

The ABEL membrane pump appears to be applicable to flowable feedstock, but not all HTL feedstocks are expected to be flowable. Biomass solid concentrations above $10 \mathrm{wt} \%$ may be challenging, and, unlike the other pump options explored in this report, may require preprocessing of the feed to a smaller particle sizes. ABEL indicated that if the feedstock can be made to flow into the pump, the membrane pump is preferrable to the solids piston pump because it is more efficient, easier to maintain, and does not require a standalone hydraulic system.

Finally, ABEL literature states that their HTM series pump is designed for hydraulic solids transfer, including pumping suspensions with high dry substance content and high specific weight. However, HTL feedstocks typically have a low specific weight, especially when compared to mine slurries. If fine grain material is being pumped with solids loading around $10 \mathrm{wt} \%$ or less, the ABEL membrane pump is a pump to consider.

\section{References}

More details related to the ABEL membrane pump discussed in this section can be found at the ABEL website: http://www.abel.de.

\subsection{Diaphragm Hose Pump (FELUWA)}

\subsubsection{Description}

Diaphragm hose pumps (subsequently referred to as hose pumps) are positive displacement pumps. This pump works like a typical membrane pump (see description in Section 3.1), but instead of a membrane (flat) surface, the diaphragm surface is cylindrical and, during pumping, squeezes the media in a similar fashion to a human vein pumping blood (Figure 3.3). Hose pump membranes are moved by a hydraulic action; typically using a crankshaft-driven piston to displace the hydraulic fluid, which in turn moves the hose diaphragm. Hose pumps come in various configurations, but are often ganged together in duplex, triplex, and quinplex configurations to increase the total flow and/or reduce the pulsation peaks by offsetting the timing between ganged pumps. This offset is typically defined by a drive system, which consists of an engine-type crankshaft, rods, and pistons. 
PNNL-21981

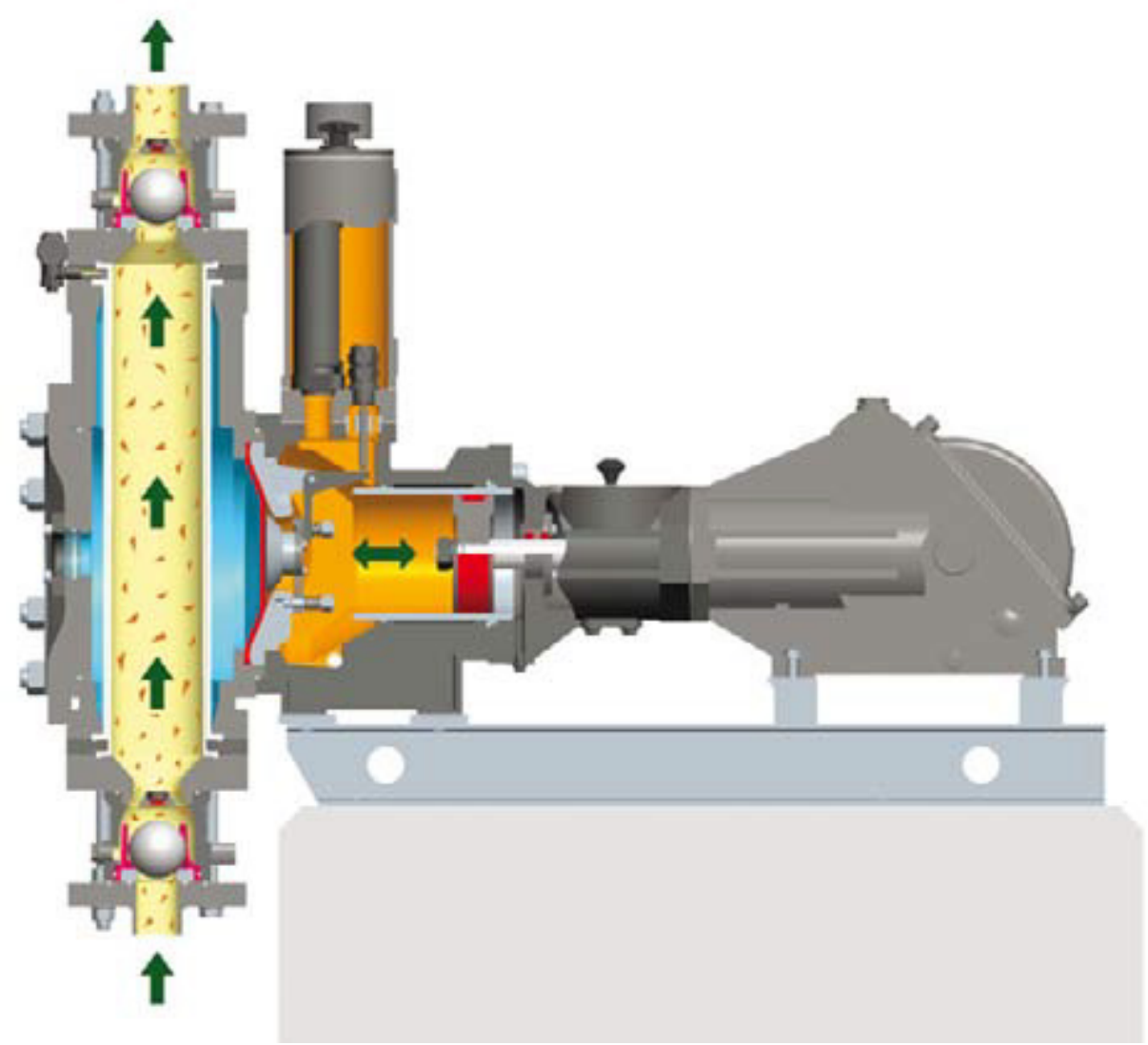

Figure 3.3. MULTISAFE Double Hose-Membrane Pump - Schematic (information from FELUWA literature)

\subsubsection{Operation}

Material to be pumped is drawn into the pump cavity by the suction force of first closing the discharge valve, then opening the suction valve, and then moving the membrane to increase the cavity volume (i.e., suction). When full cavity volume is obtained by membrane movement, the suction valve closes, the discharge valve opens, and membrane is moved to decrease pump cavity volume and thus push materials out of the pump with increasing pressure. This synchronous process is repeated to create continuous pump flow. Pump flow can be adjusting by varying the stroke rate.

\subsubsection{Vendors Identified}

Hose pumps discussed here for industrial applications are much less common than membrane pumps. Peristaltic hose pumps are different than diaphragm hose pumps because peristalic pumps use a mechanical roller to deform a hose against a hard surface to move material instead of the constricting action used by the diaphragm hose pump. Diaphragm hose pump manufacturers identified for consideration in HTL application are FELUWA and Weir Minerals. The FELUWA hose pump is fully developed to meet HTL applications. The Weir Mineral hose pump is not developed at this time to meet HTL applciation requirements, but could, in the future, be an option to consider becuase of some unique features that may be useful for HTL biomass pumping. To simplify the discussion, only the FELUWA hose pump will be discussed. FELUWA was the sole vendor to propose a hose pump for HTL application. 
PNNL-21981

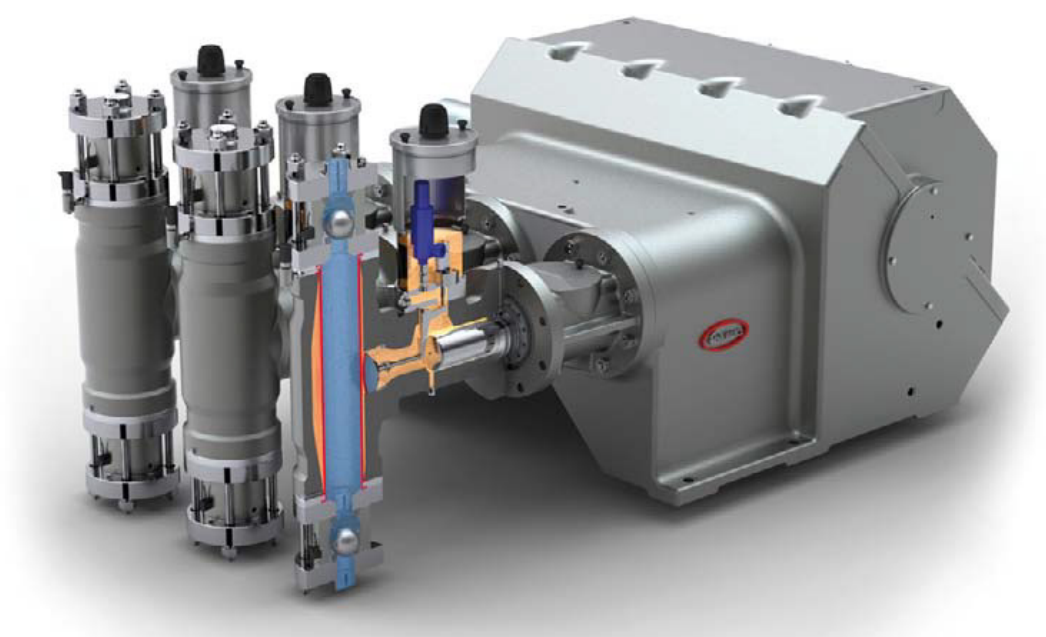

Figure 3.4. MULTISAFE Triplex Double Hose-Membrane Pump (information from FELUWA literature)

\subsubsection{Vendor Capabilities for HTL Applciation}

The FELUWA hose pump is a robust pump built for industial application and continous operation. FELUWA custom designs each pump and associated equipment for the application and, therefore, long lead times can be expected. FELUWA offers two types of hose pumps. Both use a double diaphragm design where the inner diaphragm is driven by the outer diaphragm with a small volume of hydraulic fluid in between. FELUWA's standard hose pump uses a diaphragm membrane pump to activate the inner hose diaphragm. FELUWA's specialized, but more expensive, MULTISAFE pump uses a double hose configuration with the membrane diaphragm in its standard hose pump replaced with a hose diaphragm so that the outer hose diaphragm is driving the inner hose diaphragm through an intermediate hydraulic fluid. These hose pumps are slightly more complex than standard diaphragm pumps, but offer several advantages, including the ability to pump more viscous material and increased reliability due to the fact that the pump can still operate with a rupture of the inner hose diaphragm. FELUWA has indicated that its MULTISAFE hose pump is preferrable if any abrasive material is expected in the HTL feedstock. These hose pumps can operate at $257^{\circ} \mathrm{F}\left(125^{\circ} \mathrm{C}\right)$ with standard diaphragm materials and up to $392^{\circ} \mathrm{F}$ $\left(200^{\circ} \mathrm{C}\right)$ with special diaphragm membrane materials.

FELUWA has specified a quinplex MULTISAFE diaphragm hose pump for HTL application that should produce a continous flow with small pulsation variations. Pumps are sychronized 72 degrees apart. If required, pulsation variations can be reduced further with pulsation dampers. This pump was recommended because it is highly reliable, has increased flexibility to handle various types of feedstock, and handles abrasive material. The hose pump requires valves to operate and FELUWA promotes its experience in the design of process-specific valves, including free-floating, spring-loaded, and forcedcontrol (e.g., hydraulically activated) valves. The details of pump valve configuration for HTL application requires further investigation; however, one option that should be considered is hydraulically actuated ball valves. 
FELUWA states that for the hose pump to operate, the conveying fluid needs to arrive and be injected into the pump chamber. FELUWA considers a pumpable media to have a viscosity less than 5 Pas (5000 times the viscosity of water). Media with viscosities above 5 Pas can be pumped, but often require the addition of forced-control valves (e.g., hydraulically activated ball valves) and worm feed (e.g., screw conveyor) to inject the media into the pump chamber. FELUWA has stated that more challenging HTL feedstock will require these additional components.

This assessment has verified that FELUWA's biomass pumping experience includes primary biosolids related to sewage treatment and feedstock that may be more fibrous (e.g., a ground corn mixture). FELUWA confirmed that its hose pumps should be capable of pumping HTL feedstock concentrations of $15 \mathrm{wt} \%$ or higher.

\subsubsection{Assessment for HTL Application}

The FELUWA hose pump is an exellent candidate for HTL application. The FELUWA hose pump is unique and it is likely this type of pump has not been considered previously in the biomass community for high-pressure biomass pumping. The FELUWA hose pump is capable of the highest maximum pressure (4600 psi [320 bar]) among the vendors and equipment assessed in this report. This hose pump appears to be capable of pumping HTL-type biomass feedstock with solid loading beyond $15 \mathrm{wt} \%$. FELUWA's rheology testing on HTL samples gives additional creedence to its pump assessment. The FELUWA hose pump appears to be elogant, highly reliable, and compares favorably to other pump types. In addition, maintenance requirements are less than those of solids piston pumps. However, hose pumps may not handle more viscous biomass feedstock as well as solids piston pumps.

Because of the hose pump's ability to handle higher solid content feedstock, it appears to exhibit greater flexiblity than the membrane pump for HTL application. Transporting material into the pump chamber is likely easier with a solids piston pump than with a hose pump. Finally, solids piston pumps have been used historically for hard-to-pump applications and have an advantage in techology maturity and available knowledgebase.

\section{References}

More details related to the FELUWA diaphragm hose pump discussed in this section can be found at the FELUWA website: http://www.feluwa.de/en/news/.

\subsection{Solids Piston Pump (Schwing Bioset, Weir Minerals, Putzmeister)}

\subsubsection{Description}

Solids piston pumps are positive displacement pumps. Piston pumps work on the principle of filling the piston chamber with media as the piston is retracted (suction stroke) and then forcing the media out of the piston chamber on the return stroke (discharge stroke) (Figure 3.5). Valves (see Section 4.1.3), are used to isolate and open the piston pump chamber to the discharge line during the piston stroking action. In single-acting pumps, the media being pumped is only exposed to one side of the piston. On double acting pumps, the media is exposed to both sides of the piston and suction/discharge is occurring simultaneously on different sides of the piston. Piston pumps come in various configurations. In general, in larger applications, either a single-piston or dual-piston chamber is used. More than two pistons are used in some applications; however, it is uncommon. 


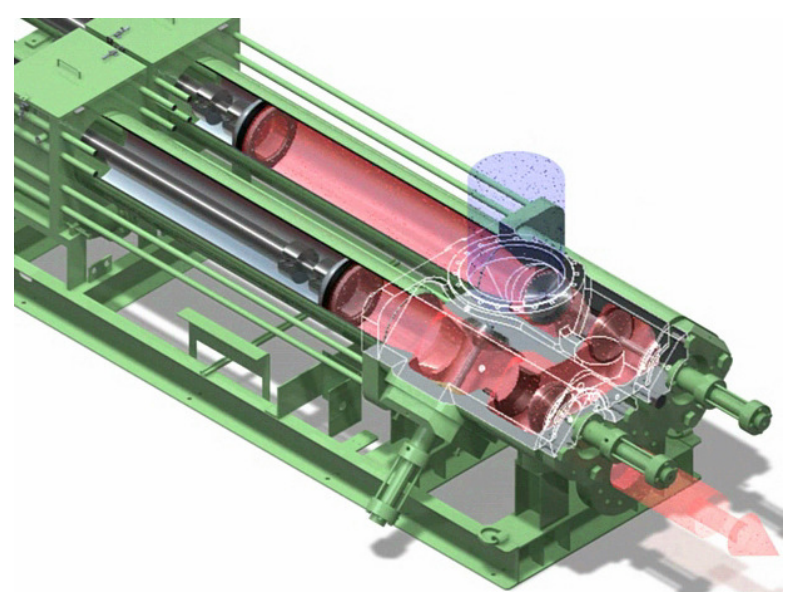

Figure 3.5. Solids Piston Pump - Dual Cylinder (information from Weir Minerals literature)

\subsubsection{Operation}

Media to be pumped is first drawn into the pump cavity by sealing off the discharge line (closing the discharge valve or moving the S-swing pipe), then opening the material feed (suction valve or equivalent). The piston is moved to increase the cavity volume and media is drawn into the pump by the resulting suction, gravity, and/or optional feeder system. In cases where more viscous material is being pumped, the cylinder chamber fill is aided by a feeder system (e.g., twin screw feeder) that pushes the media into the chamber. When full cavity volume is obtained by piston movement, the material feed is isolated (suction valve is closed or equivalent) and the discharge line is opened (opening the discharge valve or moving the S-swing pipe). The piston is moved to decrease pump cavity volume and thus push materials out of the pump with increasing pressure. This synchronous process is repeated to create continuous pump flow. Pump flow can be varied by adjusting the stroke rate. In general, the flow pulsation from piston pumps is higher than comparable diaphragm or rotary pumps.

The pumps considered for HTL application are all single-acting pumps but in a dual cylinder application (Figure 3.5 and Figure 3.6) where two pistons are operated 180 degrees out of phase, both discharge into a single output pipeline. In this configuration, the dual pump chambers are alternately being filled and emptied, creating a steady output flow. Single-acting pumps in a single-cylinder application offer no advantage over the dual-cylinder application and have the disadvantage of large flow pulsations. [Note that that the continuous flow HTL bench-scale development testing uses two positive displacement Teledyne ISCO metering pumps operating in a similar manners the dual cylinder piston pump].

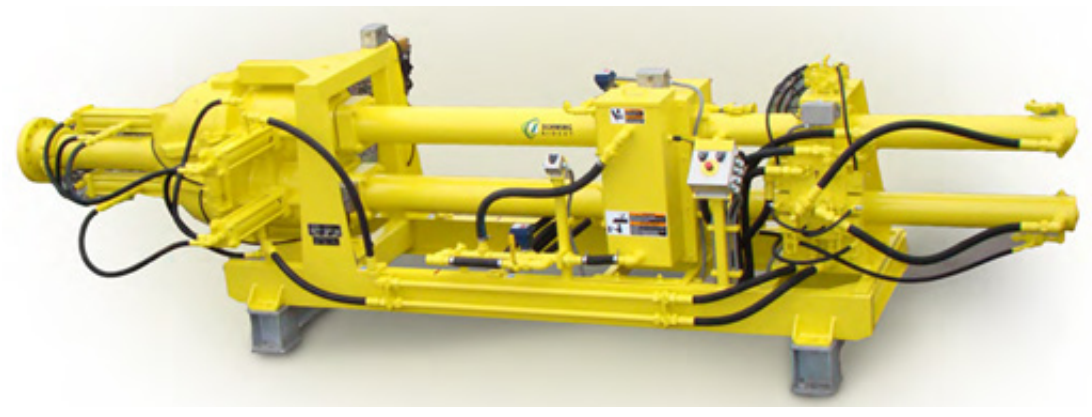

Figure 3.6. Solids Piston Pump - Dual Cylinder (information from Schwing Bioset literature) 
PNNL-21981

\subsubsection{Vendors Identified}

Solids piston pumps are made by many manufacturers. Those identified for consideration in HTL application are manufactured by Schwing Bioset and Weir Minerals. ABEL and Putzmeister also supply solids piston pumps, but the solids piston pumps in their product lines did not have the capability to generate the required HTL pressure of 3000 psi (206 bar) and, therefore, were not offered for HTL application. Weir Minerals also offers diaphragm pumps, but elected to specify its solids piston pump because it can handle more viscous materials. To simplify the discussion, the Schwing Bioset and Weir Minerals pumps will be the main focus of the following discussions because both vendors proposed solids piston pumps for HTL application that could meet all HTL design requirements.

\subsubsection{Vendor Capabilities for HTL Application}

All vendors offering solids piston pumps provide robust solids piston pumps built for industrial application and continuous operation. These vendors customize their standard solids piston pump designs for specialized applications by specifying various options (e.g., feeders and valves) and materials. All vendors have the capability of providing new baseline solids piston pump designs, but it is costly and schedule-prohibitive compared to adapting their baseline unit. In general, the pumps described in this section are built as needed and therefore long lead times can be expected; especially with large volume pumps customized with specific options (e.g., feeders and forced-control valving).

Both Schwing Bioset and Weir Minerals have proposed similar solids piston pumps and have similar pump options including valves and feeder systems. On the feed side, ABEL, Putzmeister, Schwing Bioset, and Weir Minerals offer twin screw feeders that operate in a similar manner but can be configured in different orientations. On the discharge side, various types of check valves are offered to channel the media out of the pump chamber to the discharge line.

Check valves are either free-floating or forced-control (Section 4.1). Forced-control valves have been specified by Schwing Bioset and Weir Minerals for HTL application. The hydraulically activated swing pipe valve system allows the passage of the largest particle sizes (e.g., up to $\sim 2$ in. [50.8 mm]). However, only Schwing Bioset offers this valve to work up to the HTL design pressure of 3000 psi (206 bar). Hydraulically activated poppet valves, offered by all solids piston pump vendors, limit the maximum particle size to approximately $0.5 \mathrm{in} .(12.8 \mathrm{~mm})$. However, this valve system can operate at higher pressures than the swing tube valve and can take advantage of Weir Minerals higher pump pressure capabilities if needed.

In general, the maximum pressure capabilities of these solids piston pumps are less than comparably sized membrane or hose pumps. However, two solids piston pump manufacturers (i.e., Schwing Bioset and Weir Minerals) were able to meet or exceed the HTL pressure requirement of $3000 \mathrm{psi}$ (206 bar). Schwing Bioset's solids piston pump achieves the HTL design pressure of 3000 psi (206 bar) but has no excess pressure capacity without specialized design. Schwing Bioset offers its large opening S-Turn swing pipe valve design at HTL pressures, whereas, the similar valve from Weir Minerals does not. Therefore, Weir Minerals only offered its hydraulically operated poppet valves for HTL application. Schwing Bioset has investigated designs for increasing the pressure of its solids piston pumps to 3200 3600 psi (220-248 bar), but to date has not built a pump in this pressure range. 
The maximum operation temperatures of these pumps are similar and are limited by the rubberized material used on the piston ram. All pumps from these vendors can meet the HTL temperature requirement of $210^{\circ} \mathrm{F}\left(99^{\circ} \mathrm{C}\right)$ even though Putzmeister states the maximum temperature of its pump is just slightly below this requirement. The use of specialized rubber materials, such as Viton, on the ram allows the Putzmeister piston pump to operate at a slightly higher temperature in the range of 250 to $260^{\circ} \mathrm{F}$ $\left(121\right.$ to $\left.130^{\circ} \mathrm{C}\right)$.

These vendors have been verified to have biomass experience including wood chips, wood dust, paper sludge, corn stover, and straw, all of which are similar in nature to the HTL biomass feed streams. In general, vendors offering multiple pump types specify solids piston pumps for the toughest pumping conditions, especially for extreme slurries, sludge, and paste with high viscosity, fiber content, and large particle sizes.

According to solids piston pump vendors, organic/biomass-type material in excess of $15 \mathrm{wt} \%$ dry solids is routinely pumped. The largest biomass application of solids piston pumps among the vendors is the pumping of dewatered sewage/municipal sludge. All vendors with solids piston pumps were confident of pumping the HTL media with 4-in. slump and small particle size; however, HTL feedstock with high solid content and minimal slump (non-flowable) would be more difficult to pump and pumpability testing would be required.

\subsubsection{Assessment for HTL Application}

Solids piston pumps are among the best candidates for HTL application primarily because they routinely handle material that is difficult to pump. Solids piston pumps have been proven effective in varied applications, including biomass, and have been proven to operate reliably over a number of years in industrial sludge pumping. Schwing Bioset and Weir Mineral make very similar, high-quality pumps that meet HTL requirements. Either pump would be acceptable. For HTL application, Weir Mineral picked the solids piston pump over its equivalent diaphragm membrane pump and its centrifugal pump. Putzmeister has proven that solids piston pumps can pump a variety of biomass and highly viscous materials, but like ABEL, it cannot currently meet the HTL pressure requirement

For HTL application, the key advantage of solids piston pumps over diaphragm and rotary lobe pumps, is the proven ability of solids piston pumps to feed/pump highly viscous material. Disadvantages of solids piston pumps include a more complex design and more rigorous maintenance requirements.

\section{References}

More details related to the solids piston pumps discussed in this section can be found at the vendor websites:

- Schwing Bioset: http://www.schwingbioset.com

- Weir Minerals: http://www.weirminerals.com

- Putzmeister: http://www.putzmeister.com

- ABEL: http://www.abel.de 


\subsection{Rotary Lobe Pump (Zeilfelder Pumpen)}

\subsubsection{Description}

Rotary lobe pumps are positive displacement pumps. The media being pumped flows around the interior of the pump casing in the lobe cavity. However, the lobes do not make contact with each other like gear pumps do. The lobes rotate on a pump shaft that is typically connected to a gear box and driven by a motor. Rotary lobe pumps do not require valves to operate, unlike membrane/hose diaphragm and solids piston pumps. Rotary lobe pumps do require pressure relief valves to prevent over-pressurization. Rotary lobe pumps come in a number of lobe (also called wing) configurations including single and multiple lobes. The lobes can be concave or convex (Figure 3.7) depending on the application. The flow rate of the pump is adjusted by changing the rotation speed of the lobes. These pumps typically can be run at very slow speeds (less than $10 \mathrm{rpm}$ ). Typical rotary lobe pumps can run dry for a period of time and be rotated in either direction. They are manufactured using a variety of materials to allow many specialized applications.
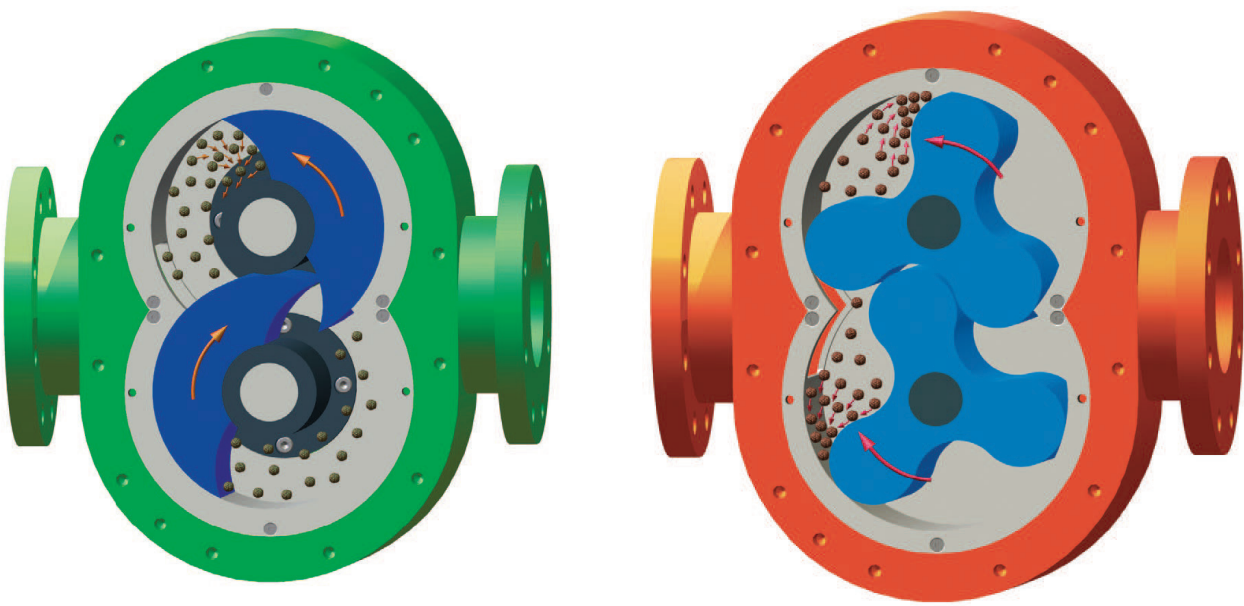

Figure 3.7. Rotary Lobe Shapes Convex (left) and Concave (right) (information from Zeilfelder Pumpen literature)

\subsubsection{Operation}

As the lobes rotate, pump cavity volume simultaneously increases on the inlet side of the pump and decreases on the outlet side of the pump. When the lobes are creating an expanding volume (coming out of mesh) on the inlet side of the pump, media flows into the pump cavity and is trapped by the lobes as they continue to rotate. The media travels around the interior casing of the pump in a pocket between the lobes and the casing; no media passes between the lobes. Finally, the volume of the cavity is decreased by the meshing of the lobes which forces the media through the outlet port under pressure. This process is repeated to create continuous pump flow. Pump flow can be adjusted by varying the rate of rotation of the lobes.

Rotary lobe pumps are made by many manufacturers but the only one identified for consideration in HTL application is by Zeilfelder Pumpen. Zeilfelder Pumpen has specialized the rotary lobe pump for biomass applications and high temperature. The specializations make this pump rather unique. 


\subsubsection{Vendor Capabilities for HTL Application}

Zeilfelder Pumpen's new T-Rex series rotary lobe pump has been proposed for HTL application (Figure 3.8). This pump is a robust rotary lobe pump and built for industrial applications and continuous operation. Zeilfelder Pumpen custom designs each pump for each application and therefore long lead times can be expected. The T-Rex rotary lobe pump comes with convex chopper lobes (Figure 3.7a) that are designed to handle coarse, fiber-containing media such as the more challenging HTL feedstock. These specialized lobes chop and push the media through the pump, whereas the more common concave lobes tend to squeeze the media, resulting in additional component wear. In addition, the T-Rex rotary lobe pump has replaceable wear components, including the convex lobe cutting edge, that extend the life and maintainability of the pump.

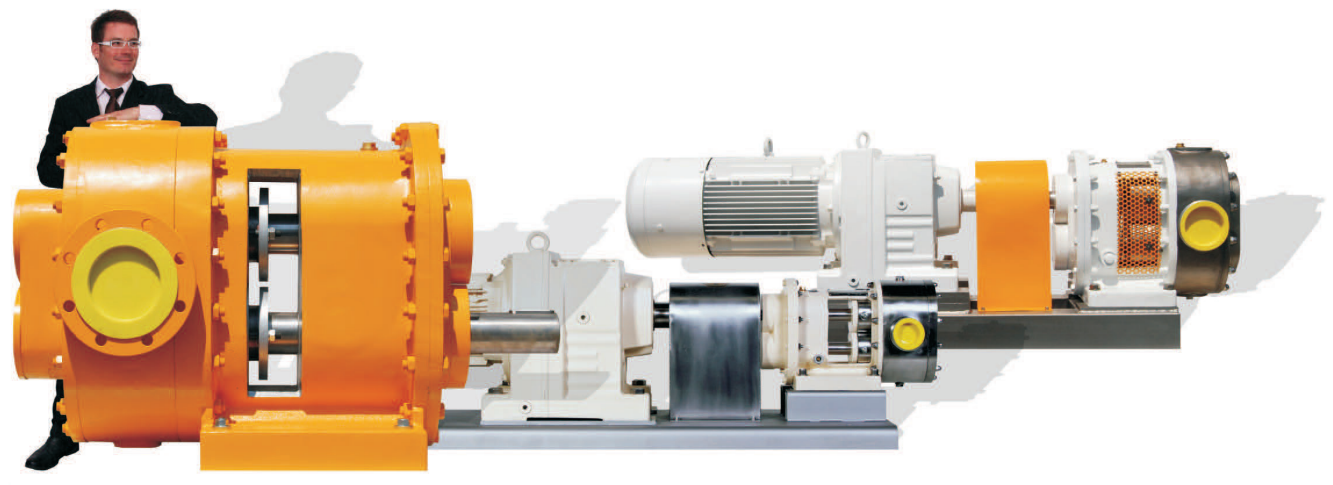

Figure 3.8. Rotary Lobe Pump - T-Rex (information from Zeilfelder Pumpen literature)

The rotary lobe pump has unique features not available on the other pumps reviewed that may be useful in HTL operations. With special materials, this pump can operate at temperatures as high $842^{\circ} \mathrm{F}$ $\left(450^{\circ} \mathrm{C}\right)$, which is significantly higher than any of the other pumps reviewed and allows this pump to operated at $\mathrm{HTL}$ process temperature $\left(662^{\circ} \mathrm{F}\left[350^{\circ} \mathrm{C}\right]\right)$ with a margin of safety. Using its high temperature capacity, this rotary lobe pump can also be considered for use as an in-process booster pump to maintain the required HTL pressure that may otherwise be lost to process pipe wall friction or other pressure reducing processes. The other unique feature is the ability of this rotary lobe pump to run backwards from high pressure to low pressure. When connected to a generator, this rotary lobe pump can recover energy. For HTL, as the high-pressure process completes, the energy efficiency of the process could be enhanced by recovering energy as the product is brought down to atmospheric pressure.

Zeilfelder Pumpen rotary lobe pumps are limited to pressure increases of $710 \mathrm{psi}$ (50 bar). To reach higher pressures, the pumps are staged in series. In staged pumping, operating pressures as high as $3625 \mathrm{psi}(250 \mathrm{bar}$ ) can be achieved. To reach the HTL design pressure of $3000 \mathrm{psi}$ (206 bar), six pumps would be used. Flow pulsations from this pump are minimal and likely less than the other types of pumps that are not benefiting from specialized pulse-damping accessories.

The T-Rex rotary lobe pump has the ability to pump biomass and silage containing up to $90 \mathrm{wt} \%$ fibers and solids. Its rotor design can chop through solid and fibrous material. This type of pump is being used for biomass feed to gasifiers. The optional changeable wear elements on this pump allow handling of abrasive materials. 


\subsubsection{Assessment for HTL Application}

The rotary lobe pump with chopper lobes is an excellent candidate for HTL application. With its ability to operate at HTL process temperatures, the rotary lobe pump could also serve as booster pump, if necessary, to make up pressure losses in the downstream HTL reactor. Key advantages of this pump are its simple design and its specialization for handling fibrous material. Another key operational advantage is the fact that it is operated without check valves. The key disadvantage of this pump is the added complexity associated with having multiple pumps in series to achieve pressures above $710 \mathrm{psi}$ (50 bar). Another considerations is that Zeilfelder Pumpen only supplies pumps and the intergration of multiple pumps, along with accessories (e.g., feeders, pressure relief valves, integrated pump control) would require using other vendors. Finally, because the inlet of the pump requires material to be drawn into the pump chamber, it is expected that some flow of the material or feeder system would be required-similar to the diaphragm pumps.

\section{References}

More details related to the Zeilfelder Pumpen rotary lobe pump discussed in this section can be found at the Zeilfelder Pumpen website: http://www.zeilfelder-pumpen.com/ 
PNNL-21981

\subsection{Pump and Feeding System Components}

\subsection{Valves}

All pumps, except for the rotary lobe pump, require check-type valves to operate. Valve operation is a concern in biomass operations because the larger, fibrous material tends to hang up, bridge, and pack at locations where constrictions are smaller or force is not sufficient to fully close and seal the valve. Because the rotary lobe pump does not require valves other than auxiliary pressure relief valves, this type of pump does not have this problem.

For pumps that require valves, forced-control valves are generally specified over free-floating valves. Free-floating valves depend on pumped media pressure changes to open and close the valves. Freefloating valves are typical in diaphragm pump operation and, though uncommon, can also be used with solids piston pumps. Free-floating valves commonly use floating balls which are a concern when dealing with fibrous material and larger particle size. In general, forced-control valves are hydraulically operated and require a separate hydraulic pump and controller, which brings additional complexity. Less aggressive forced-control valves may use a spring force similar to an engine valve.

Forced-control valves proposed by pump vendors include the following types: 1) poppet cone valves; 2) ball valves; and 3) swing pipe valves. The forced-control ball and swing pipe valves have large openings capable of handling the largest particle sizes among the valve types. Each of the three types of forced-control valves is discussed below.

\subsubsection{Poppet Cone Valves}

Poppet cone valves operate like the valves on an engine. For the dual cylinder/ram solids piston pumps, valves are used to direct feed into each individual charge cylinder and then out to a single discharge line. In general, poppet valves are hydraulically operated and with a very positive open and close actuation that will not move against pump pressure. Because the poppet cone valve has a limited opening size, it limits the size of material it can pass (i.e., typically a maximum of $0.5 \mathrm{in}$. [50.8 mm]) for HTL-sized pumps. Fibrous material likely can be caught in the valve seat. The forced action of the valve most likely will either cut the material or smash the material on the seat to provide a sufficient seal, although the possibility exists that material could build up on the valve seat if the pumping action does not clear out the material each time. The Weir Minerals poppet valve design (Figure 4.1) incorporates smooth surfaces and gentle bends to maximize the ability of pumped material to pass through the valve system and valve seat.

\subsubsection{Ball Valves}

The ball valve, as described by FELUWA, is an option for forced-control valving on its diaphragm hose pump to handle the more challenging, viscous, fibrous HTL feedstock. These valves operate on the principle of a rotation action that is hydraulically activated. The ball valve design should have a very positive closure capable of high pressures and tend to cut material as it closes and opens. [Note, forced control ball valves are used in the system for the HTL process development testing.] 
PNNL-21981

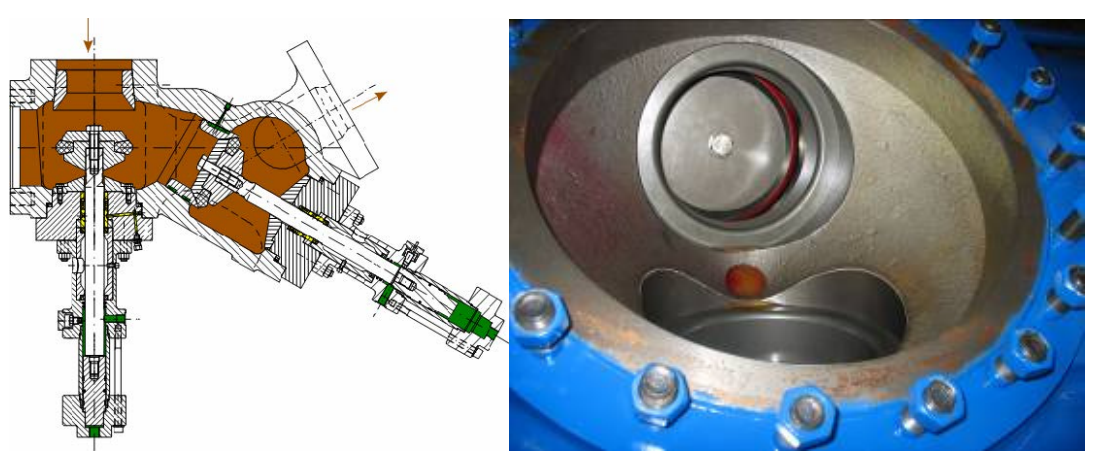

Figure 4.1. Poppet Cone Valves (information from Wier Minerals literature)

\subsubsection{Swing Pipe Valves}

The swing pipe valve is referred to by many different names from different vendors (e.g., rock valve, s-tube) and may be considered a valve-less design. In this document, we have arbitrarily called this design a swing pipe valve to best describe it function. The swing pipe valve was initially developed for dual cylinder piston pumps for pumping concrete with minimal back pressure and restriction. The swing pipe valve is typically hydraulically activated.

The swing pipe valve is essentially a bent pipe or tube, designed such that one side maintains its position on the discharge line but on the other side moves (i.e., swings) between the two piston pump chamber discharge openings. As the swing pipe valve switches between piston chambers, it opens the discharge line to one piston pump chamber as it seals off the other piston pump chamber. This movement is timed to correspond with the dual cylinder piston pump's charge and discharge cycles. Seals along the pivoting surfaces of the swing valve are used to maintain pressure. The edge of the swing pipe valve, as it pivots between the two piston pump chambers, provides cutting action for fibrous and large materials.

Swing pipe valve designs may have some limitations that affect HTL application. Schwing Bioset was the only vendor that proposed the use of the swing pipe valve (i.e., rock valve, see Figure 4.2) up to, but not above, HTL design pressures of $3000 \mathrm{psi}$ (206 bar). This maximum pressure may have been a limitation on the piston pump design and not the swing pipe valve design. Some swing pipe valve designs are susceptible to a condition wherein pipe movement between cylinders exposes the pipe to both piston pump chambers for a moment, creating a "short circuit" that is not suitable for installations with a static or process pressure in the discharge line.

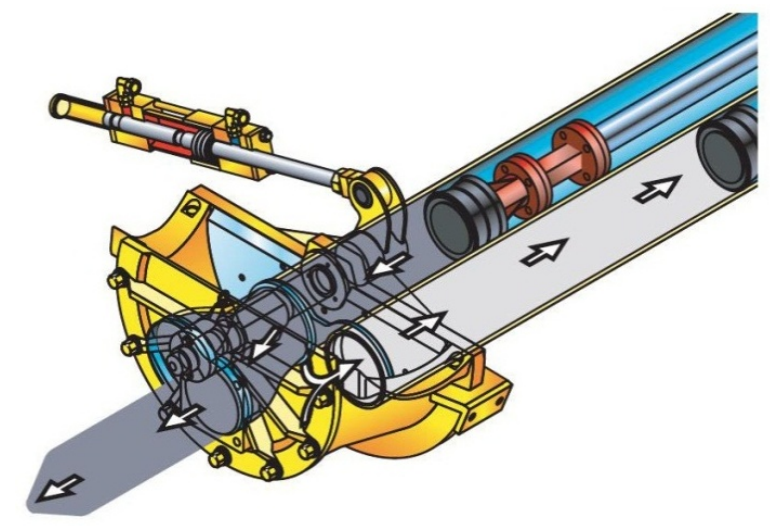

Figure 4.2. Swing Tube Valve (information from Schwing Bioset literature - "Rock Valve") 


\subsection{Drives}

The pump vendors in general seemed to prefer hydraulic drive systems for pumps; however, other drive options are available. For the HTL production scale system of $2300 \mathrm{gpm}\left(522 \mathrm{~m}^{3} /\right.$ hour $)$ and $3000 \mathrm{psi}$ (206 bar), the estimated power requirement is between 5000 and 10,000 kW (6700 and $13,400 \mathrm{HP}$ ) based on values received from the diaphragm and solids piston pump vendors.

\subsection{Pump Feeding Equipment}

HTL feedstock cannot be pumped unless the feedstock can be moved from the local storage location to the pump and subsequently fed into the pump. Biomass, being a fibrous substance, can be a challenge to move because of its high viscosity, its tendency to stick together, and bridging. HTL feedstock pump feeding may be challenging due to HTL process needs, including 1) maximizing the wt $\%$ solids in the HTL feedstock to increase process efficiency and 2) waste conditioning, such as adding a recycle water stream and process additives, which will likely need to take place at some point in the feed and pumping process.

The pump vendors in this review were limited in scope to local feeding of HTL feedstock feed into the pump. In all cases, the vendors proposed or discussed screw feeders at the pump to assist in feeding the material to be pumped into the pumping chamber. Screw feeders are discussed in the following section.

\subsubsection{Screw Feeders/Augers}

Screw feeders or augers are used to assist in feeding less flowable media, like biomass, into the pump cavity. In general, all pump types provide some suction force (or use gravity) to help draw feedstock into the pump chamber. However, assistance is required for some highly viscous and difficult to move feedstock. For efficient pumping, pump cavity fill in the range of 70 to 80 percent or more is desired. Screw feeders and augers can be used to move media into the pump and to increase the fill in the pump chamber. In general, for solids piston pumps, twin screw feeders were specified for HTL application. Screw feeders and augers can have many configurations (e.g., single, twin) but for HTL application, the twin screw feeder was most often discussed. Some vendors discussed feeder applications where the feed auger entered into the pump as far as possible to aid in pump cavity fill. Schwing Bioset and Weir Minerals both proposed twin screw feeders for their solids piston pump for HTL application. FELUWA discussed using screw feeders, as required, with its diaphragm hose pump. Zeilfelder Pumpen has also proposed using a screw feeder with its rotary lobe pump.
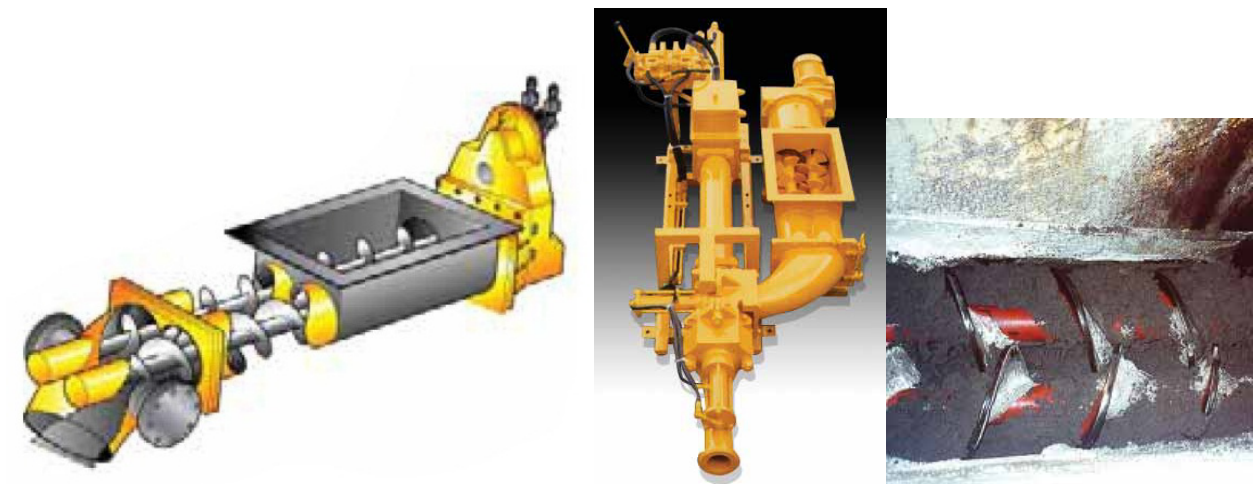

Figure 4.3. Twin Screw Feeder (information from Schwing Bioset literature) 
Incorporation of a localized feed system is strongly recommended for any HTL pump application to maintain the maximum flexibility for dealing with variable feedstock. No downsides were identified for including a feeder, other than the additional cost.

\subsubsection{Raw Feedstock Storage and Transport Systems}

Methods for transporting biomass feedstock from local storage to the pump were reviewed outside pump vendor interactions. One pump vendor, Schwing Bioset, provides biomass transport equipment (e.g., silos, hoppers, push floors, sliding frames), which would allow it to provide a full turnkey system from feedstock storage to pumping. Other pump vendors may also be able to provide biomass transport systems and equipment. Investigations into bulk biomass transport found that the biomass pelletizing, briquetting, and cubing industries routinely move bulk biomass in process similar to what would be required for a HTL process production facility. The pelletizing/briquetting industry is well established throughout the world and many companies that provide the biomass transport equipment and/or full turnkey systems for that industry could be used for HTL.

\subsubsection{Push Floor}

Push floors (Figure 4.4) are proven systems for moving a variety of non-free-flowing and difficult to handle bulk solid materials, from dry silage and wood chips to wet sludge. In general, push floors are designed for square and rectangular storage bunkers. Push floors function by moving a number of parallel ladder structures in reciprocating motion across the bunker floor to dig into feedstock/material and move it to a screw conveyor or other equipment.
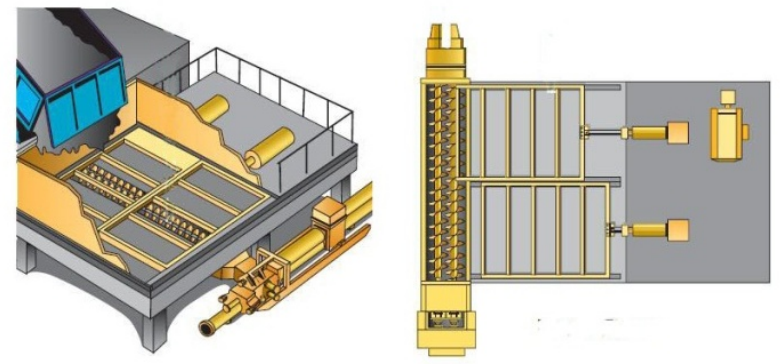

Figure 4.4. Push Floor (information from Schwing Bioset literature)

\subsubsection{Sliding Frame}

Sliding frames perform a similar function as push floor but are designed for flat bottom silos, as shown in Figure 4.5. 
PNNL-21981

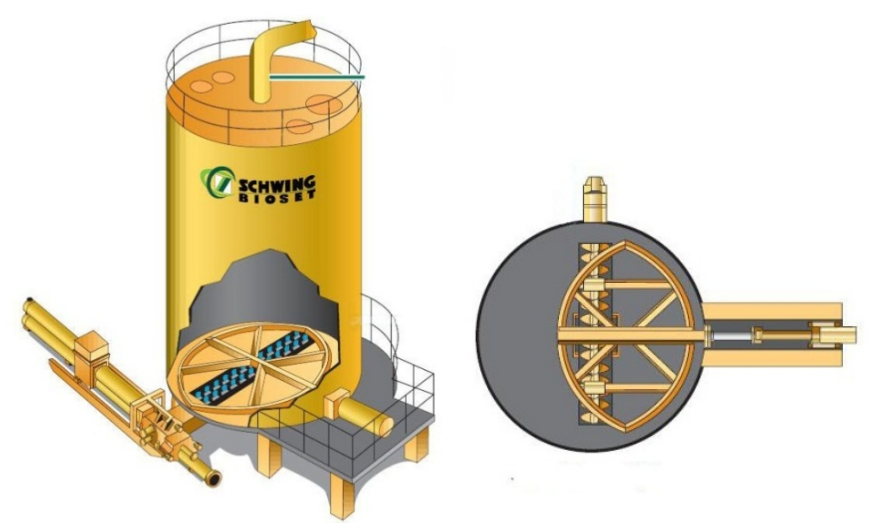

Figure 4.5. Sliding Frame (information from Schwing Bioset literature)

\subsection{Specialized Component}

\subsubsection{Pipeline Injection System}

One downstream component that may be useful for HTL pumping is a pipeline injection system (also called pipeline grease rings and other similar terms). Injection systems can be used when hard-flowing materials or material conveyed over long distance causes excessive pressure loss and possibly exceeds available pumping capability. Injection systems introduce a small amount of fluid along the pipe wall to reduce friction, which results in less downstream pressure loss. Various lubricants can be used, including water, grease, oil, and polymers.

Per Putzmeister literature, "With special lubricants, it is possible to reduce the pressure in the delivery line by up to $2 \%$ of the initial value." In discussions with Putzmeister, lubricant amounts between 0.5 percent and 2 percent by volume are injected. An ideal lubricant would act as a boundary layer, and not be absorbed into the material too fast. Water is very cheap and polymer is quite expensive. In the past, with lower organic content cake, water alone would provide a good pressure reduction. Currently, the trend is that higher organic content is expected and water alone helps a lot less than it used to; thus, a polymer blend is much more helpful. For installations where lubricant is absorbed into the pumped media, more pipeline injection systems may be required. To inject lubricant into the pipeline, the injection system needs to exceed the pipeline pressure. For high-pressure applications, clean lubricating fluid is required.
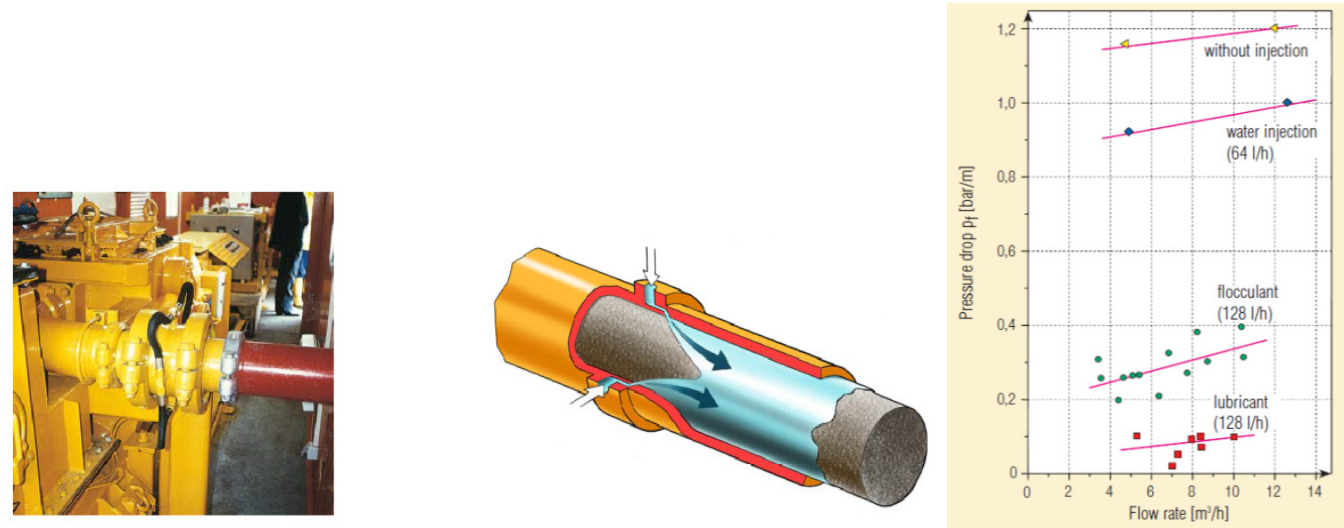

Figure 4.6. Pipeline Injection System (information from Putzmeister literature) 

PNNL-21981

\subsection{Feed and Pump System HTL Application}

\subsection{HTL Processing Parameter Considerations}

\subsubsection{Pressure}

The HTL pressure requirement of 3000 psi (206 bar) can be met by a number of pump vendors and different pump types. Solids piston pumps and diaphragm pumps (membrane and hose) can reach the requirement in a single stage. The rotary lobe pump cannot reach HTL pressure requirement in a single stage; multiple pumps in series are required to obtain the HTL pressure. Some vendors' pumps are able to exceed the HTL pressure requirement by over 45 percent (1351 psi [94 bar]), for a maximum pressure of 4350 psi (300 bar). Additional pressure may be beneficial for HTL to accommodate expected high downstream pipe pressure losses. However, running a pump at higher pressures is countered by 1) a possible reduction in maximum flow rate and 2) higher cost related to the required power increase of the drive system to generate pressure and the corresponding increased pressure rating required of downstream equipment. Reduced flow rate from pumps running at higher pressure may necessitate more pumps to maintain maximum flow rate. Maximum pressure for many of the pumps may be limited more by the capacity of the drive unit's hydraulic pump than by the structural strength of the working fluid pump body.

\subsubsection{Temperature}

The HTL temperature requirement for the front end pumping of the HTL process is $210^{\circ} \mathrm{F}\left(99^{\circ} \mathrm{C}\right)$ and can be met by a number of pump vendors and different pump types. Downstream of this front end pumping, the temperature is increased to $662^{\circ} \mathrm{F}\left(350^{\circ} \mathrm{C}\right)$ to meet $\mathrm{HTL}$ in-process temperature requirements. For the diaphragm and piston pumps, the HTL temperature requirement for front end pumping could be exceeded, but not substantially, using specialized seals/rubber products. The rotary lobe pump was the only pump type assessed that could operate at HTL in-process temperatures $\left(662^{\circ} \mathrm{F}\right.$ $\left[350^{\circ} \mathrm{C}\right]$ ) and above (up to $842^{\circ} \mathrm{F}\left[450^{\circ} \mathrm{C}\right]$ ).

\subsubsection{Flow Rate}

The HTL production plant flow rate requirement of $2300 \mathrm{gpm}\left(522 \mathrm{~m}^{3} /\right.$ hour $)$ can be met by all evaluated pump types. However, because no single pump can meet this flow rate, multiple pumps in parallel configurations are required. The flow of all pump types in this review can be adjusted under operational conditions by changing the operating frequency. There are limitations to pump flow adjustability; however, the diaphragm and solids piston pumps allow the widest range of flow rate variation. The flow rate on the rotary lobe pump is adjusted by changing the operating frequency (i.e., rotation speed). Such applications for pumps in series are often realized using master/slave configurations for the variable frequency drives.

Various production plant operations and flow rate requirements may affect the overall pump design for the HTL process. Some plant operations to consider include the following:

- Operations at reduced capacity: Because feedstock supplies may not always be available to run the plant at maximum flow rate, the plant should have the flexibility to operate at lower flow rates. This 
could be accomplished by shutting down pump lines where pumps are configured in parallel or by adjusting pump flow rates.

- Plant maintenance: Maintenance on the pump and pump lines without process shutdown would require standby pump lines or configurations with parallel pumps where a single pump line could be shut down with a corresponding reduction in throughput.

- Critical operating conditions: A fixed flow rate or flow rate range may be required to make the HTL process work efficiently at a prescribed residence time. Further, a minimum transport velocity may be required to avoid solids deposition (i.e., keep heavy materials from settling) or stratification. This type of requirement has the potential to constrain the HTL pumping operations more than any other requirements.

\subsubsection{Particle Size}

Particle size can affect the HTL process in many ways. HTL raw feedstock can be large (up to 3 in. [76 mm]) with potentially large aspect ratios due to fibrous material. Reducing the size of biomass can be difficult, especially when trying to maintain consistency in grainy, fibrous, high-moisture material. In addition, operations to reduce biomass size can be energy intensive and costly, especially reduction to the small sizes ( $\sim 00012$-in / 30 micron / $0.03 \mathrm{~mm}$ ) currently needed for laboratory-scale pumpability. Larger particle sizes (i.e., on the order of 0.079 to 0.24 [2 to $6 \mathrm{~mm}$ ]) are expected to be processed in pilot and production plants. Batch studies indicate that the quality of the HTL product (oil) is independent of material particle size; however, this would need to be validated in pilot-scale studies.

Rheology testing on HTL wood feedstock has shown that several adverse trends appear with increased particle size, including 1) less flowable feedstock, 2) dewatering of slurry (i.e., separation) under pressure, and 3) a potential increase in bridging effects. As particle sizes increase above approximately 0.079 to $0.10 \mathrm{in}$. ( 2 to $4 \mathrm{~mm}$ ), standardized rheology testing becomes difficult due to the dimensions associated with the test instrumentation. Custom setups or flow loops are needed to obtain rheological characterization. In addition, as particle sizes increase, the effective scales associated with the rheology change. As the ratio between particle size and characteristic geometry (e.g., pipe diameter) becomes larger, particles no longer behave as part of a homogenous continuum consisting of both solids and liquid. Particle behavior become distinguishable from the behavior of the carrier fluid. Figure ES-1 shows slump test changes as particle size is increased from laboratory-scale $(0.0012 \mathrm{in} . / 30 \mathrm{micron} / 0.03$ $\mathrm{mm})$ to a size estimated to be near production scale (0.079 to $102 \mathrm{in}$. [2 to $4 \mathrm{~mm}$ ]).

Size reduction of HTL feedstock was outside the scope of the HTL pump investigation. However, many systems can reduce particle size. Pump vendors discussed providing size-reduction equipment upstream of the pump and have had success in similar applications where size reduction was needed.

Of the pump types reviewed in this HTL assessment, the rotary lobe pump and diaphragm hose pump can pass the largest particle sizes (i.e., up to $\sim 3$ in. $[\sim 78 \mathrm{~mm}]$ ). Solids piston pumps with swing pipe valves can accommodate particle size up to $2 \mathrm{in}$. $(50.8 \mathrm{~mm})$. Solids piston pumps with poppet cone valves and diaphragm membrane pumps are limited to a maximum particle size of around 0.25 to 0.5 in. (6 to $13 \mathrm{~mm}$ ). For transport of biomass material, it is beneficial to have a mixture of particle sizes (i.e., particle gradation) on the order of 30 percent of mixture with 30 micron $(0.0012-\mathrm{in} . / 0.03-\mathrm{mm})$ grain size 
or smaller for best pumping and to avoid deposition/sedimentation in the pipeline. Pumps should be tested to prove operation at maximum particle size with representative size distributions.

\subsubsection{Weight Percent Solid Concentration}

The highest possible weight percent solids concentration in the feedstock is desirable for HTL process efficiency. Discussions with pump vendors indicate that 10 to $15 \mathrm{wt} \%$ dry solid concentration biomass feedstock typically can be pumped, but higher solid concentrations are more difficult and generally require specialized design. PNNL's bench-scale testing of HTL feedstock found the upper limit for pumpability to be on the order of $15 \mathrm{wt} \%$ suspended solids with wood chip and corn stover feedstock. Pump vendors claim success in pumping organic materials with concentrations up to $40 \mathrm{wt} \%$ solids but this material may not be indicative of fibrous, low density HTL feedstock. Vendors claim to pump inorganic materials up to $80-90 \mathrm{wt} \%$ solids but this is likely with heavy granular material unlike HTL feedstock. Pump testing will be required to prove the applicability and limits of weight percent solid concentration with various HTL feedstock and particle sizes.

\subsubsection{Fibrous Nature}

The fibrous nature of biomass material creates unique flow and pumpability challenges that require attention in feeding and pumping system design. These challenges are associated with the characteristics of particles generated from fibrous material, which tend to be cohesive (i.e., stick together), easily entangled, non-uniform in shape and size, and compacted and dewatered under pressure. These characteristics result in slurries where solids are readily segregated and sometimes difficult to re-disperse via fluid turbulence.

Locations with constriction or obstructions are major area of concern with fibrous HTL feedstock. These locations can cause fibrous material to hang up, resulting in significant bridging, which can lead to flow restrictions and even plugging. Even if the material breaks free, it often does so in a clump/agglomeration that can be significantly larger than the individual particles. In the past, valve systems on diaphragm and solids piston pumps have had problems handling fibrous biomass; especially free-floating valve systems with balls at valve seats. Forced-control valve systems, proposed by most all vendors, should handle fibrous material in HTL application as detailed in Section 4.1.

\subsubsection{Abrasive Material}

HTL biomass feedstock is expected to contain some abrasive material (e.g., dirt, sand, rocks) due to its outdoor harvesting, transport, and storage. HTL pump systems will need to handle such materials. All reviewed pump vendors can provide pumps that deal with abrasive materials (e.g., concrete) using specific pump options (e.g., material selection and replaceable wear parts).

\subsection{Vendor Summary - Pumpability Assessment}

Pump vendors were asked about providing pumps for an HTL pumpability assessment (see Appendix D). All vendors indicated that pump testing was required to prove the pumpability of HTL feedstock and determine actual pump performance and corresponding limits of feedstock variables (e.g., weight percent solid concentration, particle size). No vendors had testing capabilities appropriate for 
HTL conditions at their facility or at third-party facilities. No detailed estimate has been made for a full pump assessment program to test HTL feedstock and variables but rough estimates indicate the cost is likely to exceed \$1 million.

One pump assessment option proposed by a vendor was using a pump that did not meet full HTL pressure requirements. The vendor's engineers concluded that a pump assessment at near 50 percent HTL pressure should indicate the success/failure of higher pressure pumping. Pump testing at lower pressures to assess the pumpability of a material (biomass in this case) is not an uncommon practice and is often done to evaluate the feasibility of putting pumps in series. However, lower pressure pump testing requires the assessment of higher pressure phenomena (e.g., dewatering). Because pumps are available that can reach full HTL pressure for a pumpability assessment, low pressure testing may be too risky, especially when dealing with a variety of HTL feedstock types and variables.

A full-scale pumping system is recommended for any pump assessment. For HTL application where multiple pumps are in parallel, testing of a single pump line would be considered full scale. See Section 5.3 for further information about why a full-scale test is recommended.

\subsection{Vendor Summary - Pilot Plant}

HTL pilot plant systems (including two solids piston pumps, a diaphragm membrane pump, a diaphragm hose pump, and a rotary lobe pump) were offered by five of the six vendors. Putzmeister did not propose a pilot plant system because it could not offer a system that could meet the HTL pressure requirement of 3000 psi (206 bar). The most complete systems, both solids piston pumps including screw feeders, were provided by Schwing Bioset and Weir Minerals. In addition, the diaphragm pump vendors FELUWA and ABEL could provide similar complete systems. Pump cost ranged from $<\$ 100,000$ to $\sim \$ 600,000$ depending on the flow rate and pump features provided. Delivery times ranged from 20 to 60 weeks.

One vendor warned against pilot-scale testing. That vendor's experience indicated that it is difficult to pump feedstock like HTL in small-scale pilot-plant testing like that proposed by PNNL for HTL demonstration. Pump systems do not scale well because certain factors (e.g., pump clearances, internal strain rates) for a given pump design do not scale. Reduced-scale testing can indicate process failure in a viable production-scale design. Revisiting the HTL pilot-plant scale may be warranted to assess how to minimize a false conclusion for scale-up to a production plant relative to pump/transport system design. For pump systems with multiple pumps in parallel, the testing of one line of pumps could be considered a full-scale test.

\subsection{Vendor Summary - Production Plant}

HTL production plant systems (including three solids piston pumps, a diaphragm membrane pump, a diaphragm hose pump, and a rotary lobe pump) were offered by all six vendors. Putzmeister, in its production plant system proposal, added additional cost to upgrade its pumps to meet the HTL pressure requirement of $3000 \mathrm{psi}$ (206 bar). All costs for these systems were budgetary and ranged from $\$ 4$ to 10 million with some variations on pump and pump options being provided. Delivery times ranged from 26 to 60 weeks. 


\subsection{Suggested HTL Configuration and Options to Consider}

This assessment has located reputable, viable vendors that can provide a variety of pump systems and pump types to meet HTL application.

The dual cylinder piston pump is the most proven pump system to meet HTL application requirements and one vendor has experience with a pilot demonstration of a similar HTL process. A twin screw feeder or similar feed system is recommended to ensure a wide variety of HTL-type biomass materials can be moved into the pump chambers to aid in pumping and pumping efficiency. Putzmeister manufactures a piston pump setup close to that chosen for HTL application. The setup includes a biomass feed, recycled process liquid, a twin screw feeder, and a dual cylinder solids piston pump; see Figure 5.1.

The FELUWA hose pump is a very unique pump that should be further assessed for HTL application. The Zeilfelder Pumpen rotary lobe pump has many unique features not available from any of the other pump vendors, including 1) operation at high temperature, allowing it to be used as an HTL booster pump and 2) the ability to run backwards for process energy recovery; for HTL a single stage unit likely would be used for both of these options.

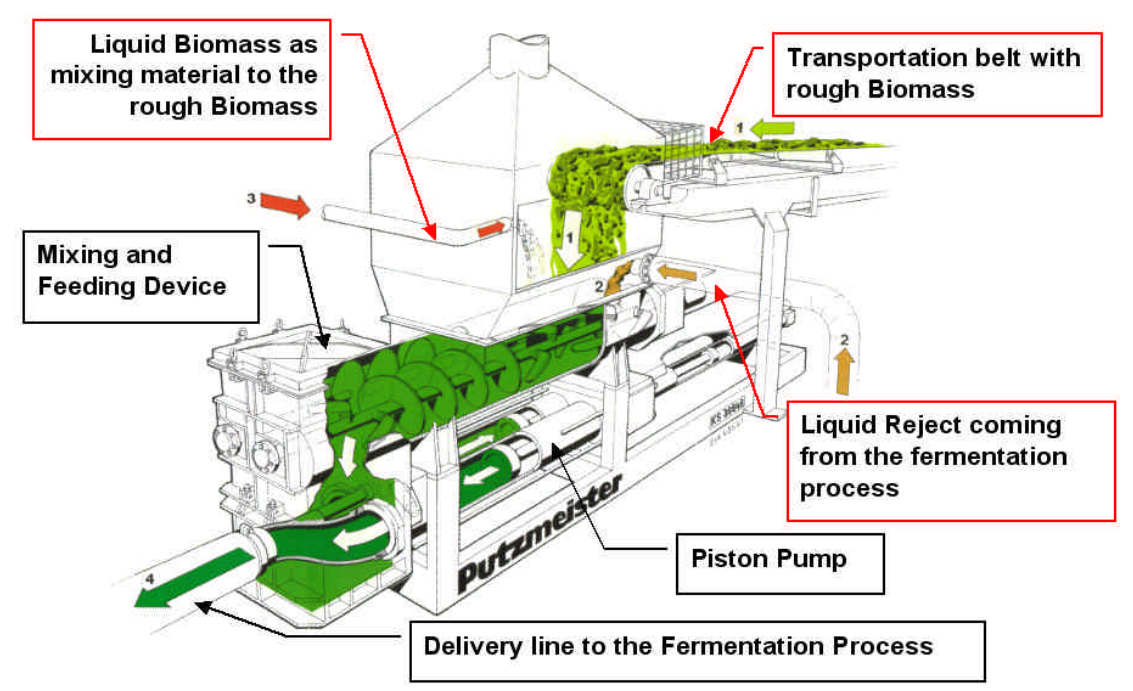

Figure 5.1. Biomass Pumping Application (information from Putzmeister literature) 

PNNL-21981

\subsection{Conclusion}

Feeding and pumping HTL biomass appears to be viable with COTS equipment and specialized designs. All evaluated pumping vendors were confident of feeding and pumping a flowable biomass like the HTL finely ground $(0.0012$-in./30-micron/0.03-mm) wood feedstock at $15 \mathrm{wt} \%$ dry solids with the measured 4-in. (101-mm) slump used to perform laboratory bench-scale testing. HTL feedstock for the pilot and production plants likely will be more challenging to pump because of the desire to maximize the economics of the overall HTL process resulting in biomass feedstock with larger particle size estimated on the order of 0.08 to 0.16 in. ( 2 to $4 \mathrm{~mm}$ ) or greater. All pump vendors concur that specialized design of the feed/pump system followed by pump testing is necessary to validate and optimize the biomass pumping at HTL pressure and temperature operating conditions.

A key economic factor to consider with pumping is the size reduction (i.e., grinding) of raw HTL feedstock as large as 3 in. (76 mm), which is energy intensive and costly. Size reduction was outside of the scope of this pump assessment; however, all biomass pumps have particle size limitations. Larger particles may be more difficult to pump because of various operating phenomena (e.g., biomass feedstock dewatering in the pump cavity) that result in decrease flowability and pumpability of the biomass material. Size-reduction costs increase as target particle size decreases and some discussions indicate that costs may increase significantly once a threshold is reached (e.g., 0.08 in. [2 mm] and smaller). HTL scoping tests conducted using specific particle sizes in a batch autoclave indicate similar HTL process yields of oil, gas, and solids for particle sizes in the range of 0.08 to $0.24 \mathrm{in}$. ( 2 to $6 \mathrm{~mm}$ ). Therefore, the progression to larger size particles is not expected to affect the process chemistry.

Because biomass feedstock can have many variables (e.g., type, particle size, moisture content), pumpability testing is highly recommended for any new biomass feedstock, including HTL feedstock, for pump selection and required feed and pump options. For many materials, pumpability assessments can be made at operating pressures below the maximum. This is often done in instances where a series of pumps are required to obtain the desired final operating pressure. The assessment is first performed using a single pump to determine pump performance. In the case of coarse (i.e., large particle) biomass slurries, dewatering (i.e., material segregation) within the pump can become a factor at higher operating pressures. Therefore, the assessment of the pumpability of a biomass feedstock at reduced pressure introduces/increases technical risk with an increase in the particle size that is not experienced with other materials. A pumpability assessment at full-scale and maximum operating pressure is recommended.

For this HTL pumping application, solids piston pumps are well-proven designs and likely the base choice to be considered. Diaphragm pumps, especially the hose pump, should be considered due to unique pumping characteristics that may be favorable in this pumping application. The rotary lobe pump with chopper blades is unique and lends itself well to the front-end HTL pumping application and to inprocess applications at HTL temperatures as a booster pump. In addition, it can be configured in reverse for energy recovery via pressure letdown. Past success with feeding and pumping HTL-type biomass at high pressures has been limited and at reduced scale. Various new feed and pumping options (i.e., piston, diaphragm, and rotary lobe) from the vendors assessed in this report and recent successes in pumping challenging feedstock command renewed optimism for the pumpability of high-pressure HTL biomass feedstock. 

PNNL-21981

\section{Appendices}

Appendix A - Pump Vendor Comparison Summary

Appendix B - Pump Vendor Contact Details

Appendix C - "PNNL Biomass Process Feed \& Pump Equipment Needs" dated November 3, 2011

Appendix D - "Pumpability Assessment Query by PNNL to Vendors" dated early December, 2011

Appendix E - Other Vendors Explored/Contacted/Summary Results 



\section{Appendix A}

\section{Pump Vendor Comparison Summary}





\section{Appendix A}

\section{Pump Vendor Comparison Summary}

\begin{tabular}{|c|c|c|c|c|c|c|}
\hline & Putzmeister & Schwing Bioset & Weir Minerals & FELUWA & ABEL & Zeilfelder Pumpen \\
\hline \multicolumn{7}{|l|}{ PUMP PROPOSED } \\
\hline Pump Type & Piston & Piston & Piston & Diaphragm (Hose) & Diaphragm (Membrane) & Lobe (Specialized Chopper) \\
\hline Pump Cylinders & Two & Two & Two & $\mathrm{NA}$ & $\mathrm{NA}$ & $\mathrm{NA}$ \\
\hline Stroke Rate (strokes/minute) & \multicolumn{2}{|c|}{ Typically less than 10} & \multicolumn{2}{|c|}{ Varies, High up to 50, Low down to less than 10 , Typical $15-35$} & \multicolumn{2}{|c|}{ NA (Rotary) } \\
\hline \multicolumn{7}{|l|}{ PUMP CHARACTERISTICS } \\
\hline Pressure (continuous) & $1885 \mathrm{psi}(130 \mathrm{bar})^{(\mathrm{c})}$ & 3000 psi (206 bar) & 3200 psi (220 bar) & 3000 psi (206 bar) & 3625 psi (250 bar) & $\begin{array}{c}3625 \mathrm{psi}(250 \mathrm{bar}) / \\
710 \mathrm{psi}(50 \mathrm{bar}) \mathrm{per} \text { stage }\end{array}$ \\
\hline Max Pressure (continuous) Available & $1885 \mathrm{psi}(130 \mathrm{bar})^{(\mathrm{c})}$ & 3000 psi (206 bar) & $4350 \mathrm{psi}(300 \mathrm{bar})$ & $4600 \mathrm{psi}(320 \mathrm{bar})$ & $3625 \mathrm{psi}(250 \mathrm{bar})$ & $\begin{array}{c}3625 \mathrm{psi}(250 \mathrm{bar}) / \\
710 \mathrm{psi}(50 \mathrm{bar}) \text { per stage }\end{array}$ \\
\hline Temperature (Normal) & $194^{\circ} \mathrm{F}\left(90^{\circ} \mathrm{C}\right)^{(\mathrm{c})}$ & $210^{\circ} \mathrm{F}\left(99^{\circ} \mathrm{C}\right)$ & $210^{\circ} \mathrm{F}\left(99^{\circ} \mathrm{C}\right)$ & $257^{\circ} \mathrm{F}\left(125^{\circ} \mathrm{C}\right)$ & $392^{\circ} \mathrm{F}\left(200^{\circ} \mathrm{C}\right)$, elastomer limit & $\begin{array}{l}99^{\circ} \mathrm{C}\left(210^{\circ} \mathrm{F}\right) \\
\text { to less than } 350^{\circ} \mathrm{C}\left(662^{\circ} \mathrm{F}\right)\end{array}$ \\
\hline Temperature (High) Special Materials & $212-221^{\circ} \mathrm{F}\left(100-105^{\circ} \mathrm{C}\right)$ & $250^{\circ} \mathrm{F}\left(121^{\circ} \mathrm{C}\right)$ & $266^{\circ} \mathrm{F}\left(130^{\circ} \mathrm{C}\right)$ & $392^{\circ} \mathrm{F}\left(200^{\circ} \mathrm{C}\right)$ & $572^{\circ} \mathrm{F}\left(300^{\circ} \mathrm{C}\right)$ & $450^{\circ} \mathrm{C}\left(842^{\circ} \mathrm{F}\right)$ \\
\hline Maximum Particle Size (Proposed) & 0.315 in. ( $8 \mathrm{~mm} / 8000$ microns $)$ & 2 in. (50.8 mm / 50,800 microns) & 0.5 in. $(12.7 \mathrm{~mm} / 12,700$ microns $)$ & $\begin{array}{c}\text { Large } 3+\text { in. }(75 \mathrm{~mm} / 75,000 \\
\text { microns) }\end{array}$ & 0.25 in. $(6.35 \mathrm{~mm} / 6500$ microns $)$ & 4 in. (101 mm / 101,000 microns) \\
\hline Maximum Solid Content - Biomass & $45 \%$ (biosolids) & $40 \%$ (biosolids) & $22 \%$ (organic sludge) & $15 \%+{ }^{(a)}$ & up to $10 \%$; more if flowable & up to $18 \%$ \\
\hline Maximum Solid Content-Other & up to $85 \%$ & up to $80 \%$ & up to $85 \%$ (coal slurry) & up to $80 \%$ & up to $75 \%$ & up to $90 \%$ \\
\hline Identified Fibrous Biomass Experience & paper sludge, corn stover, straw & wood chips, wood dust & None identified (sewage sludge) & ground corn mixture & wine lees, wood chips? & grass, straw, corn silage \\
\hline Vendors Offering Similar Pumps & $\begin{array}{l}\text { Schwing Bioset, } \\
\text { Weir Minerals, ABEL }\end{array}$ & Weir Minerals, Putzmeister, ABEL & Schwing Bioset, Putzmeister, ABEL & $\begin{array}{c}\text { Weir Minerals } \\
\text { (Undeveloped for biomass) }\end{array}$ & FELUWA, Weir Minerals & None \\
\hline \multicolumn{7}{|l|}{ PUMP VALVES } \\
\hline Valve Proposed & Poppet (i.e., Disk) & Swing Tube (i.e., Rock Valve) & Poppet (i.e., Poppet Cone) & Poppet or Special Design & Poppet (Cone Valve) & $\begin{array}{c}\text { None Required } \\
\text { (Only Pressure Relief) }\end{array}$ \\
\hline Valve Force & Hydraulic & Hydraulic & Hydraulic & Hydraulic & Spring & $\mathrm{NA}$ \\
\hline \multicolumn{7}{|l|}{ BIOMASS PUMPING ASSESSMENT } \\
\hline Pump Base HTL Feedstock ${ }^{(\mathrm{a})}$ ? & Yes & Yes & Yes & Yes & Yes (solid content around 10\%) & Yes \\
\hline \multicolumn{7}{|l|}{ COMPANY } \\
\hline Company Location (Country) & Germany & USA & Netherlands & Germany & Germany & Germany \\
\hline Company Size (employees) & Large & Small & Large & Medium & Medium & Small \\
\hline Years In Pumping Business & $25+$ & $20+$ & $50+$ & $50+$ & $50+$ & $50+$ \\
\hline \multicolumn{7}{|l|}{ RELATED FEED/PUMP EQUIPMENT } \\
\hline Screw Feeders Available? & Yes & Yes & Yes & Yes & Yes & Yes, External Purchase \\
\hline Turnkey System Available? & Yes & Yes & Yes & Yes & Yes & No \\
\hline
\end{tabular}




\begin{tabular}{|c|c|c|c|c|c|c|}
\hline \multirow[b]{2}{*}{ Other Pump Type Options Available? } & Putzmeister & Schwing Bioset & Weir Minerals & FELUWA & ABEL & Zeilfelder Pumpen \\
\hline & Unknown & No & $\begin{array}{c}\text { Yes, Diaphragm } \\
\text { (Hose \& Membrane) }\end{array}$ & Yes, Diaphragm (Membrane) & Yes, Piston Pump & Gear \\
\hline \multicolumn{7}{|l|}{ PILOT PLANT INFORMATION } \\
\hline Cost & \multicolumn{3}{|c|}{ None (No proposal) } & \multicolumn{3}{|c|}{ Ranging from $\$ 100,000$ to $\$ 750,000^{(b)}$} \\
\hline Pump Model & None (No proposal) & KSP $65 \mathrm{H}(\mathrm{HD}) \mathrm{R}$ & DHC 10180 & ZGL 30/130-K $56-$ DS 4 HD & HMT-Q-100-0060 & T-REX 32 \& T-REX 50 \\
\hline Number of Pumps & None (No proposal) & 1 & 1 & 1 & 1 & 6 in series to achieve pressure \\
\hline Flow rate & None (No proposal) & $30 \mathrm{gpm}\left(6.81 \mathrm{~m}^{3} / \mathrm{hr}\right)$ & $0.5-40 \operatorname{gpm}\left(0.114-9.1 \mathrm{~m}^{3} / \mathrm{hr}\right)$ & $0.5-3 \mathrm{gpm}\left(0.14-0.83 \mathrm{~m}^{3} / \mathrm{hr}\right)$ & $44 \mathrm{gpm}\left(12.2 \mathrm{~m}^{3} / \mathrm{hr}\right)$ & $\begin{array}{c}4.23-39.63 \mathrm{gpm} \\
\left(1.17-10.98 \mathrm{~m}^{3} / \mathrm{hr}\right)\end{array}$ \\
\hline Total Power Required & None (No proposal) & $250 \mathrm{HP}(186 \mathrm{~kW})$ & $160 \mathrm{HP}(120 \mathrm{~kW})$ & $40 \mathrm{HP}(30 \mathrm{~kW})$ & $125 \mathrm{HP}(93 \mathrm{~kW})$ & $151 \mathrm{HP}(113 \mathrm{~kW})$ \\
\hline Estimated Lead Time & \multicolumn{3}{|c|}{ None (No proposal) } & \multicolumn{3}{|c|}{$20-60$ weeks } \\
\hline \multicolumn{7}{|l|}{ PRODUCTION PLANT INFORMATION } \\
\hline Cost & \multicolumn{6}{|c|}{ Ranging from $\$ 4$ to 10 million $^{(b)}$} \\
\hline Pump Model & HSP $25100 \mathrm{HP}$ or HSP $2180 \mathrm{HP}$ & KSP $65 \mathrm{H}(\mathrm{HD}) \mathrm{R}$ & DHC 26280 & QGK 1000/500 & HMT-Q-1000-2000 & T-Rex 50 / T-REX 80 \\
\hline Number of Pumps & 7 & $12^{(\mathrm{S} 1)}$ & 6 & 2 & 3 & $\begin{array}{c}6 \text { in series to achieve pressure, } \\
\text { maybe } 2 \text { lines }\end{array}$ \\
\hline Total Power Required & \multicolumn{6}{|c|}{ Some Unknown, Others Ranging from 6000 to $8000 \mathrm{HP}(4500-6000 \mathrm{~kW})$} \\
\hline Estimated Lead Time & \multicolumn{6}{|c|}{ Some Unknown, Others $24-60$ weeks } \\
\hline $\begin{array}{l}\text { (a) HTL finely ground (30 micron) wood feed } \\
\text { (b Cost conversion base on September } 2012 \text { a } \\
\text { (c) Does not meet minimum HTL requiremen }\end{array}$ & $\begin{array}{l}\text { Istock at } 15 \% \text { weight dry solids wit } \\
\text { average of } \$ \text { US 1.29/EURO. } \\
\text { ts - Reference: "PNNL Biomass } \mathrm{Pr}\end{array}$ & $\begin{array}{l}\text { ed 4-in. slump } \\
\text { \& Pump Equipment }\end{array}$ & of November 3, 2011 & & & \\
\hline
\end{tabular}


Appendix B

\section{Pump Vendor Contact Details}





\section{Appendix B}

\section{Pump Vendor Contact Details}

\begin{tabular}{|c|c|c|c|c|c|c|}
\hline Contact Information & ABEL & FELUWA & Putzmeister & Schwing Bioset & Weir Minerals & Zeilfelder Pumpen \\
\hline Contact & Rick Kesler & Heinz Naegel & Robert "Bob" Liebermann (Pumpaction Corp.) & Joshua R. Di Valentino & Charilos Karambalis & Christian Bornstein \\
\hline Contact Title & Area Sales Manager & Managing Director & Western US Sales Manager at Pumpaction Corporation & Western Reginal Sales Manager & Product Manager GEHO Pumps & Owner \\
\hline Contact E-mail & rkesler@abelpumps.com & Naegel@feluwa.de & bliebermann@pumpaction.com & jdivalentino@schwingbioset.com & c.karambalis@weirminerals.com & bornstein@zeilfelder-pumpen.com \\
\hline Contact Phone & (303) 278-2550 & $+496594 / 10215$ & (714) 377-9348 & (715) 247-3433 & +31 773895135 & $+49(5308) 6938112$ \\
\hline Contact Cell Phone & (303) $895-8858$ & & (714) 580-9106 & (612) $867-4429$ & +31650663208 & + $49(174) 9088866$ \\
\hline Website & www.abelpumps.com & www.FELUWA.com & $\underline{\text { http://www.putzmeister-solid-pumps.com/enu/index.htm }}$ & http://www.schwingbioset.com & www.weirminerals.com & www.zeilfelder-pumpen.com \\
\hline Company Name & ABEL Pumps, L.P. & FELUWA Pumpen GmbH & Putzmeister Holding GmbH & Schwing Bioset Inc. & Weir Minerals Netherland b.v. & $\begin{array}{l}\text { Zeilfelder Pumpen - part of - ASM Dimatec } \\
\text { Deutschland GmbH }\end{array}$ \\
\hline Company Location & USA & Germany & Germany & USA & Netherlands & Germany \\
\hline Company Address & $\begin{array}{l}17778 \text { W. 59th Place } \\
\text { Golden, Colorado } \\
80403\end{array}$ & $\begin{array}{l}\text { Beulertweg } 10 \\
\text { D-54570 Murlenbach }\end{array}$ & $\begin{array}{l}\text { Max-Eyth-Str. } 10 \\
72631 \text { Aichtal } \\
\text { Germany }\end{array}$ & $\begin{array}{l}350 \text { SMC Drive } \\
\text { Somerset, WI } \\
54025\end{array}$ & $\begin{array}{l}\text { Egtenrayseweg } 9 \text { - } 5928 \text { PH Venlo - The } \\
\text { Netherlands } \\
\text { P.O. Box } 249 \text { - } 5900 \text { AE Venlo - The } \\
\text { Netherlands }\end{array}$ & $\begin{array}{l}\text { Lehmkuhlenfeld } 2 \\
\text { Wolfsburg } 38444 \\
\text { Bundesrepublik Deutschland }\end{array}$ \\
\hline
\end{tabular}





\section{Appendix C}

"PNNL Biomass Process Feed \& Pump Equipment Needs" dated November 3, 2011 
PNNL-21981

\section{Appendix C}

\section{"PNNL Biomass Process Feed \& Pump Equipment Needs" dated November 3, 2011}

\section{PNNL Biomass Process Feed \& Pump Equipment Needs}

\section{Problem Statement:}

An equipment solution for the front end portion of the biomass processing system, consisting of a Feed and Pump system (see Figure 1), is needed to move a biomass feedstock to a downstream process for both a Pilot and a Production scale system (See Figure 2).

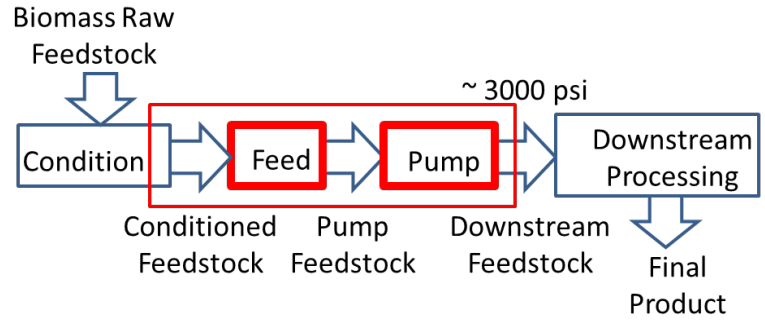

Figure 1 - Biomass Processing System

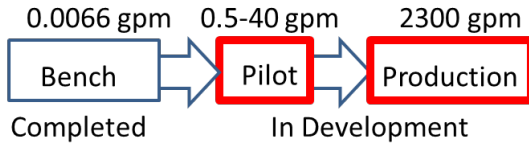

Figure 2 - Biomass Process Scale-up

Bench scale testing of a biomass processing system has been successfully completed (see History) and larger scale development and testing is required to prove the process at production levels. Near term development is a Pilot scale system on the order of 0.5 to $40 \mathrm{gpm}$ followed by a larger Production scale system on the order of $2300 \mathrm{gpm}$ (raw feedstock rate at 2000 DMTPD). The challenge is to Feed a highly viscous fibrous biomass wood / corn stover feedstock into a Pump system that subsequently provides the required 3000 psi of pressure for downstream processing. The pumping system developed for the Pilot scale must be scalable to Production scale. Feed and Pump requirements as well as associated process variances that can be considered are described in Attachment 1Table 1.

Near Term Needs From Vendor:

1. Provide a conceptual feed and pump system to meet the requirements for the Pilot and Production facilities. Include specifications/cutsheets of proposed equipment and any related options to consider.

2. Provide a rough order of magnitude (ROM) cost estimate for the proposed systems, Pilot and Production, that we can use in our technical economic analysis (TEA).

The following would be helpful in evaluating the proposed conceptual system

3. Past Experience - Describe / show any experience in similar applications at pressure; flow rate is not as important as multiple units can be used. Describe any applications that were specifically related to using biomass.

4. Extended Capabilities of System

a. Pressure verses Flow - Range of pressure / flow rates available with pumping system(s). Other pump sizes or pump options can be presented.

b. Particle Size - Describe the largest particle size that can be handled.

c. Solids Loading - Describe the highest solid loading (\% dry weight) that can be handled. 
d. Impact of Rheology Variance - Describe extent system may react to slight variances to the rheology described for the biomass feedstock.

5. For Proposed System (Pilot \& Production Scale)

a. Feed Options - Describe any feed options to consider for biomass material.

b. Fibrous Material Handling - Describe any special feature supplied to handle the fibrous biomass material. Check valves are of special concern.

c. Power Usage - Describe power consumption at the flow rate ranges for the pilot scale and production scale systems.

d. Space Requirements - Describe the space requirement for the feed and pump system including any ancillary equipment for the pilot scale and production scale systems.

e. Supporting Utilities - Describe the various outside connections (power, water, etc.) required for system operation.

\section{Future Applications:}

The activities are part of a multi-year, multi-million dollar, effort being executed by a national consortium comprised of 17 industry, national laboratory, and university partners, under the direction of the U.S. Department of Energy. The effort is focused on the development and commercial deployment of technologies to convert lignocellulosic biomass feed stocks to biofuels that are compatible with the existing transportation infrastructure. The consortium will integrate these technologies with existing refineries and distribution networks.

Near term (<2 years) activities include pilot-scale pump ability demonstrations, and the development of a pilot ready process. Longer term objectives include the commissioning of a 2000 dry metric ton per day (DMTPD) production plant, which will be followed by distributed industrial applications.

Successful demonstration of this biomass conversion process at the prototype and production phases will likely follow with industrial applications at multiple locations in the USA and beyond.

Feed \& Pump Process Description: (Reference Figure 1 and Attachment 1 - Table 1)

Raw biomass feedstock is obtained from the harvesting of wood and corn. The raw wood feedstock is forest-type materials that have been size reduced by a chipper or grinder and the raw corn stover feedstock is dried corn stalks that have been chopped. Biomass feedstock is shipped to the processing plant and staged until used. Further condition may be done at the plant prior to feeding and may include further size reduction and the addition of water to lower the solid content. Some final biomass feedstock conditioning steps that use recycled process "water" and small volumes of process materials are described under Biomass Feedstock Properties and Characteristics.

The feed system acquires the biomass feedstock by either a batch or continuous loading process and then continuously feeds the biomass feedstock to the pump inlet. From the pump inlet, the pump internally pressurizes the biomass feedstock to the required downstream system pressure and passes the biomass feedstock into the downstream processing piping.

Note: A batch loading process could consist of using a feed hopper that is supplied with biomass feedstock from a front end loader bucket or a conveyor. Some final biomass feedstock conditioning steps may be best performed as part of the feed and pump system.

Biomass Feedstock Properties and Characteristics: (Reference Attachment 1-Table 1, Attachment 2-Biomass Feedstock Info)

The fibrous base raw feedstock is pine wood chips ( $45 \%$ dry weight solids) OR corn stover ( 90 weight \% dry solids) mixed with water to form a paste-type mixture (nominally $15 \%$ dry weight solids) that is highly viscous with nonNewtonian flow properties. Small amounts of other material may be added to this biomass feedstock to aid in downstream processing such as adjusting the $\mathrm{pH}$, etc. (i.e., $\mathrm{Na}_{2} \mathrm{CO}_{3}$, added at about $1 \%$ weight on slurry). In the 
prototype and production scale systems, an aqueous stream (process recycle) containing $5 \%$ weight organic acids and alcohols (glycolic acid, acetic acid, methanol, ethylene glycol) will be used as the make-up water for the biomass slurry.

Current available information about the biomass feedstock is summarized in Table 1 . Attachment 2 contains current information and references related to the biomass raw feedstock and biomass conditioned feedstock. Rheological characterization is still in progress for some of the biomass feedstock and variables being considered. Key process variables are particle size and solid loading \% dry weight. Other process variables to be considered are pressure and temperature.

\section{History - Bench Scale Testing:}

Laboratory bench-scale testing has been successfully completed. The feed system for the bench scale system was to mechanically batch load the pine wood / water mixture (20 micron grind) into vertical cylinders that were pressurized with $30 \mathrm{psi}$ air to move the material through piping to the pumping system. The pumping system utilized two small syringe pumps operating alternately in tandem to achieve the 3000 psi pressure and continuous flow. The syringe pumps are not scalable to production scale so therefore are not being considered for prototype / production testing. Flow rate of the bench-scale system ranged from 0.5 to 4 liters/hour with a nominal flow rate of 1.5 liters/hour. After pressurization, the approximate slurry velocity in the 0.37 inch ID process tubing is approximately $1 \mathrm{~cm} / \mathrm{sec}$. Significantly higher velocities are being targeted in the prototype and production scale systems.

\section{Process Enhancements Desired:}

Reduction in cost of the overall process is highly desirable and may include some of the following that could affect the feed and pumping systems:

1. Accept Larger Particle Size - Currently larger raw feedstock requires additional cost to further reduce the particle size down to as small as 20 micron by chopping, grinding, and milling operations. This size reduction is done to aid in biomass feedstock flowability and consistency to the downstream processes. Less particle size reduction or particle size blending should reduce feedstock conditioning cost and may reduce overall capitol and operational cost. Downstream processing is unaffected by particle size, however, the feedstock rheology and consistency changes due to larger and/or blended particle sizes is unknown.

2. Accept Higher Solids Loading - Currently raw feedstock solids loading, ranging from 45 to $90 \%$ dry weight solids, is reduced to as low as $13 \%$ dry weight solids to increase feedstock flowability and consistency. Lower solid content reduces the downstream process efficiency. Solids loading above $18 \%$ dry weight solids or more likely would result is lower finished product cost. Very high solids loading on the order of $20-35 \%+$ dry weight solids would be highly desirable for process efficiency. Feedstock rheology changes and consistency changes due to increased solid loading is unknown but is expected to make the feedstock much more viscous, dry, and sticky.

\section{Contact:}

Eric Berglin, Pacific Northwest National Laboratory, 902 Battelle Boulevard or P.O. Box 999, MSIN K5-22, Richland, WA 99352 USA, Telephone: 509-372-4832, eric.berglin@pnnl.gov

Carl Enderlin, Pacific Northwest National Laboratory, 902 Battelle Boulevard or P.O. Box 999, MSIN K7-15, Richland, WA 99352 USA, Telephone: 509-374-2141, cougar.enderlin@pnnl.gov

Andrew Schmidt, Pacific Northwest National Laboratory, 902 Battelle Boulevard or P.O. Box 999, MSIN K7-15, Richland, WA 99352 USA, Telephone: 509-375-2280, andy.schmidt@pnnl.gov 
PNNL-21981

Attachment 1

Table 1- Feed \& Pump Requirements

\begin{tabular}{|c|c|c|c|c|}
\hline & Bench Scale & Pilot Scale & $\begin{array}{l}\text { Production } \\
\text { Scale }\end{array}$ & Notes: \\
\hline Process Variables & $\begin{array}{l}\text { (Reference } \\
\text { Only) }\end{array}$ & (Near Term) & (Future) & \\
\hline $\begin{array}{l}\text { Biomass Raw } \\
\text { Feedstock - (As } \\
\text { Shipped) }\end{array}$ & \multicolumn{3}{|c|}{$\begin{array}{l}\text { a. Woody Chips (with bark) - Size: Length ( } 2-8 \\
\text { inches) by Width ( } 1-2 \text { inches) by Thickness (up } \\
\text { to } 0.5 \text { inch); } 45 \text { - } 50 \% \text { dry weight solids. } \\
\text { b. Corn stover (dried corn stalks) - Size: Smaller } \\
\text { than woody chips; } 95 \% \text { dry weight solids. }\end{array}$} & $\begin{array}{l}\text { As received raw material with no } \\
\text { processing and no size reduction. } \\
\text { Shipped dry bulk. [See tab } \\
\text { "Wood\&CornFeedstock-AsReceived"] }\end{array}$ \\
\hline $\begin{array}{l}\text { Biomass } \\
\text { Conditioned } \\
\text { Feedstock }\end{array}$ & \multicolumn{3}{|c|}{$\begin{array}{l}\text { Feedstock to be sized reduced and \% dry solid } \\
\text { weight concentration adjusted to meet process } \\
\text { and / or pumping requirements. Processing } \\
\text { steps can occur before feed system, as part of } \\
\text { feed system, or in pump. Solids concentration } \\
\text { will be lowered by the addition process recycled } \\
\text { water and additional make-up water as needed. }\end{array}$} & $\begin{array}{l}\text { Required feedstock processing from } \\
\text { received raw material. } \\
\text { Recycled water supplied at around } 50 \\
\text { psi at approximately } 200^{\circ} \mathrm{F} \text {. } \\
\text { Some process material, like } \mathrm{Na}_{2} \mathrm{CO}^{3} \sim 1 \% \\
\text { weight, may be added to aid } \\
\text { downstream processing. }\end{array}$ \\
\hline $\begin{array}{l}\text { Biomass Feedstock } \\
\text { - Downstream } \\
\text { Feedstock }\end{array}$ & \multicolumn{3}{|c|}{$\begin{array}{l}\text { Sized reduced and solid concentration has } \\
\text { occurred to make a pumpable slurry or paste. }\end{array}$} & Feedstock at outlet of pump. \\
\hline $\begin{array}{l}\text { Particle Size - Size } \\
\text { Reduction }\end{array}$ & $\begin{array}{l}20 \text { microns } \\
\text { (0.000787 inch) }\end{array}$ & $\begin{array}{l}\text { Estimates of } r \\
\text { reduction req } \\
\text { flow and/or } p \\
\text { from } 0.25 \text { inc } \\
\text { to } 0.03125 \text { in } \\
\mathrm{mm}) \text {. }\end{array}$ & $\begin{array}{l}\text { naterial size } \\
\text { uired to meet } \\
\text { umping range } \\
\text { h ( } 6 \mathrm{~mm}) \text { down } \\
\text { h (less than } 1\end{array}$ & $\begin{array}{l}\text { Minimal processing of raw feedstock is } \\
\text { desired based on economics. Blending } \\
\text { of particle sizes is acceptable and may } \\
\text { have benefits for minimizing voids / air } \\
\text { entrainment. } \\
\text { Downstream processing is not affected } \\
\text { by particle size. }\end{array}$ \\
\hline $\begin{array}{l}\text { Solids } \\
\text { Concentration }\end{array}$ & $\begin{array}{l}10-18 \% \text { dry } \\
\text { weight solids }\end{array}$ & $\begin{array}{l}\text { Nominally } 15 \\
\text { solids. Maxin } \\
\text { weight solids } \\
\text { limited by flo } \\
\text { Moisture con } \\
\text { at } 98 \% \text { water } \\
\text { acids and alcc }\end{array}$ & $\begin{array}{l}6 \text { dry weight } \\
\text { um } 20 \% \text { dry } \\
\text { or more as } \\
\text { vability. } \\
\text { ent is estimated } \\
\text { with } 2 \% \text { organics } \\
\text { hols. }\end{array}$ & $\begin{array}{l}\text { Higher \% dry solids weight is desired } \\
\text { based on economics. Higher solids } \\
\text { concentration may be limited by } \\
\text { resulting pumpability. Based on past } \\
\text { experience, limit of solids concentration } \\
\text { may be on the order of } 20-25 \% \text { dry } \\
\text { weight solids. } \\
\text { Downstream processing is not affected } \\
\text { by increased solids concentration. }\end{array}$ \\
\hline
\end{tabular}


PNNL-21981

\begin{tabular}{|c|c|c|c|c|}
\hline Feed System & \multicolumn{3}{|c|}{$\begin{array}{l}\text { Raw or pre-processed feedstock is piled and } \\
\text { stored at the facility prior to use. Feedstock is } \\
\text { then moved to the feed system by various means } \\
\text { that could include batch and/or continuous } \\
\text { processes. Production scale feed is } 2000 \text { dry } \\
\text { metric tons per day. }\end{array}$} & $\begin{array}{l}\text { Simplest initial feed process is likely a } \\
\text { loader moving material from the pile to } \\
\text { a hopper or conveyance belt. }\end{array}$ \\
\hline Feed Pressure (psi) & \multicolumn{3}{|l|}{ As needed. } & $\begin{array}{l}\text { Various feed system may require } \\
\text { pressure or other mechanisms to feed } \\
\text { feedstock to the high pressure pump; } \\
\text { this could include lower pressure } \\
\text { pumping systems. }\end{array}$ \\
\hline $\begin{array}{l}\text { General Feedstock } \\
\text { Properties }\end{array}$ & \multicolumn{3}{|c|}{$\begin{array}{l}\text { pH Range: } 5 \text { - } 8 \\
\text { Abrasitivity: Up to } 3 \% \text { weight ash content }\end{array}$} & $\begin{array}{l}\text { Feedstock ranges from neutral to } \\
\text { slightly acidic. Abrasitivity is mild. } \\
\text { Fibrous materials based from wood } \\
\text { feedstock (chopped forest growth) and } \\
\text { corn feedstock (dried corn stalk and } \\
\text { husks). }\end{array}$ \\
\hline $\begin{array}{l}\text { Rheology - In } \\
\text { Process Material }\end{array}$ & $\begin{array}{l}\text { For wood } \\
\text { feedstock see } \\
\text { Datasheet WP } \\
\text { (20 micron). } \\
\text { For corn stover } \\
\text { feedstock see } \\
\text { Datasheet } \\
\text { CP(???). }\end{array}$ & \multicolumn{2}{|c|}{$\begin{array}{l}\text { Rheology data is in progress. } \\
\text { For wood feedstock see } \\
\text { Datasheets WP (???) } \\
\text { For corn stover feedstock see } \\
\text { Datasheets CP (???) }\end{array}$} & $\begin{array}{l}\text { Material to be pumped is highly vicious } \\
\text { and exhibits non-Newtonian flow } \\
\text { properties. The rheology will be } \\
\text { affected by the variances in particle } \\
\text { size/distribution, solids concentration, } \\
\text { and to some extent temperature. } \\
\text { Specific gravity is }>1 \text { but generally not } \\
\text { more than } 1.05 \text {. }\end{array}$ \\
\hline Pump System & \multicolumn{3}{|c|}{$\begin{array}{l}\text { Feedstock is fed to the pump inlet by the Feed } \\
\text { System. Air entrainment should be minimized. } \\
\text { Some flow pulsation likely can be tolerated. } \\
\text { Continuous pumping of feedstock is required at } \\
\text { pump outlet to downstream process. }\end{array}$} & $\begin{array}{l}\text { The pump can contain all or part of the } \\
\text { Feed System. }\end{array}$ \\
\hline $\begin{array}{l}\text { Pump Outlet } \\
\text { Pressure }\end{array}$ & $\begin{array}{l}3000 \text { psi } \\
\text { (206 bar) }\end{array}$ & $\begin{array}{l}2700-3200 \\
\text { psi } \\
(186-220 \\
\text { bar) }\end{array}$ & $\begin{array}{l}3000-3200 \mathrm{psi} \\
(206-220 \text { bar })\end{array}$ & $\begin{array}{l}\text { Maintaining high pressure is required } \\
\text { for the downstream process to convert } \\
\text { and maintain the biomass and water } \\
\text { media to a liquid phase. Liquefaction of } \\
\text { biomass occurs at } 300^{\circ} \mathrm{C} \text { and above. } \\
\text { For water to remain a liquid, the } \\
\text { temperature of the water must remain } \\
\text { below its critical temperature of } 374^{\circ} \mathrm{C} \text {. } \\
\text { The expected } 350^{\circ} \mathrm{C} \text { processing } \\
\text { temperature with a } 10^{\circ} \mathrm{C} \text { error margin } \\
\text { requires } 2,800 \text { psi to keep water in its } \\
\text { liquid phase. Maximum pressure of } \\
3200 \text { psi is used to allow for up to } 500 \\
\text { psi downstream pressure loss. }\end{array}$ \\
\hline
\end{tabular}


PNNL-21981

\begin{tabular}{|c|c|c|c|c|}
\hline Pump & NA & \multicolumn{2}{|c|}{$210^{\circ} \mathrm{F}\left(99^{\circ} \mathrm{C}\right)$} & Estimated based on mixed temperature \\
\hline $\begin{array}{l}\text { Flow Rate (gpm) } \\
\text { of } 15 \% \text { dry weight } \\
\text { solids }\end{array}$ & $\begin{array}{l}0.0066 \\
(0.0245 \\
\text { liters } / \mathrm{min})\end{array}$ & $\begin{array}{l}0.5-40 \\
(2-150 \\
\text { liters/min) }\end{array}$ & $\begin{array}{l}2300 \\
(8706 \\
\text { liters/min) }\end{array}$ & $\begin{array}{l}\text { Flow rate can be obtained by using } \\
\text { multiple pump units. For the pilot } \\
\text { scale, a split flow can be used to meet } \\
\text { flow rate. Flow rate can be reduced for } \\
\text { higher solids loadings. }\end{array}$ \\
\hline Flow Velocity & \multicolumn{3}{|c|}{$\begin{array}{l}\text { Scale up from Bench may require the flow to } \\
\text { reach turbulent conditions. }\end{array}$} & $\begin{array}{l}\text { Flow velocity can be adjusted by } \\
\text { downstream process pipe sizing as } \\
\text { required. }\end{array}$ \\
\hline $\begin{array}{l}\text { Estimated } \\
\text { Maximum Pipe } \\
\text { Diameter } \\
\text { Downstream of } \\
\text { Pump (inches) }\end{array}$ & NA & $\begin{array}{l}0.75-1.00 \\
(19-25 \\
\mathrm{mm})\end{array}$ & $\begin{array}{l}2.0-4.0 \\
(51-102 \mathrm{~mm})\end{array}$ & $\begin{array}{l}\text { Estimated only. This should not } \\
\text { influence pump outlet size. } \\
\text { Downstream piping may vary } \\
\text { depending on process requirements } \\
\text { including manifolding up or down for } \\
\text { multiple process streams. }\end{array}$ \\
\hline $\begin{array}{l}\text { Equipment } \\
\text { Operation }\end{array}$ & Continuous & \multicolumn{2}{|c|}{$\begin{array}{l}\text { Continuous with } 90 \% \text { on } \\
\text { stream }\end{array}$} & $\begin{array}{l}\text { Feed system is allowed batch } \\
\text { processing as long as feedstock exiting } \\
\text { pump to process is continuous. }\end{array}$ \\
\hline Plant Resources & NA & \multicolumn{2}{|c|}{ Power, Water, Steam } & $\begin{array}{l}\text { Power }>240 \mathrm{~V}, 1 \text { or } 3 \text { Phase } / 60 \mathrm{~Hz}(480 \mathrm{~V} \\
\text { likely available at Production scale) } \\
\text { Water }>\text { As Needed } \\
\text { Steam }>\text { Likely at Production scale }\end{array}$ \\
\hline
\end{tabular}


PNNL-21981

Attachment 2

\section{Biomass Feedstock Information}

\section{Biomass Feedstock Currently Under Consideration for Use In Process}

\section{a. Wood Feedstock}

i. Raw Feedstock - Southern Pine Residual Forest Product (RFP)

1. See Raw Feedstock Description

ii. Conditioned Feedstock - Made from Raw Feedstock

1. Immersion Milled Pine Slurry - Finely Ground to 20 micron. In small bench scale testing, after feed preparations (immersion milling and water addition) for a solids loading of $13 \%$ dry weight solids, the pine wood mixture has flow properties similar to play dough (i.e. when a small ball of material is squeezed in a hand the material will uniformly squeeze out between the fingers). Particle size is primarily 20 microns or less (D50) with some particles as large as 400 microns (D99) scattered in the mix.

a. See Rheology Testing

i. Shear

ii. Slump

b. See Particle Size Distribution

2. -1/16-in. Pine Slurry - Mill to pass through a $1 / 16$ - inch screen

b. Corn Feedstock

3. $-1 / 4-i n$. Pine Slurry - Mill to pass through a $1 / 4$ - inch screen

i. Raw Feedstock

1. See Raw Feedstock Description

ii. Conditioned Feedstock - Made from Raw Feedstock

1. Corn Stover-200 to 400 microns

2. Some rheology for the corn stover mixture has been published (Stickel et al. 2009, Viamajala et al., 2009)

c. $\quad$ Reference Material (* downloadable from Internet)

i. *Article - Particle Concentration and Yield Stress of Biomass Slurries During Enzymatic Hydrolysis at High-Solids Loadings (Christine M. Roche, Clare J. Dibble, Jeffrey S. Knutsen, Jonathan J. Stickel, Matthew W. Liberatore) Published online 27 April 2009 in Wiley InterScience (www.interscience.wiley.com) DOI 10.1002/bit.22381

ii. * Report - Particle Morphology Characterization and Manipulation in Biomass Slurries and the Effect on Rheological Properties and Enzymatic Conversion (Clare J. Dibble, Tatyana A. Shatova, Jennie L. Jorgenson, and Jonathan J. Stickel) DOI 10.1002/btpr.669, Published online in Wiley Online Library (wileyonlinelibrary.com).

iii. * Report - PNNL- 16079, 3.1.1.2 Feed Processing and Handling DL2 Final Report (DC Elliott, JK Magnuson, CF Wend) September 2000

iv. *Article - Rheological Study of Comingled Biomass and Coal Slurries with Hydrothermal Pretreatment (Wei He, Chan S. Park, and Joseph M. Norbeck), Energy Fuels 2009, 23, 4763-4767 : DOI:10.1021/ef9000852, Published on Web 05/26/2009

v. *Report - Rheology of corn stover slurries at high solids concentrations - Effects of saccharification and particle size (Sridhar Viamajala, James D. McMillan, Daniel J. Schell, Richard T. Elander), Bioresource Technology

vi. * Report - Rheology measurements of a biomass slurry: an inter-laboratory study (Jonathan J. Stickel, Jeffrey S. Knutsen, Matthew W. Liberatore, Wing Luu,DouglasW. Bousfield, Daniel J. Klingenberg · C. Tim Scott, Thatcher W. Root, Max R. Ehrhardt, Thomas O. Monz) Rheol Acta (2009) 48:1005-1015 DOI 10.1007/s00397-009-0382-8 
vii. *Article - Rheology and extrusion of high-solids biomass (C.Timothy Scott, Joseph R. Samaniuk, Daniel J. Klingenberg) MAY 2011 | TAPPI JOURNAL

viii. *Article - Physical Pretreatment - Woody Biomass Size Reduction - for Forest Biorefinery - In Sustainable Production of Fuels, Chemicals, and Fibers from Forest Biomass; Zhu, J., et al.; ACS Symposium Series; American Chemical Society: Washington, DC, 2011

ix. *Article - Particle Morphology Characterization and Manipulation in Biomass Slurries and the Effect on Rheological Properties and Enzymatic Conversion (Clare J. Dibble, Tatyana A. Shatova, Jennie L. Jorgenson, and Jonathan J. Stickel) DOI 10.1002/btpr.669 Published online in Wiley Online Library (wileyonlinelibrary.com)

\section{Raw Feedstock Description}

a. Wood Feedstock

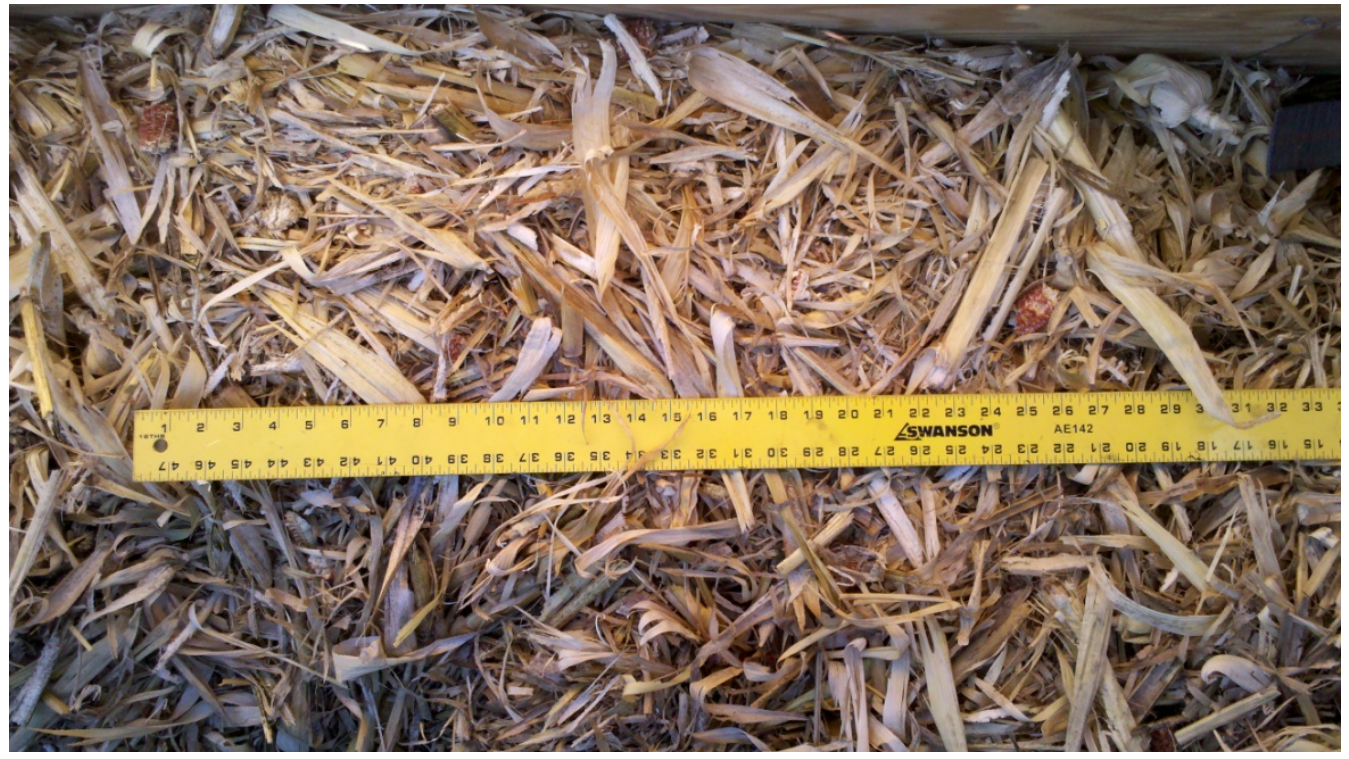




\section{b. Corn Feedstock}

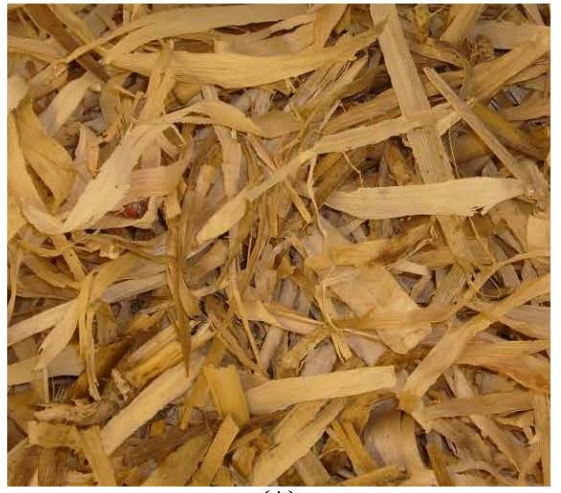

(A)

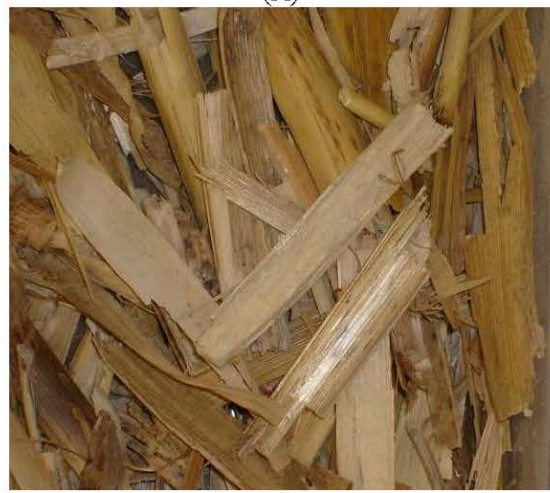

(C)

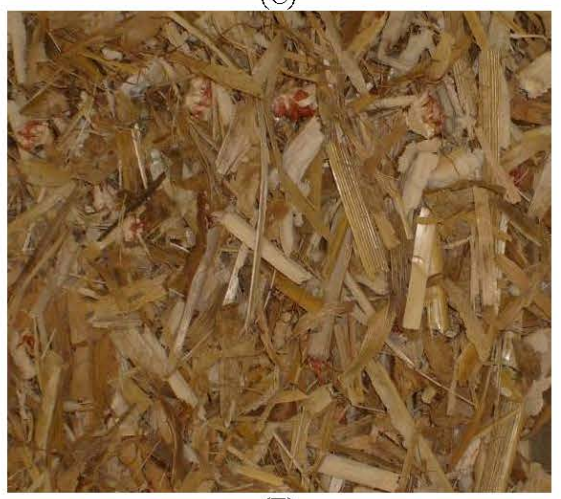

(E)

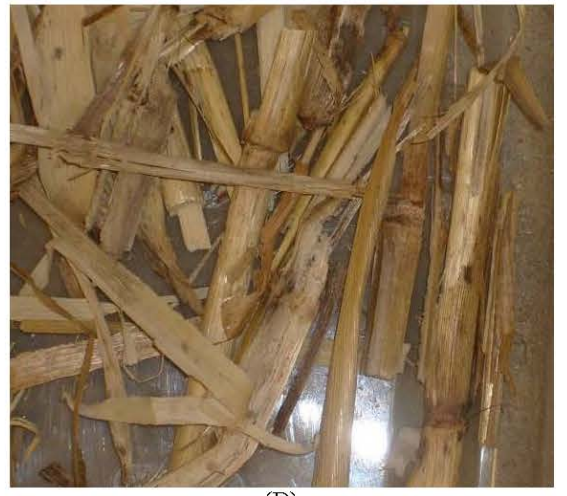

(B)

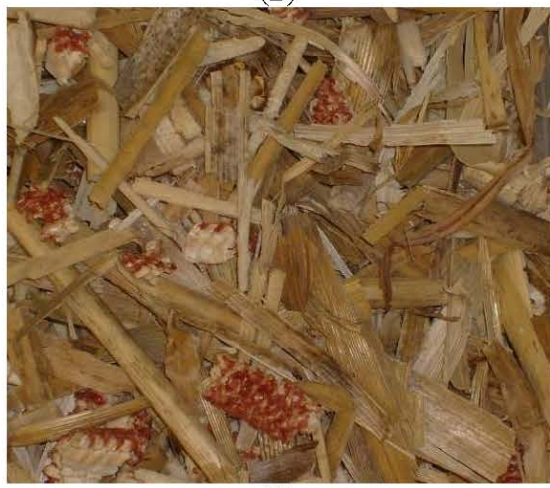

(D)

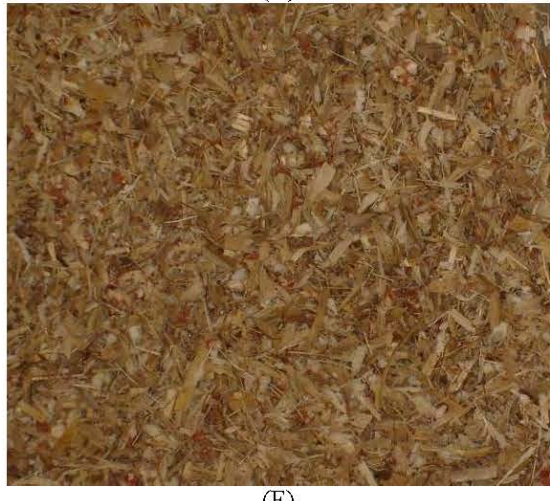

(F)

Figure B2. Photographs of raw stover material collected from rear of combine with row crop head and prototype shear type chopper. Material collected over $7.62 \mathrm{~cm}$ screen (A), $5.08 \mathrm{~cm}$ screen (B), $2.54 \mathrm{~cm}$ screen (C), $1.27 \mathrm{~cm}$ screen (D), $0.635 \mathrm{~cm}$ screen (E) and above pan (F), are shown. 


\section{Conditioned Feedstock Description}

a. Size Reduction Steps

The conditioned feedstock material sent to PNNL was not sieved pan material. After collection and drying all material (wood and stover) was ground using an Arts-Way Hammer mill through a $1 / 4$ inch screen, and placed in 220 gal bulk containers.

Further size reduction of the material was carried out with Schutte-Buffalo Circ-U-Flow model 18-7-300 Hammer mill (capacity $200 \mathrm{lbs}$./hour). To reduce material to the 0.5 $1.5 \mathrm{~mm}$ feedstock specifications, 20 mesh screen $(0.853 \mathrm{~mm}$ opening) was utilized and for the 200-400 micron specifications, the 20 mesh screen was replaced with a screen with approximately 400 micron screen opening.

Therefore all material sent was not screened material, it was the complete material sized to by initial reduction in the Arts-Way to $1 / 4$ inch then further reduction to the smaller sizes using the Schutte-Buffalo.

The corn stover and wood chips were treated to the same size reduction methods, although how they responded was very different. In general, the wood chips produced a much narrower size distribution and lower fines (and therefore less dust), while the corn stover had much greater particle size distribution and produced much more fines particularly when dry.

\section{b. Conditioned - Wood Feedstock (20 micron)}

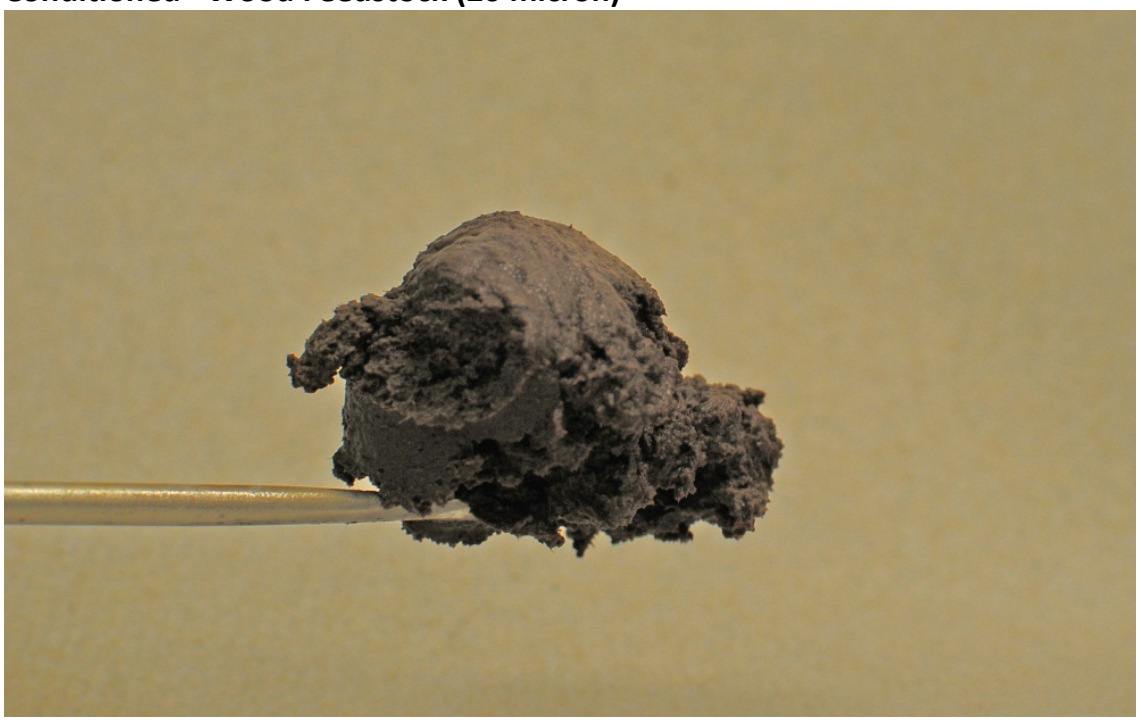

c. Conditioned - Corn Feedstock

No photo available at this time. 
PNNL-21981

4. Rheology Testing - Wood Feedstock (20 micron)

Biomass RHEOLOGY Update - October 20, 2011

Background: A series of rheology tests have been planned for the two different biomass feedstocks of wood product \& corn stover. The feedstock parameters to be varied in these tests include particle size (up to 400 micron), moisture content (above 20 weight \% solids), and in some cases temperature (up to $80^{\circ} \mathrm{C}$ ). Rheology testing will include shear vane, rheograms, and slump.

\section{Rheology Test Results:}

These are preliminary results. Plans call for additional rheology testing including constant strain rate tests and slump test. These results will be passed along as soon as they are available.

Biomass Feedstock Tested: Wood Product - Forest Product Run (FPR) Post Immersion Mill, 13 weight \% Solids, Particle Size $\sim 20$ micron d(0.5). See photo and particle size distribution information / figures following. Note: The Pilot and Production application is expected to have larger particle size (400 micron or greater) but may have a similar solid loading ( $12-15$ weight $\%$ solids or greater).

Two types of rheology tests were performed: 1) shear vane tests for direct measurement of shear strength and 2) rheogram for shear rates between 200 and $500 \mathrm{~s}^{-1}$. This data was used to model the material as a Bingham plastic:

$$
\begin{aligned}
\tau=\gamma \mu+Y_{s} & \text { where: } \\
\tau & =\text { applied shear stress }(\mathrm{Pa}) \\
\gamma & =\text { shear rate }\left(\mathrm{s}^{-1}\right) \\
\mu & =\text { plastic viscosity (Pa s) } \\
\mathrm{Y}_{\mathrm{s}} & =\text { Yield stress in shear }
\end{aligned}
$$

This results in a plastic viscosity on the order of 0.8 to $1 \mathrm{~Pa} s$ and Yield stress in shear of approximately $650 \mathrm{~Pa}$. Rheograms for shear rates from 0 to $200 \mathrm{~s}^{-1}$ indicate a shear thinning behavior.

Contacts: Eric Berglin, Pacific Northwest National Laboratory, 902 Battelle Boulevard or P.O. Box 999, MSIN K5-22, Richland, WA 99352 USA, Telephone: 509-372-4832, eric.berglin@ pnnl.gov or Carl Enderlin, Pacific Northwest National Laboratory, 902 Battelle Boulevard or P.O. Box 999, MSIN K7-15, Richland, WA 99352 USA, Telephone: 509-374-2141, cougar.enderlin@pnnl.gov 
PNNL-21981

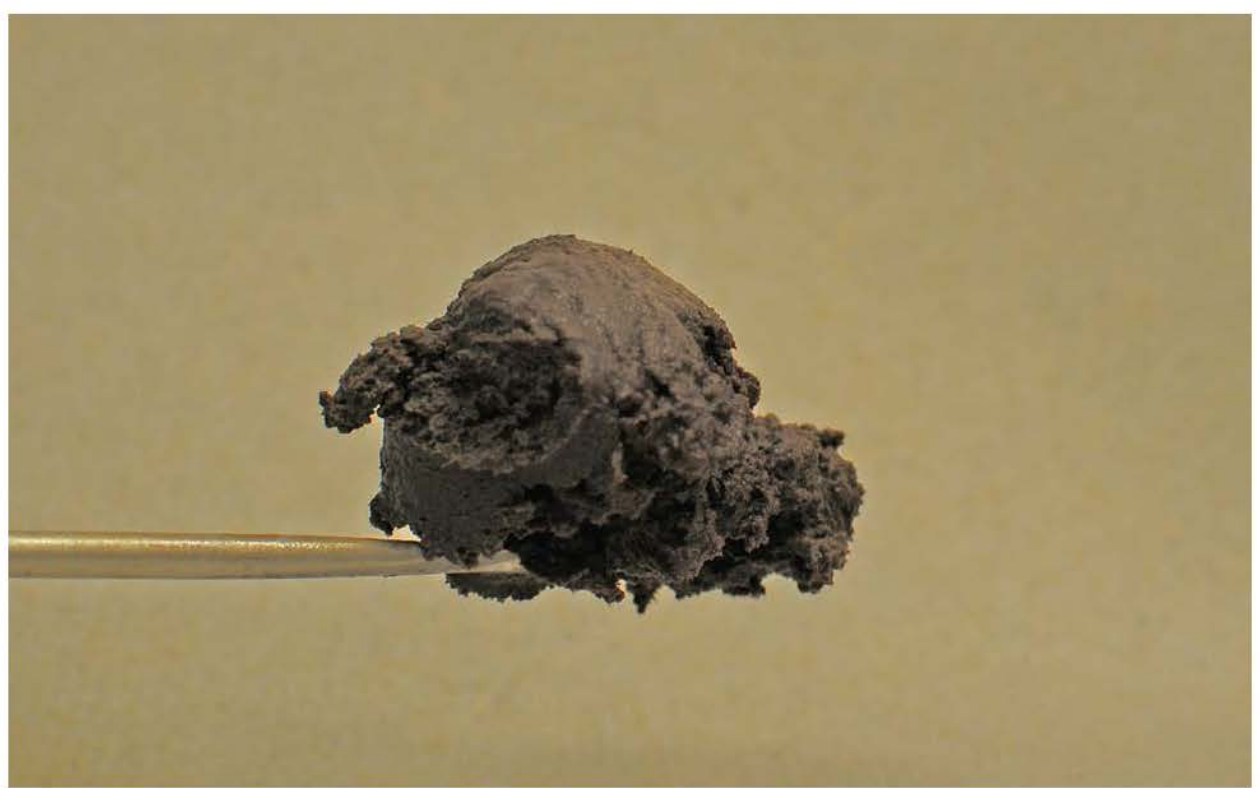

Photo - Biomass Wood Product

Particle Size Distribution Analysis (Two Runs)

Result: Average $\quad d(0.1)=4.0$ microns, $\quad d(0.5)=19$ microns $\quad d(0.9)=75$ microns 
PNNL-21981

5. Slump Testing - Wood Feedstock (20 micron)

PNNL Biomass Product Slump Testing - October 26, 2011

\section{A. Preparation of Slurries of Biomass Product (wet Pine) for Slump Test $\quad$ Updated 10-27-11}

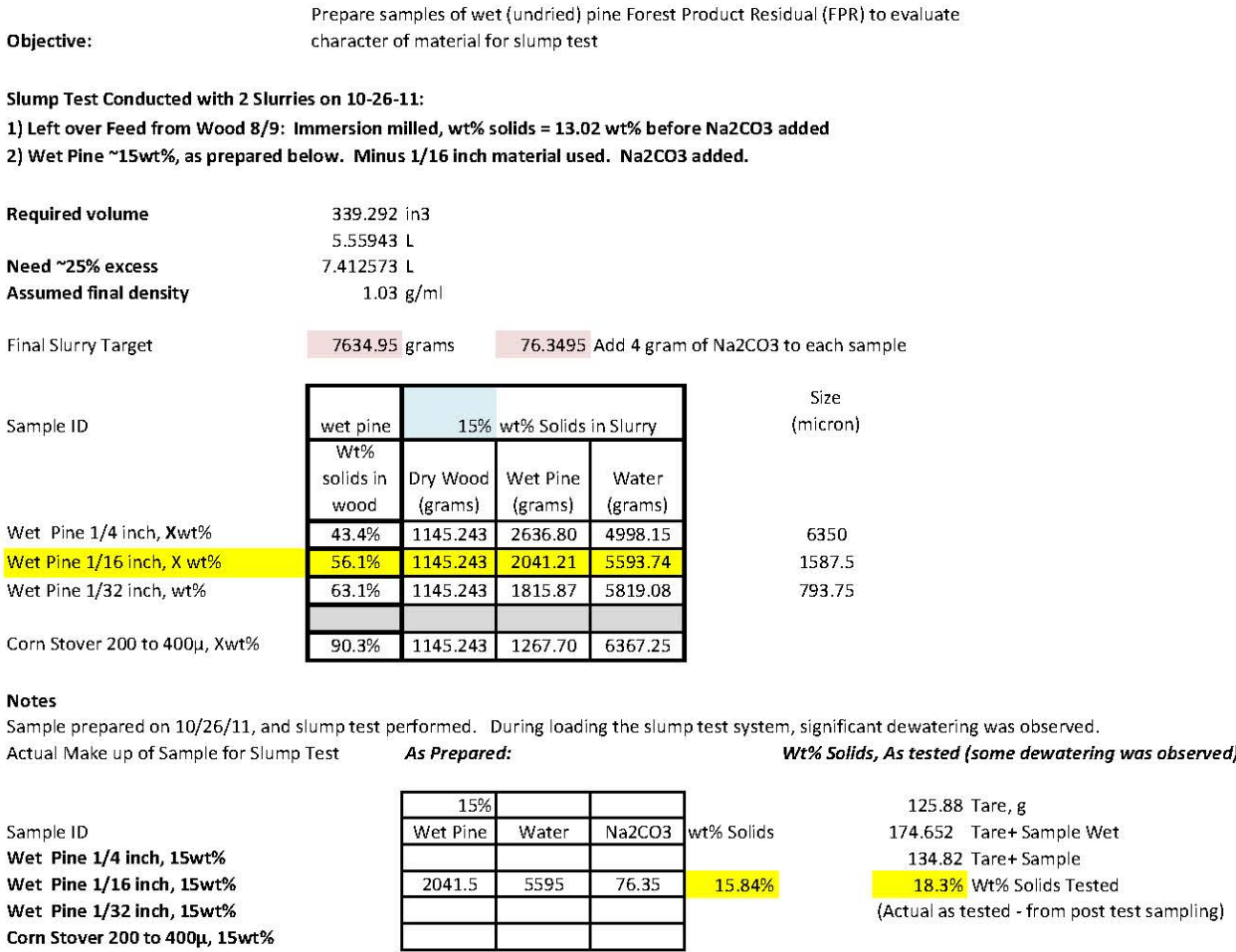

\section{B. Slump Testing Setup:}

Slump Test Procedures: Slump testing procedures were based on ASTM C143/C143 M - 10 a "Standard Test Method for Slump of Hydraulic-Cement Concrete". The test apparatus consisted of a cone ( 12 inches tall, 8 inch diameter base, 4 inch ciameter top) and tamping rod that met these ASTM standards.

Test procedures were modified to limit dewatering cause by the ASTM procedure for tamping. Test procedure modification involved inverting the cone during filling to minimize voids, with some tamping and tapping on the side. Next the cone was rapidly flipped over. Tamping and tapping were performed, and refilling of the top of the cone of material that oozed out at the bottom. For these feed materials, tapping the side of the cone was more effective at removing voids than tamping with the rod. This was the case in the two primary tests. In the very first tests (test depicted in two small photos), failure to tap on the side of the cone during cone lifting did not give good release of the product from the cone walls. 
PNNL-21981

PNNL Biomass Product Slump Testing - October 26, 2011

\section{c. Slump Testing:}

\section{C1. Immersion Milled Wood, Size 20 micron (Dp50):}

C1a: Initial Slump Test with Immersion Milled Wood, Size 20 micron (Dp50), 13 Wt\% Solids, Result > Repeat Test in C1b Note: Test is not valid because cone did not release well when lifting and was repeated as $\mathrm{C} 1 \mathrm{~b}$ below.
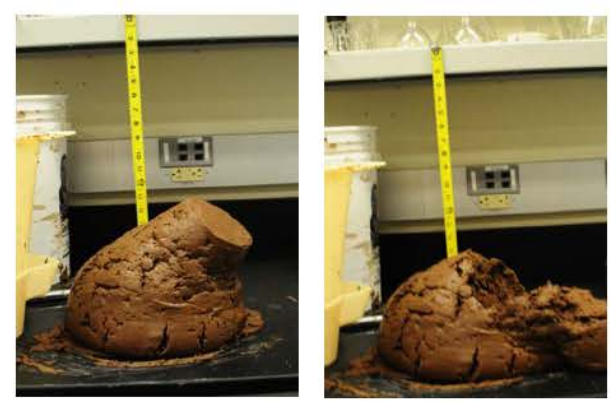

Initial Slump Test with Immersion Milled Wood 13 wt\%.

Left, 1 minute; Right, 2 minutes, No Slump Data Resulted

C1b: Slump Test with Immersion Milled Wood, Size 20 micron (Dp50), 13 Wt\% Solids > Result: 4 inch of Slump

Note: Repeat test after $\mathrm{C} 1 \mathrm{a}$ test failure. Material from $\mathrm{Cla}$ was reused and this time successfully released from the cone was achieved by additional tapping/vibrating of the cone when lifting.

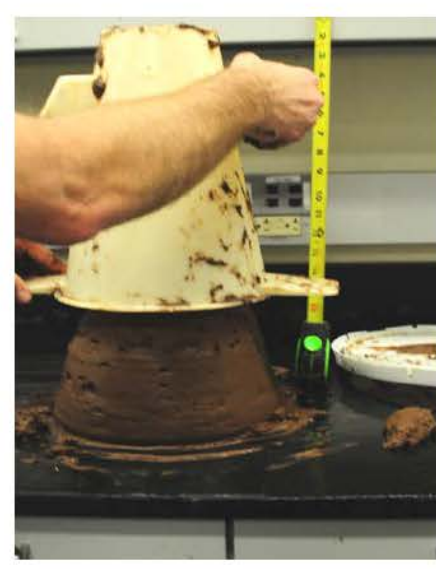

Slump Test, Immersion Milled Wood Feed, $13 w t \%$ Solids, Start of test

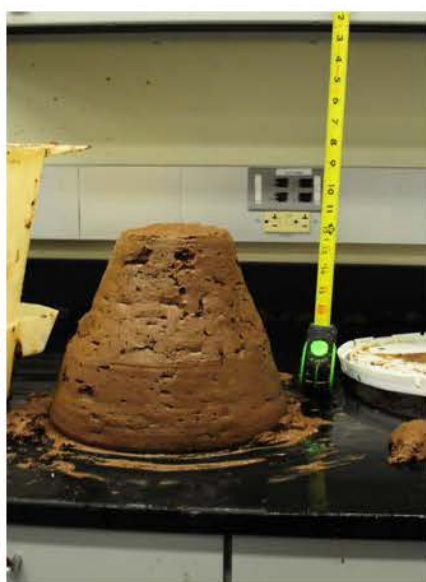

Slump Test, Immersion Milled Wood Feed, $13 w t \%$ Solids, 1 minute.

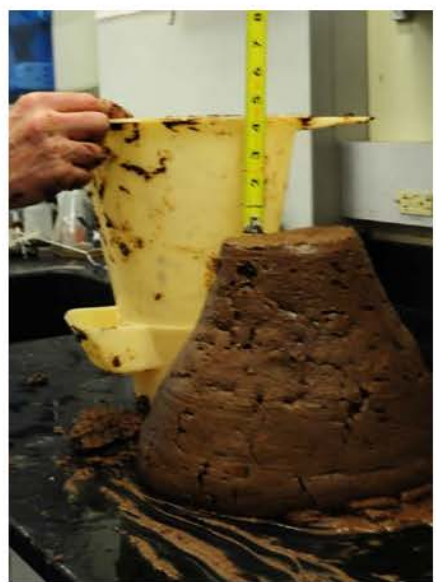

Slump Test, Immersion Milled Wood Feed, $13 w t \%$ Solids, 2.5 minutes, 4 inches of slump. 
PNNL-21981

PNNL Biomass Product Slump Testing - October 26, 2011

\section{C2. Minus $1 / 16$ - inch Wet Wood}

\section{C2a: Slump Test, Performed with Minus 1/16 - inch Wet Wood (18.3 wt\% post-test) > Result: 0.5 inch of Slump}

Note 1: Solid content of material was measured at $15.84 \mathrm{wt} \%$ pre-test and remeasured after test as $18.3 \mathrm{wt} \%$. Higher solid content after test from dewatering during test setup and continued dewatering during testing. Tamping material during test setup exacerbated the dewatering so tamping was reduced. Additional dewatering was visible during slump test time of 4 minutes. Note 2: If a handful of this material is squeezed in hand, some dewatering will occur.

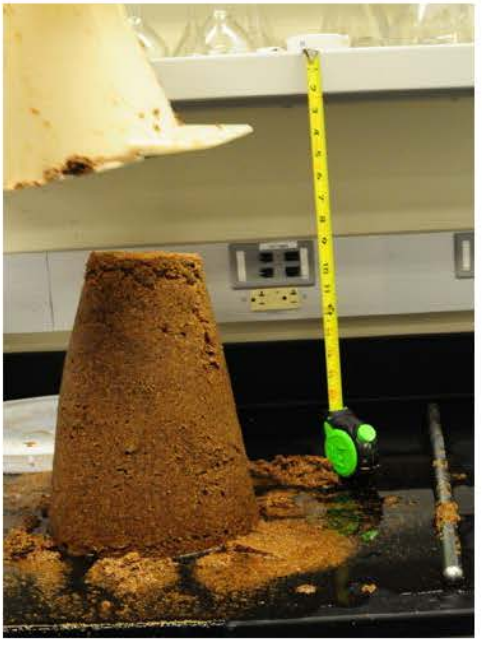

Slump Test, -1/16-in. Wet Wood, $18 \%$ Solids, Start of Test. (Note dewatering of Material)

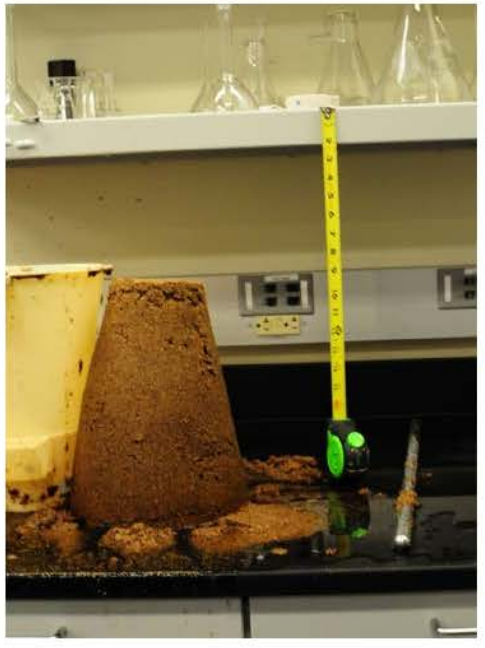

Slump Test, - $1 / 16$-in. Wet Wood, $18 \%$ Solids, After 4 minutes, 0.5 inches of slump. Further dewatering is evident. 
6. Particle Size Distribution - Wood Feedstock (20 micron)

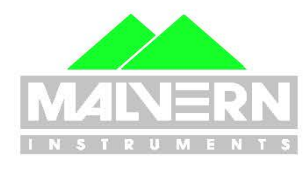

FPR Slurry Feed-1-Unsonicated - Average

Sample Source \& type:

Sample bulk lot ref:

\begin{tabular}{ll}
\hline Particle Name: & Accessory Name: \\
Sawdust & Hydro 2000G (A) \\
Particle RI: & Absorption: \\
1.530 & 0.1 \\
Dispersant Name: & Dispersant RI: \\
Water & 1.330 \\
\hline Concentration: & Span: \\
$0.0123 \quad \%$ Vol & 3.944 \\
Specific Surface Area: & Surface Weighted Mean D[3,2] \\
$0.656 \quad \mathrm{~m}^{2} / \mathrm{g}$ & $9.143 \quad$ um
\end{tabular}

SOP Name:

Measured by:

D3M966

Result Source:

Averaged

MASTERSIZER

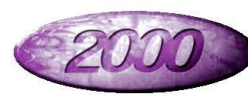

\title{
Result Analysis Report
}

Measured:

Monday, September 19, 2011 4:50:37 PM

Analysed:

Monday, September 19, 2011 4:50:39 PM

9.143 um
Analysis model: Sensitivity:

General purpose Normal

Size range: Obscuration

0.020 to 2000.000 um $9.42 \%$

Weighted Residual: Result Emulation

$0.801 \%$ Off

Uniformity: Result units:

1.52 Volume

Vol. Weighted Mean D[4,3]:

37.761 um

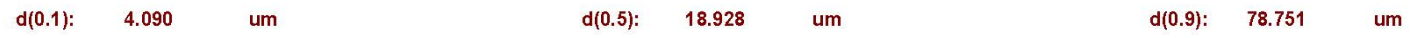

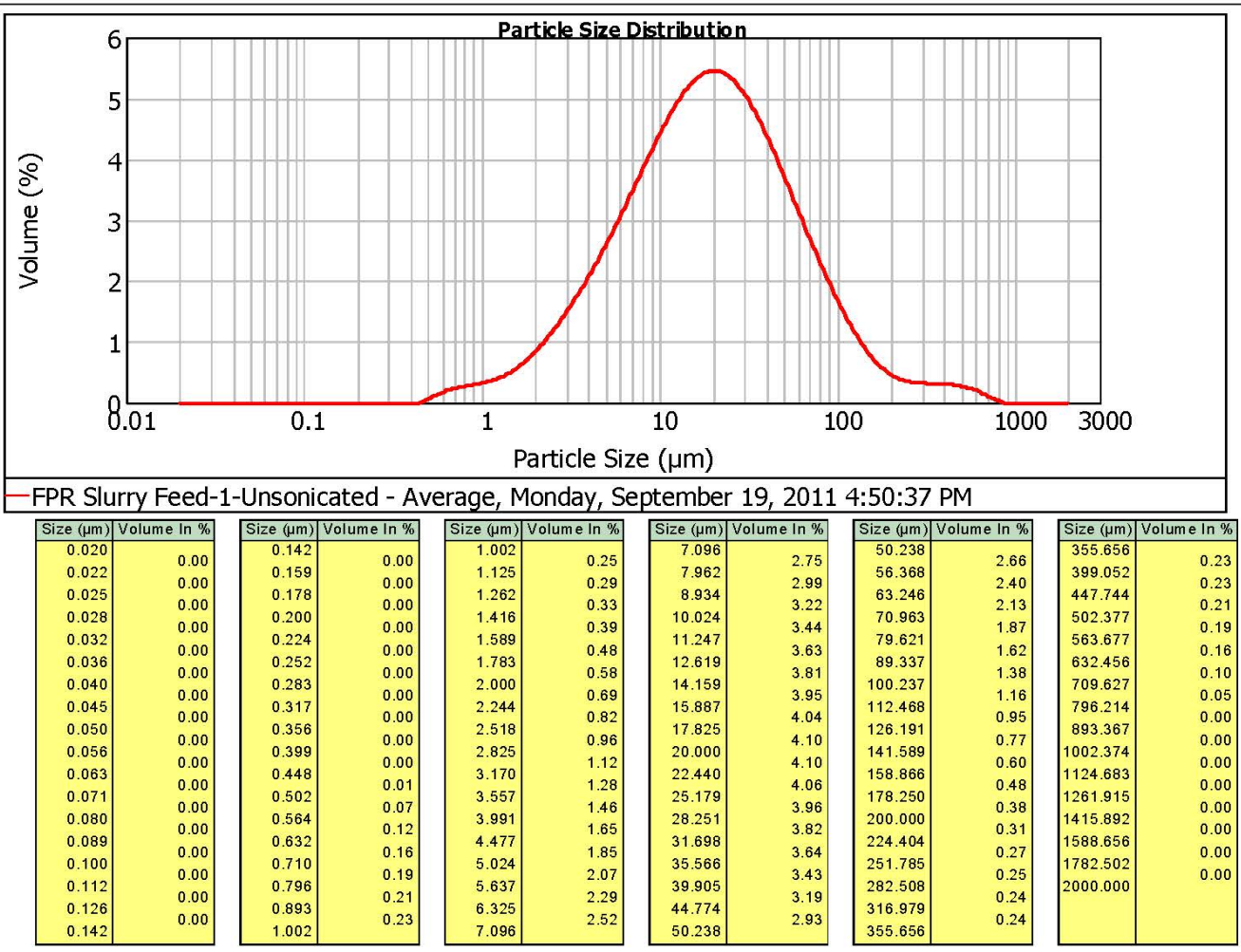

Operator notes:

Malvern Instruments Ltd.

Malvern, UK
Tel := + +441 (0) 1684-892456 Fax +[441 (0) 1684-892789
Mastersizer 2000 Ver. 5.60

Serial Number : MAL1019545
File name: Biomass sample AJS.mea

Record Number: 4

9/19/2011 4:58:45 PM 
PNNL-21981

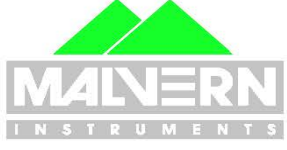

FPR Slurry Feed-1-Sonicated - Average

Sample Source \& type:

Sample bulk lot ref:

\section{MASTERSIZER 2000}

\section{Result Analysis Report}

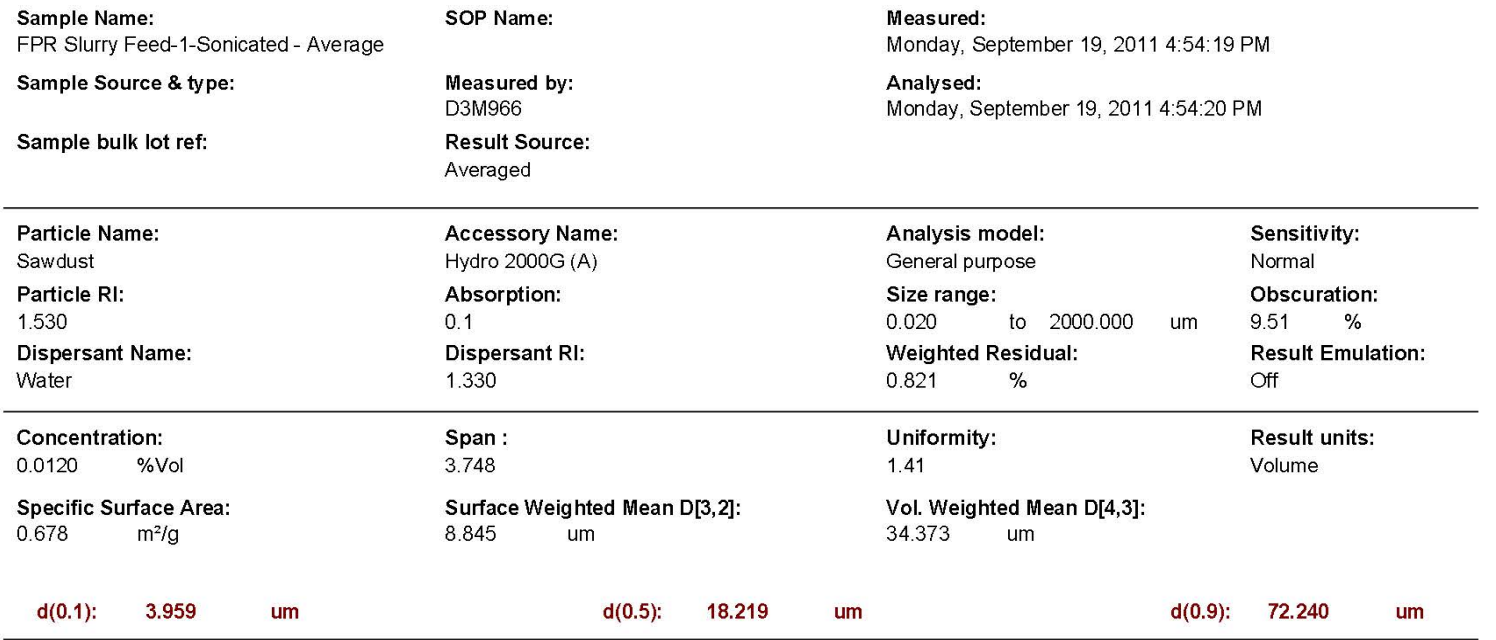

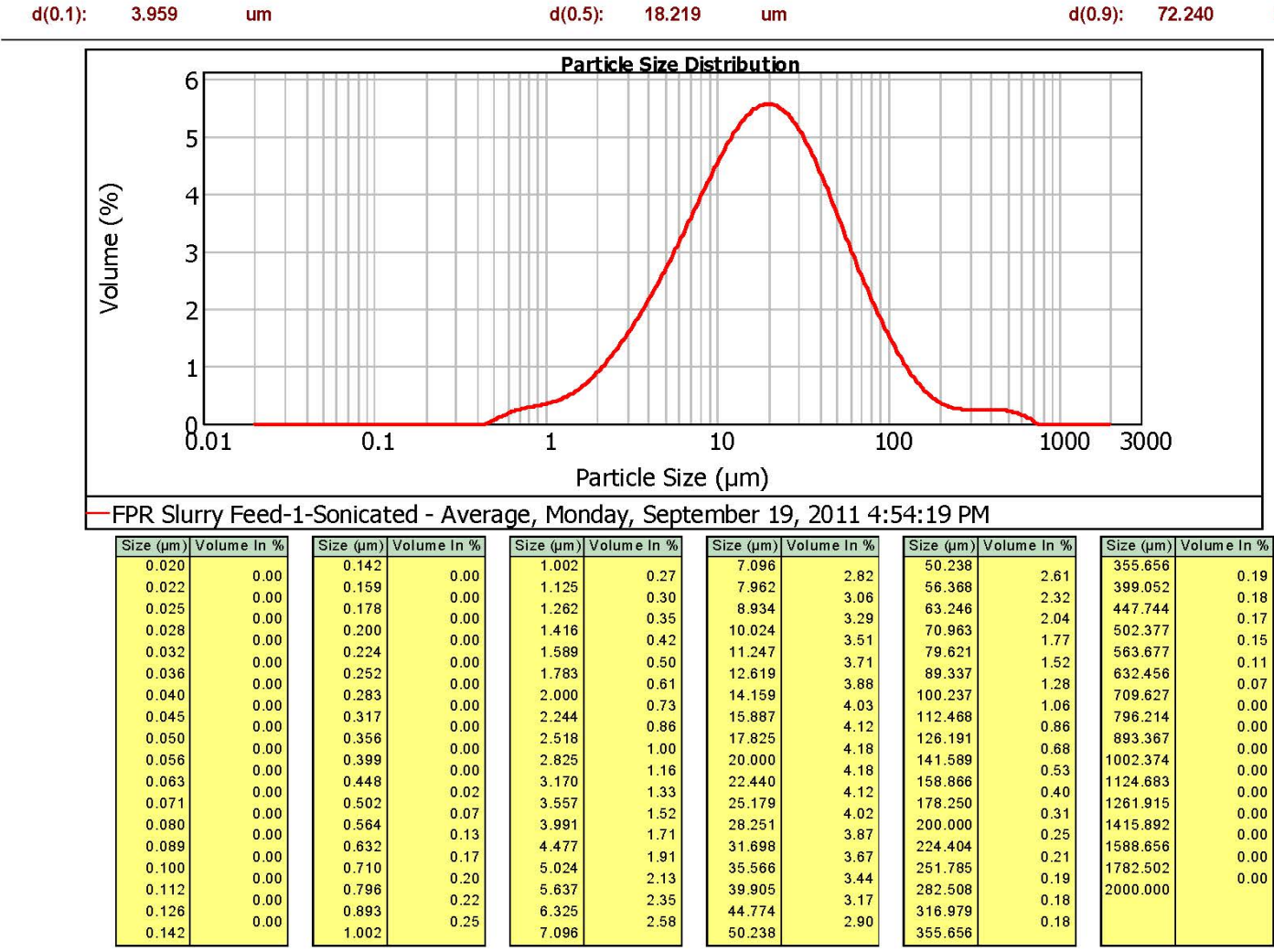

Operator notes:

Malvern Instruments Ltd.

Malvern, UK

Tel := +「441 (0) 1684-892456 Fax +[441 (0) 1684-892789
Mastersizer 2000 Ver. 5.60 Serial Nurnber : MAL1019545
File name: Biomass sample AJs.mea Record Number: 8 9/19/2011 4:58:45 PM 


\section{Appendix D}

"Pumpability Assessment Query by PNNL to Vendors" dated early December, 2011 

PNNL-21981

\section{Appendix D}

\section{“Pumpability Assessment Query by PNNL to Vendors” dated early December, 2011}

We are now seriously considering performing a near term pumpability assessment. In this pumpability assessment we would be looking for:

- reassurance that our fibrous feedstock material can be introduced and pumped with your equipment;

- determining any special feed/pump features or upgrades that may need to be incorporated into the equipment for:

- PILOT - Short term demonstration

- PRODUCTION - Full scale, long term plant success

We would anticipate testing some variations in the feedstock (type, particle size, moisture content) to determine ability to feed/pump the feedstock, as well as process limits and tradeoffs for overall process efficiency.

For this pumpability assessment, the ability to start testing quickly (3-6 month time frame) and to minimize cost may take some innovative thinking. Various options could be considered including using an existing test apparatus, testing at a facility with an installed pumping system, or providing a feed/pump system that could be installed at a third-party testing facility or PNNL.

1. What options can you provide that would allow a pump assessment to be performed?

2. What is the smallest pump you have available that you believe could adequately address feedstock pumpability and scale-up to the PILOT/PRODUCTION flow rates?

3. What parameters/metrics would you consider most important to verify during pumpability assessment for your equipment performance in the PNNL application to minimize uncertainty in the assessment of scale-up.

4. What unique features* are available in your equipment to address possible problems that may arise during the pumpability assessment that may need to be included for either the PILOT or PRODUCTION scale equipment?

* Unique features include seal types, valve types, material of construction, replaceable wear components, alternate/addition components, etc. Parameters that may require additional features to be incorporated would include fibrous nature of biomass material, dealing with abrasive materials in the feedstock (e.g. ash, sand, dirt), reducing biomass feedstock transport friction to minimize pressure loss, eliminating material bridging during pump feeding, running dry, and eliminating air induction that could cause pump cavitation.

If you have any better ideas we would appreciate this information for consideration. This may include not using your specific equipment but the same type of equipment available at a smaller scale or at a 
PNNL-21981

facility. A larger scale system will be considered if positive tradeoff between schedule and additional cost (e.g. additional feedstock, scale of testing, etc.). PNNL is interested in identifying partners for both collaboration and investment in this endeavor though the National Advanced Biofuels Consortium (NABC). Information about the NABC can be found at website http://www.nabcprojects.org/. 


\section{Appendix E}

\section{Other Vendors Explored/Contacted/Summary Results}





\section{Appendix E}

\section{Other Vendors Explored/Contacted/Summary Results}

\begin{tabular}{|c|c|c|c|}
\hline Vendor & Equipment & Notes & Contact/Related Websites \\
\hline Aker Wirth GmbH & 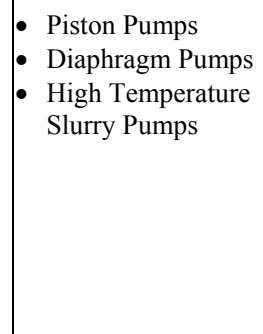 & $\begin{array}{l}\text { No vendor response to e-mail. } \\
\text { Makes a variety of pumps for the mining industry. }\end{array}$ & $\begin{array}{l}\text { akerwirth.info@akersolutions.com } \\
\text { martina.rohe@,wirth-europe.com } \\
\text { Address: } \\
\text { Koelner Strasse 71- 73 } \\
\text { Erkelenz 41812 Germany } \\
\text { Related Website(s): } \\
\text { www.akersolutions.com/akerwirth } \\
\text { www.wirth-europe.com } \\
\end{array}$ \\
\hline ANDRITZ INC & $\begin{array}{l}\text { MSD Impressafiner / } \\
\text { Plug Screw Feeder }\end{array}$ & $\begin{array}{l}\text { High-pressure feeder for a variety of feed material types ranging from wood chips (high bulk density) } \\
\text { to wheat straw (low bulk density) } \\
\text { Vendor Response: Andritz biomass feeding and pumping systems are unfortunately not designed for } \\
\text { the pressures you need. We can currently only handle up to } 25 \text { bar ( } \sim 360 \text { psig) with some exceptions at } \\
\text { lower design pressures. We have expertise in pumping wood fibers at lower pressures, and can reach } \\
\text { maybe } 15 \text { to } 16 \% \text { dry solids content with difficulty. The friction losses at higher solids make } \\
\text { engineering and operation of the pumping system very difficult, so we use rotary valve, plug screw } \\
\text { feeder, or lock-hopper systems instead. Particle size and particle characteristics will, of course, } \\
\text { influence the behavior of the suspension, but water inclusion in the fiber walls and hydrogen bonding } \\
\text { are tough to overcome. }\end{array}$ & $\begin{array}{l}\text { Bertil Stromberg } \\
\text { ANDRITZ PULP AND PAPER } \\
\text { Fiber and Chemical Division } \\
\text { Vice President, Biofuel } \\
\text { Bertil.Stromberg@andritz.com } \\
\text { Address: } \\
\text { 13 Pruyn's Island Dr. } \\
\text { Glens Falls, NY 12801, USA } \\
\text { Related Website(s): } \\
\text { http://www.andritz.com/ANONIDZ42B1DFB77 } \\
\text { 98CE26B/reactorfeedequipment- } \\
\text { msdimpressafiner } \\
\end{array}$ \\
\hline $\begin{array}{l}\text { BMA } \\
\text { Braunschweigische } \\
\text { Maschinenbauanstalt } \\
\text { AG }\end{array}$ & $\begin{array}{l}\text { "Steam-drying" } \\
\text { biomass processing }\end{array}$ & $\begin{array}{l}\text { Located in Germany } \\
\text { No response }\end{array}$ & $\begin{array}{l}\text { sales@bma-de.com } \\
\text { Address: } \\
\text { Am Alten Bahnhof } 5 \\
38122 \text { Braunschweig } \\
\text { Germany } \\
\text { Related Website(s): } \\
\text { http://www.bma- } \\
\text { worldwide.com/products/biomass.html }\end{array}$ \\
\hline
\end{tabular}




\begin{tabular}{|c|c|c|c|}
\hline Vendor & Equipment & Notes & Contact/Related Websites \\
\hline Boerger, LLC & Rotary Lobe Pump & $\begin{array}{l}\text { This pump operates at a relatively low pressure so it would have to be used as a feeder pump. } \\
\text { Vendor Response: We have pumps that can go as low as } 5 \mathrm{gpm} \text { on up to } 5000 \mathrm{gpm} \text {. The only } \\
\text { difference is that on the pumps at the lower end of the flow range we do not offer replaceable radial } \\
\text { liners. }\end{array}$ & $\begin{array}{l}\text { Steve Doyle } \\
\text { sdo@boerger-pumps.com } \\
\text { T: } 612-435-7327 \\
\text { Address: } \\
\text { 2860 Water Tower Place } \\
\text { Chanhassen, MN 55317 USA } \\
\text { Related Website(s): } \\
\text { www.boerger-pumps.com } \\
\end{array}$ \\
\hline ChemGrout & $\begin{array}{l}\text { - Grout Pump } \\
\text { Progressive } \\
\text { - Cavity } \\
\text { Plunger Pump }\end{array}$ & $\begin{array}{l}\text { Generally less than } 500 \mathrm{psi} \text {. The primary pumps in this line are progressive cavity pumps. The highest } \\
\text { pressure pump available is plunger pump with an upper pressure range of } 1000 \text { to } 2000 \mathrm{psi} \text {. }\end{array}$ & $\begin{array}{l}\text { Related Website(s): } \\
\text { http://www.chemgrout.com/groutpumps.htm }\end{array}$ \\
\hline Coperion GmbH & Twin Screw Extruder & Twin screw feeder/extruder in Germany & $\begin{array}{l}\text { info@coperion.com } \\
\text { Tel.: +49 (0) } 711 \text { 897-0 } \\
\text { Address: } \\
\text { Theodorstraße } 10 \\
\text { 70469 Stuttgart Germany } \\
\text { Related Website(s): } \\
\text { http://www.coperion.com/en/ } \\
\end{array}$ \\
\hline Delta Industries Inc., & $\begin{array}{l}\text { Progressive Cavity } \\
\text { Pump }\end{array}$ & 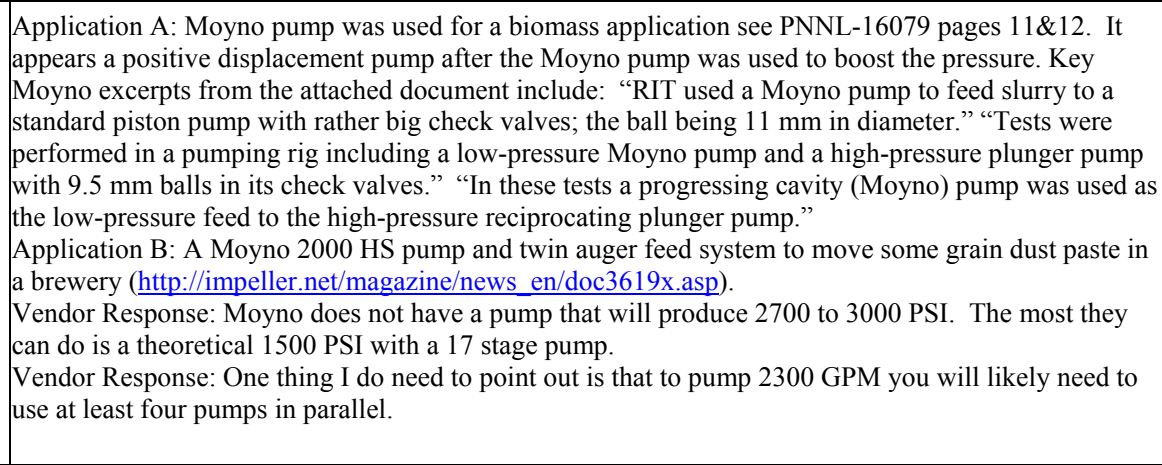 & $\begin{array}{l}\text { Mike Foteff } \\
\text { mike.foteff@deltaindustriesinc.com } \\
\text { Phone 503-288-5011 } \\
\text { Toll Free: 800-242-5011 } \\
\text { Fax: (503) 288-5014 } \\
\text { Address: } \\
16142 \text { N.E. Mason Street, Portland, OR } 97230 \\
\text { Related Website(s): } \\
\text { httt://www.moyno.com/ } \\
\text { http://www.deltaindustriesinc.com/ }\end{array}$ \\
\hline Discflo Corporation & Disc Pump & $\begin{array}{l}\text { Discflo is best known for its innovative Disc Pump technology, a unique laminar-flow, non- } \\
\text { impingement pumping system that cuts maintenance and downtime, while increasing pump life. The } \\
\text { Disc Pump has been proven to: pump abrasives with minimal wear, pump efficiently at viscosities over } \\
10,000 \text { cPs, handle large or stringy solids without clogging, and pump water/oil fluids without } \\
\text { emulsifying. Not a metering pump as flow varies unless a check valve is introduced. Check valves are } \\
\text { a problem with highly vicious materials. Will pump very viscous material up to maybe } 400 \text { psi but } \\
\text { higher than that then pumps need to be put in series and this is complicated with highly vicious } \\
\text { material as elbows are required that have high friction losses. Material to be pumped has to flow into } \\
\text { the pump. Cost-effective alternative to centrifugal, progressive cavity, lobe, and screw pumps. }\end{array}$ & $\begin{array}{l}\text { No response } \\
\text { discflo@discflo.com } \\
\text { Address: } \\
\text { 10850 Hartley Rd } \\
\text { Santee, CA 92071 USA } \\
\text { Related Website(s): } \\
\text { http://www.discflo.com/ }\end{array}$ \\
\hline
\end{tabular}




\begin{tabular}{|c|c|c|c|}
\hline Vendor & Equipment & Notes & Contact/Related Websites \\
\hline $\begin{array}{l}\text { Inno Engineered } \\
\text { Products Pte Ltd }\end{array}$ & Positive Lobe Pump & $\begin{array}{l}\text { Durrex Lobe Pump - Located in Singapore } \\
\text { (http://www.innopumps.com/positive lobe.htm\#http://www.innopumps.com/positive lobe.htm\#) one } \\
\text { of the stated features was "capable to pump the viscous material below } 2 \text { million cp and pulp with the } \\
\text { solid volume of } 60 \% \text {." } \\
\text { Vendor Response: Will not work for HTL application. }\end{array}$ & $\begin{array}{l}\text { Simon Han } \\
\text { simon@innopumps.com } \\
\text { Address: } \\
\text { 48 Siglap Drive Singapore } 456173 \\
\text { Related Website(s): } \\
\text { http://www.innopumps.com/index.htm }\end{array}$ \\
\hline LEWA GmbH & Diaphragm Pump & 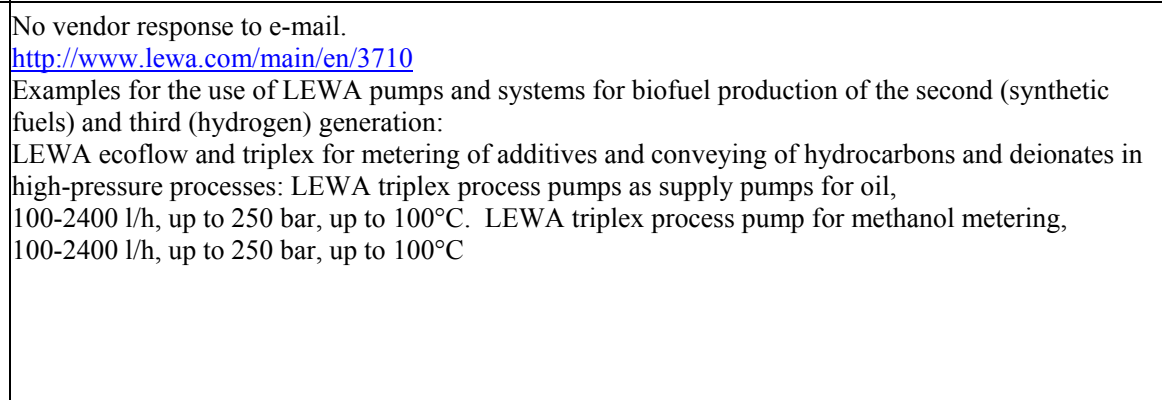 & $\begin{array}{l}\text { Technical Inquires: } \\
\text { lewa@lewa.de } \\
\text { Phone: }+49 \text { 7152 14-0 } \\
\text { Address: } \\
\text { Ulmer Straße 10 } \\
\text { 71229 Leonberg } \\
\text { Germany } \\
\text { Related Website(s): } \\
\text { www.lewa.de } \\
\end{array}$ \\
\hline $\begin{array}{l}\text { LF Pumping (Europe) } \\
\text { Ltd. }\end{array}$ & Material Handling & $\begin{array}{l}\text { Biomass and wood chip, pellets and shavings drying - http://www.lfpumping.com/biomass-and-wood- } \\
\text { chips.php }\end{array}$ & $\begin{array}{l}\text { Technical Enquiries - info@lfpumping.com } \\
\text { Related Website(s): } \\
\text { http://www.lfpumping.com } \\
\end{array}$ \\
\hline LobePro Rotary Pumps & Rotary Lobe Pump & $\begin{array}{l}\text { Vendor Response: Our rotary lobe pumps are rated up to max. } 175 \text { psi continuous differential pressure } \\
\text { only. }\end{array}$ & $\begin{array}{l}\text { Nico Ramos } \\
\text { nicor@lobepro.com } \\
\text { Tel. } 912.466 .0304 \\
\text { Address: } \\
2610 \text { Sidney Lanier Drive, Brunswick, Georgia } \\
31525 \\
\text { Related Website(s): } \\
\text { http://www.lobepro.com/eng-data-sludge- } \\
\text { engineering.php } \\
\end{array}$ \\
\hline $\begin{array}{l}\text { Liberty Process } \\
\text { Equipment }\end{array}$ & Progressive Cavity & $\begin{array}{l}\text { Have a variety of pumps specializing in progressive cavity pumps. Looks like maximum discharge } \\
\text { pressure is } 800 \text { psi. }\end{array}$ & $\begin{array}{l}\text { (847) 640-7867 } \\
\text { Related Website(s): } \\
\text { http://www.libertyprocess.com } \\
\end{array}$ \\
\hline LSM Pumps USA & Peristaltic hose pump & $\begin{array}{l}\text { LSM manufacture Hose Pumps in all sizes from } 3 / 8 \text { " to } 8 \text { ". The LSM size } 8 \text { " is the World's Largest } \\
\text { Peristaltic Pump. } \\
\text { Vendor Responses: } \\
\text { Second Response: The factory has decided that this media is not suitable for our pumps. We think it } \\
\text { will only create problems as it is too viscous to flow into the pump by the suction created when the } \\
\text { rollers run over the hose. We think that a piston pump would be better. Please look at a supplier as }\end{array}$ & $\begin{array}{l}\begin{array}{l}\text { Louis Gundorph Moller } \\
\text { louisgm@aol.com }\end{array} \\
\text { Phone: (713) 893-7413 } \\
\text { Address: } \\
14655 \text { Champion Forest Dr. }\end{array}$ \\
\hline
\end{tabular}




\begin{tabular}{|c|c|c|c|}
\hline Vendor & Equipment & Notes & Contact/Related Websites \\
\hline & & $\begin{array}{l}\text { Putzmeister or similar. www.putzmeisteramericas.com } \\
\text { First Response: We do not have that much experience with wood chips. We have pumped it but the } \\
\text { condition of the chips we have seen so far varies quite a bit. } \\
\text { We do pump numerous different materials as chopped hay, remains from slaughterhouses (blood, fat } \\
\text { and chopped solid remains), chicken and cattle manure, grass and hay in different stages/solutions, } \\
\text { Urine from hogs and cattle, molasses, waste from the fishing industry and other similar by-products. } \\
\text { In Europe they use little corn as biomass, but they use all the remains from production at flour mills } \\
\text { (husks etc.) as well. There must be some liquid present in the media pumped. Peels from sugar beets, } \\
\text { leftover from sugar production etc. are also used frequently matter. We have also pumped concrete } \\
\text { with stones, chewing gum, mining slurry, and other crazy fluids - some with extreme viscosities. }\end{array}$ & $\begin{array}{l}\text { Unit } 701 \\
\text { Houston, TX } 77069 \\
\text { Related Website(s): } \\
\text { Www.1smpumpsusa.com }\end{array}$ \\
\hline Megator Corporation & Rotary Lobe Pump & $\begin{array}{l}\text { Vendor Responses: } \\
\text { Second Response: The Sliding Shoe design is limited to a maximum pressure of } 110 \text { PSI and the } \\
\text { product must be free flowing and be free from abrasive particle. The Rotary Lobe design can handle up } \\
\text { to } 400 \text { PSI but is dependent upon a product with high viscosity. } \\
\text { First Response: Regrets but the design requirements exceed our maximum pressure. }\end{array}$ & $\begin{array}{l}\text { Lou Beatty } \\
\text { lou@,megator.com } \\
\text { (412) 963-9200 } \\
\text { Address: } \\
\text { 1721 Main Street } \\
\text { Pittsburgh PA 15215, USA } \\
\text { Related Website(s): } \\
\text { http://www.megator.com/solutions/ } \\
\text { http://www.megator.com/lobe pumps.htm }\end{array}$ \\
\hline Milton Roy & Metering Pumps & $\begin{array}{l}\text { Milton Roy has supplied these pumps for use on the Renmatix project it which biomass solids at fairly } \\
\text { high viscosity and up to near } 20 \% \text { dry weight solid content is being achieved. I do believe their pilot- } \\
\text { scale process is less than } 43 \text { gpm so therefore the Milton Roy pump capacity fits their application. } \\
\text { Vendor Responses: } \\
\text { Milton Roy (and all metering pumps) live in the GPH world (not GPM). Also, high viscosity fluids } \\
\text { with high solids contents are not a good fit for these pumps. Basically, the scope of your project is } \\
\text { outside of our capabilities. The largest pumps we can offer are } 2600 \mathrm{GPH}(43 \mathrm{gpm} \text { ). The pressure } \\
\text { ratings are no problem.... we go up to } 30,000 \text { PSI. I believe there are other styles of pumps that would } \\
\text { be better suited to your application. }\end{array}$ & $\begin{array}{l}\text { Henri Bouscaren } \\
\text { henri@finelineinstrument.com } \\
\text { Fine Line Instrument } \\
\text { T: 425-861-1110 } \\
\text { Address: } \\
\text { 201 Ivyland Road } \\
\text { Ivyland, PA 18974 } \\
\text { Phone: } 215-441-0800 \\
\text { Related Website(s): } \\
\text { www.miltonroy.com }\end{array}$ \\
\hline $\begin{array}{l}\text { MURPHY \& DICKEY, } \\
\text { INC. }\end{array}$ & Feeder Pump - Type ? & $\begin{array}{l}\text { Vendor Response Voice Message: Have provided some feed pumps for Viron Technologies out of } \\
\text { Madison, WN but only up to } 1800 \text { psi. }\end{array}$ & $\begin{array}{l}\text { Mark L. } \\
\text { (847) 778-4269 } \\
630.655 .1080 \\
\text { Address: } \\
930 \text { N.York Road Suite } 205 \\
\text { Hinsdale, IL } 60521 \\
\text { Related Website(s): } \\
\text { http://www.murphyanddickey.com/PUMPS.htm } \\
1\end{array}$ \\
\hline Neptune & Metering Pumps & Meets temperature $180 \mathrm{~F}$ and $3000 \mathrm{psi}$, and $1 \mathrm{gpm}$ requirements but is limited to $10 \%$ solids with & Tim Fegin \\
\hline
\end{tabular}




\begin{tabular}{|c|c|c|c|}
\hline Vendor & Equipment & Notes & Contact/Related Websites \\
\hline & & metering tubular pump (http://www.neptune1.com/pumps/tubpump.htm) & $\begin{array}{l}\text { (215) 699-8700 } \\
\text { pump@neptune1.com } \\
\text { Related Website(s): } \\
\text { http://www.neptune1.com/pumps/index.htm }\end{array}$ \\
\hline $\begin{array}{l}\text { NETZSCH Pumps North } \\
\text { America, LLC }\end{array}$ & $\begin{array}{l}\text { Progressive Cavity } \\
\text { Pump } \\
\text { Rotary Lobe Pump }\end{array}$ & $\begin{array}{l}\text { Information related to biomass pumping at } \\
\text { http://www.netzschusa.com/company_brochure_pages/Nemo/2008_Brochures/Water\%20Brochure.pdf }\end{array}$ & $\begin{array}{l}\text { No Response Back } \\
\text { John Sands } \\
\text { E-mail: john.sands@netzsch.com } \\
\text { Address: } \\
6078 \text { Highway Z } \\
\text { P. O. Box } 339 \\
\text { Spring Green, WI } 53588 \\
\text { Related Website(s): } \\
\text { http://www.netzschusa.com }\end{array}$ \\
\hline PCM (USA Contact) & $\begin{array}{l}\text { Progressive Cavity } \\
\text { Pump }\end{array}$ & $\begin{array}{l}\text { PCM is one of the world's leading manufacturers of positive displacement pumps and advanced fluid- } \\
\text { handling equipment. The company was founded in } 1932 \text { by René Moineau, the inventor of the } \\
\text { Progressing Cavity Pump. } \\
\text { Vendor Response: Unfortunately we must decline your application due to the extreme pressure and } \\
\text { flow ratings (prod scale). We can manage Bench and Pilot required flow rates but not the pressures. } \\
\text { Unless your pressure ratings are drastically reduced, we cannot offer a solution. }\end{array}$ & $\begin{array}{l}\text { Paul Pilisi } \\
\text { Tel.: : (713) 896-4888 Ext. } 108 \\
\text { ppilisi@pcm.eu } \\
\text { Address: } \\
11940 \text { Brittmoore Park Drive } \\
\text { Houston, TX 77041 } \\
\text { Related Website(s): } \\
\text { http://www.pcm.eu/ }\end{array}$ \\
\hline $\begin{array}{l}\text { Pratt \& Whitney } \\
\text { Rocketdyne (PWR) }\end{array}$ & Dry Biomass Pump & $\begin{array}{l}\text { Developing a high-pressure dry feed pump, including the detailed design, construction, and testing of a } \\
600 \text { ton-per-day (tpd) prototype. The PWR feed pump has the potential to significantly improve the } \\
\text { availability and efficiency of feeding dry coal/petcoke/biomass into high-pressure gasifiers. }\end{array}$ & $\begin{array}{l}\text { Contact: K. David Lyons } \\
\text { (NETL Project Manager) } \\
\text { k.david.lyons@netl.doe.gov } \\
\text { Related Website(s): } \\
\text { http://www.netl.doe.gov/publications/factsheets/ } \\
\text { project/FE42237-PWR.pdf }\end{array}$ \\
\hline \begin{tabular}{|l} 
Pulsafeeder \\
Engineered Products \\
Operation (EPO)
\end{tabular} & High-Pressure Pumps & $\begin{array}{l}\text { Never received a response back after sending Problem Statement. } \\
\text { Earlier Vendor Response: I had Pulsafeeder look at this application and they are unsure if their high- } \\
\text { pressure pump can handle the high viscosity fluid. At this time they decline to bid as they feel that } \\
\text { their pump cannot handle the viscosity. They have a Foster Vane type pump that could handle the } \\
\text { fluid, but it is not a high-pressure pump. http://www.pulsa.com/products/foster/ }\end{array}$ & $\begin{array}{l}\text { Craig Janett } \\
\text { cjanett@unitprocess.com } \\
\text { Cell 509-750-0921. } \\
\text { Tel: (585) 292-8000 } \\
\text { Address: } \\
\text { 2883 Brighton-Henrietta Townline Road } \\
\text { Rochester, NY } 14623 \\
\text { Related Website(s): } \\
\text { http://www.pulsa.com/ } \\
\text { Distributor: }\end{array}$ \\
\hline
\end{tabular}




\begin{tabular}{|c|c|c|c|}
\hline \multirow{2}{*}{ Vendor } & Equipment & Notes & Contact/Related Websites \\
\hline & & & http://www.unitprocess.com/ \\
\hline Roper Pump Company & Gear Pump & $\begin{array}{l}\text { Vendor Response: From the look of it the pressure is too high for our gear pumps. Roper Pumps } \\
\text { appreciates the opportunity to evaluate your application needs. However, we regret to inform you that } \\
\text { we do not have a pump that we could confidentially recommend to best suit your application. Roper } \\
\text { Pumps offers a wide range of pumps designed to meet our customer's needs but will not recommend } \\
\text { one unless we know it will satisfy our customer's application parameters. }\end{array}$ & $\begin{array}{l}\text { Sam McFall } \\
\text { Applications Engineer } \\
\text { Roper Pumps/ Dynamco } \\
\text { Office: } 706-336-3341 \\
\text { Tel: } 706.335 .5551 \\
\text { Address: } \\
\text { 3475 Old Maysville Road } \\
\text { Commerce, GA 30529 } \\
\text { Related Website(s): } \\
\text { hhtp://www.roperpumps.com } \\
\end{array}$ \\
\hline $\begin{array}{l}\text { Saxlund International } \\
\text { GmbH }\end{array}$ & - Solids piston pump & $\begin{array}{l}\text { Provides a variety of products including: Solids Pumps, Sliding Frame, Push Floor, Rotor Tubefeeder, } \\
\text { Chain Conveyor, Screw Conveyor, Elevator, Rotary Valve } \\
\text { Vendor Response: After studying your specification we see that the required pump pressure is } 3000 \text { psi } \\
\text { (206 bar). The max pressure of our pumps is } 100 \text { bar (1451 psi) That means the Saxlund pump will not } \\
\text { work for your application. }\end{array}$ & $\begin{array}{l}\begin{array}{l}\text { Michael Brehmer } \\
\text { michael.brehmer@saxlund.de }\end{array} \\
\text { Address: } \\
\text { Heidberg G 1,4+5 } \\
\text { 29614 SOLTAU-HARBER Germany } \\
\text { Related Website(s): } \\
\text { hhtp://www.saxlund- } \\
\text { international.de/products.html?L=1 }\end{array}$ \\
\hline Seepex GmbH & $\begin{array}{l}\text { Progressive Cavity } \\
\text { Pump }\end{array}$ & Provides progressive cavity pumps. Will not reach HTL pressure requirement. & $\begin{array}{l}\text { Max Rupert, Territory Manager - } \\
\text { West Seepex Inc. } \\
\text { Tel: (503) 307-5378 } \\
\text { mrupert@ @seepex.net } \\
\text { Distributor Address: } \\
12498 \text { SE Ashley St } \\
\text { Clackamas, OR 97015 } \\
\text { Corporate Address: } \\
\text { Postfach 10 15 64 } \\
\text { D-46215 Bottrop } \\
\text { Scharnhölzstraße 344 } \\
\text { Tel +49 2041.996-0 } \\
\text { Related Website(s): } \\
\text { http://www.seepex.com// }\end{array}$ \\
\hline Stamet Inc. & Rotary Solids Pump & $\begin{array}{l}\text { Posimetric solids pump technology. Coal/biomass mix. Pressures up to } 500 \text { psi. Technology acquired } \\
\text { by GE Energy in } 2007 \text {. }\end{array}$ & $\begin{array}{l}\text { Derek Aldred, Timoth Sanders } \\
\text { Phone: (310)719-7110 } \\
\text { Address: } \\
17244 \text { S. Main St., Gardena, CA, } 90248 \\
\text { Related Website(s): } \\
\text { No website found }\end{array}$ \\
\hline
\end{tabular}




\begin{tabular}{|c|c|c|c|}
\hline Vendor & Equipment & Notes & Contact/Related Websites \\
\hline Sulzer Pumps (US) Inc & Pumps & Never received a response back after sending Problem Statement. & \begin{tabular}{|l} 
Bob McCain, Sales Director \\
Canada, Western US and Export \\
Cellular: 1.925 .998 .4413 \\
Bob.McCain@Sulzer.com \\
\\
Address: \\
200 SW Market Street \\
Portland, OR 97201 \\
Phone: 1.503 .205 .3731 \\
Related Website(s): \\
No website found
\end{tabular} \\
\hline TK Energi A/S & $\begin{array}{l}\text { Pressurized } \\
\text { Feeding of } \\
\text { - Solid Materials } \\
\text { - Screw and Plug } \\
\text { Feeders } \\
\text { - Piston Plug Feeders } \\
\text { - High-Pressure } \\
\text { Feeders }\end{array}$ & 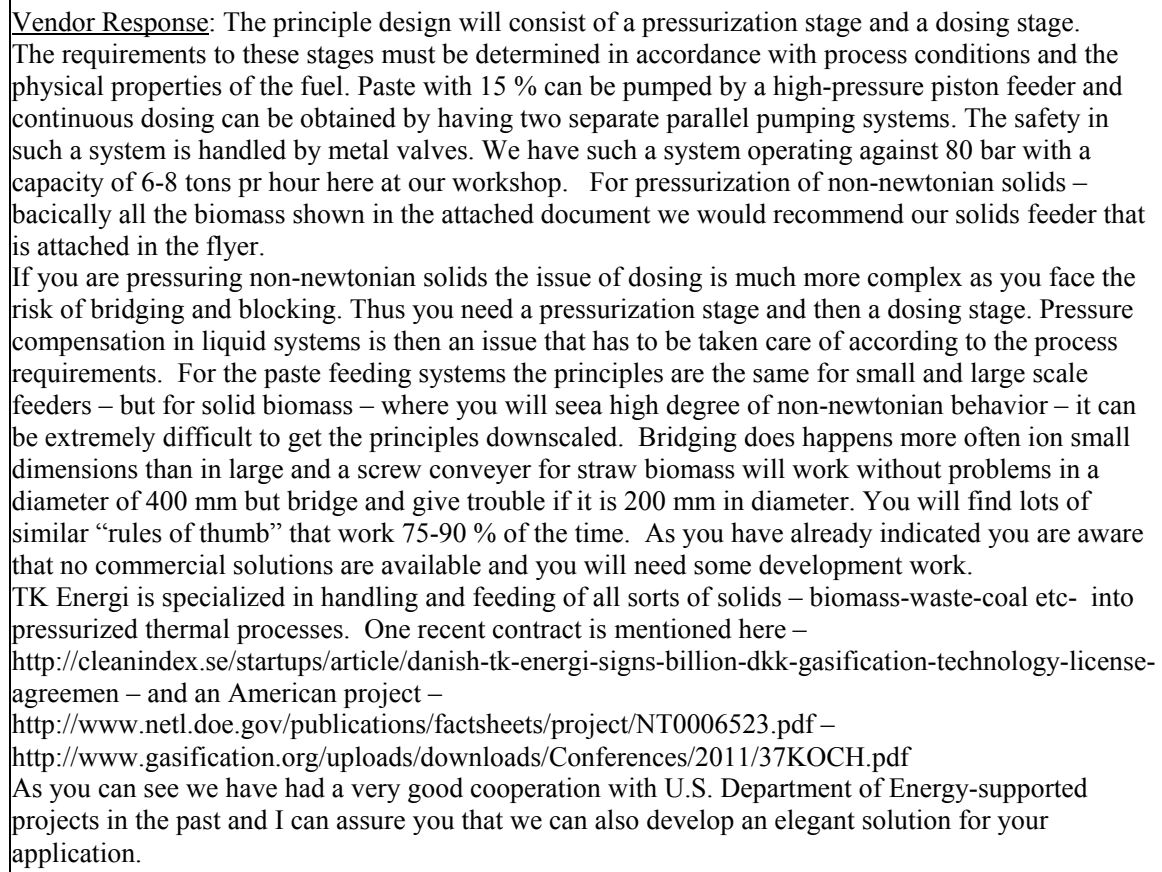 & $\begin{array}{l}\text { Thomas Koch, CEO } \\
\text { tk@tke.dk } \\
\text { phone }+4522611047 \\
\text { Address: } \\
\text { Værftsvej } 8 \\
4300 \text { Køge } \\
\text { Denmark } \\
\text { Related Website(s): } \\
\text { www.tke.dk } \\
\end{array}$ \\
\hline
\end{tabular}




\begin{tabular}{|c|c|c|c|}
\hline Vendor & Equipment & Notes & Contact/Related Websites \\
\hline Verder Inc. & $\begin{array}{l}\text { Progressive Cavity } \\
\text { Pump }\end{array}$ & $\begin{array}{l}\text { Application: Verderpro VPR feed hopper pump for high viscous } \\
\text { (http://www.verder.com/Liquidshandling/Pumps/Progressing_cavity_pumps/Verderpro_VPR). } \\
\text { Vendor Response: Unfortunately, we do not carry the products or equipment you are seeking. The } \\
\text { product you are asking about is only sold in Europe at this time. We only sell the Verder lines } \\
\text { mentioned above, which are unable to reach the parameters you have supplied us with. }\end{array}$ & $\begin{array}{l}\text { Ryan Mellinger } \\
\text { Application Engineer } \\
\text { P: (877) 476-3569 } \\
\\
\text { Address: } \\
110 \text { Gateway Drive } \\
\text { Macon, GA } 31210 \\
\text { Tel: (478) } 4717327 \\
\text { Related Website(s): } \\
\text { http://www.verder-us.com/ } \\
\end{array}$ \\
\hline Vogelsang & $\begin{array}{l}\text { - Rotary Lobe Pump } \\
\text { - Rotacut } \\
\text { - Biocut }\end{array}$ & Rotary lobe pumps and grinders. & $\begin{array}{l}\text { Address: } \\
\text { P.O. Box } 751 \\
\text { 7966 State Route } 44 \\
\text { Ravenna, OH } 44266 \\
\text { (800) 984-9400 } \\
\text { Related Website(s): } \\
\text { http://vogelsangusa.com/ } \\
\end{array}$ \\
\hline Wagen Pumps & $\begin{array}{l}\text { Progressive Cavity } \\
\text { Pump }\end{array}$ & $\begin{array}{l}\text { Vendor Response: We are manufacturers of progressive cavity pumps and also very successful in the } \\
\text { field of biogas. We regret however that your inquiry does not fit in our manufacturing program. }\end{array}$ & $\begin{array}{l}\text { Michael Leise } \\
\text { m.leise@wangen.com } \\
\\
\text { Address: } \\
\text { Pumpenfabrik Wangen GmbH } \\
\text { Simoniusstraße } 17 \\
\text { D-88239 Wangen im Allgäu } \\
\text { Tel. +49 7522 } 997-240 \\
\text { Fax +49 7522 } 997-148 \\
\text { Related Website(s): } \\
\text { www.wangen.com }\end{array}$ \\
\hline Wastecorp Pumps & $\begin{array}{l}\text { - Diaphragm Pump } \\
\text { - Pumps }\end{array}$ & Industrial pumps. No vendor response to e-mail. & $\begin{array}{l}\text { Address: } \\
\text { P.O. Box } 70 \\
\text { Grand Island, NY } 14072 \\
\text { Tel: } 888.829 .2783 \\
\text { Related Website(s): } \\
\text { http://www.wastecorp.com/ }\end{array}$ \\
\hline
\end{tabular}




\begin{tabular}{|c|c|c|c|}
\hline Vendor & Equipment & Notes & Contact/Related Websites \\
\hline $\begin{array}{l}\text { Wright Flow } \\
\text { Technologies } \\
\text { (IDEX) } \\
\text { (formerly Johnson } \\
\text { Pumps/ formerly Viking } \\
\text { Pump) }\end{array}$ & Rotary Lobe Pump & $\begin{array}{l}\text { Vendor Response: To follow up with our conversation it appears we cannot help you out with this } \\
\text { application. } \\
\text { Not high-pressure pumps. }\end{array}$ & $\begin{array}{l}\text { Wrightflow Technologies Limited - IDEX } \\
\text { Sanitary Group } \\
\text { Highfield Industrial Estate } \\
\text { Edison Road } \\
\text { Eastbourne East Sussex } \\
\text { BN23 6PT United Kingdom } \\
\text { Tel: }+44 \text { (0)1323 509211 } \\
\text { Related Website(s): } \\
\text { http://www.wrightflowtechnologies.com/en/prod } \\
\text { ucts/byTech.html } \\
\text { Rotary Lobe Pumps: } \\
\text { http://www.wrightflowtechnologies.com/en/prod } \\
\text { ucts/technology/rotaryLobe.html }\end{array}$ \\
\hline \multicolumn{4}{|c|}{ The pumps below are more related to concrete/grout pumping applications } \\
\hline Airplaco & Concrete Pump & $\begin{array}{l}\text { Will not meet HTL pressure of } 3000 \text { psi }(206 \text { bar). Shotcrete pumps have higher pressures. The } \\
\text { Procretor has a } 1300 \text { psi capacity. The Shotcrete pumps } 536 \text { and } 636 \text { have lower pressures in the } 800- \\
900 \text { psi range. }\end{array}$ & $\begin{array}{l}\text { Related Website(s): } \\
\text { http://www.airplaco.com/index.html }\end{array}$ \\
\hline Blackjack & Grout Pump & $\begin{array}{l}\text { Normal } 0-625 \text { psi with } 1200 \text { psi option. Upper volume range of } 50 \text { to } 100 \mathrm{gpm} \text {. This is a piston style } \\
\text { pump with a } 5 \text { in. diameter bore and } 8 \text { in. travel. Each stroke will take in } .33 \text { cubic feet of material. } \\
\text { Because of rubber seals a none caustic feed is preferred. The piston style pump will be most effective } \\
\text { at delivering product at high pressure with largest aggerate size. The ChemGrout pump uses an auger } \\
\text { style pump and is less forgiving and has much lower pressures. }\end{array}$ & $\begin{array}{l}\text { Perry Hochkammer } \\
\text { (800) 834-2566) } \\
\text { Related Website(s): } \\
\text { http://www.blackjackgroutpumps.com/index.ht } \\
\text { m }\end{array}$ \\
\hline HMI & Concrete Pump & HMI mudjacking pumps range from $150-750 \mathrm{psi}$ and up to 17 and $34 \mathrm{gpm}$ & $\begin{array}{l}\text { Related Website(s): } \\
\text { http://mudpumps1.reachlocal.net/equipment/mu } \\
\text { djacking/pumps }\end{array}$ \\
\hline $\begin{array}{l}\text { Reed Concrete Pumps \& } \\
\text { Gunite Machines }\end{array}$ & Concrete Pump & Suggested the B20 2100 psi as highest pressure pump. & $\begin{array}{l}\text { Duane Remus (Engineer) } \\
\text { (909) 287-2104 } \\
\text { Cell (591) 312-0747 } \\
\text { Related Website(s): } \\
\text { http://www.reedpumps.com/ }\end{array}$ \\
\hline
\end{tabular}






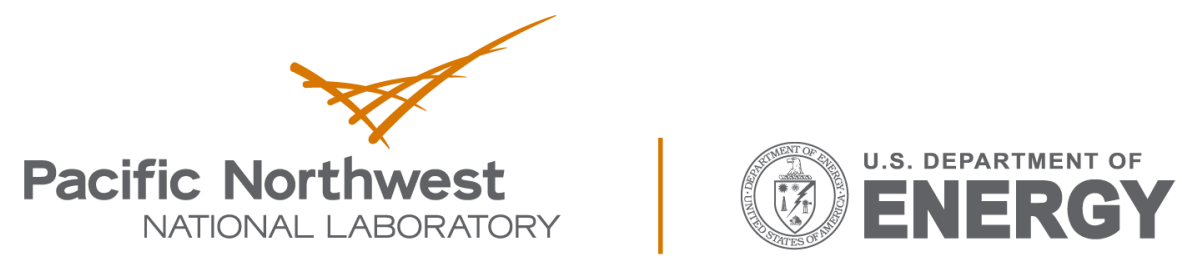

Proudly Operated by Battelle Since 1965

902 Battelle Boulevard

P.O. Box 999

Richland, WA 99352

1-888-375-PNNL (7665)

www.pnnl.gov 